\title{
Guia ilustrado dos Echinodermata da porção sul do Embaiamento Sul Brasileiro
}

\author{
Maristela de Lima Bueno ${ }^{1}$, Renata Aparecida dos Santos Alitto ${ }^{2}$, Pablo Damian \\ Borges Guilherme ${ }^{1}$, Maikon Di Domenico ${ }^{3}$ \& Michela Borges ${ }^{4}$
}

(1) Universidade Estadual do Paraná - campus Paranaguá, Laboratório de Biologia Marinha, Rua Comendador Correa Júnior 117, Paranaguá 83203-560, Paraná, Brasil. E-mail: maristelabueno04@gmail.com, pdbguilherme@gmail.com

(2) Universidade Estadual de Campinas, Instituto de Biologia, Programa de Pós-Graduação em Biologia Animal, Rua Charles Darwin, Bloco N, Cidade Universitária 13083-863, Campinas, São Paulo, Brasil. Email: renataalitto@gmail.com

(3) Universidade Federal do Paraná, Centro de Estudos do Mar, Pontal do Sul 83255-976, Pontal do Paraná, Paraná, Brasil. E-mail: maik2dd@gmail.com

(4) Universidade Estadual de Campinas, Instituto de Biologia, Museu de Zoologia “Adão José Cardoso”, Rua Charles Darwin, Bloco N, Cidade Universitária 13083-863, Campinas, São Paulo, Brasil. E-mail: borges.michela@gmail.com

Bueno M.L., Alitto R.A.S., Guilherme P.D.B., Domenico M.D. \& Borges M. (2018) Guia ilustrado dos Echinodermata da porção sul do Embaiamento Sul Brasileiro. Pesquisa e Ensino em Ciências Exatas e da Natureza, 2(2): 169-237. http://dx.doi.org/10.29215/pecen.v2i2.1071

Editor acadêmico: Silvio F. B. Lima. Recebido: 28 Setembro 2018. Aceito: 20 Dezembro 2018. Publicado: 28 Dezembro 2018.

Resumo: Este guia ilustrado apresenta 57 espécies de Echinodermata Bruguière, 1791 [ex Klein, 1734] registradas na porção sul do Embaiamento Sul Brasileiro (ESB), incluindo o litoral sul do Estado de São Paulo, todo o litoral do Paraná e norte de Santa Catarina. O guia destina-se a pesquisadores e estudantes que atuam ou gostariam de atuar com o grupo e serve de auxílio na identificação em campo e laboratório. Apresentamos uma caracterização do filo Echinodermata, uma breve descrição da área de estudo, técnicas de coleta e preservação dos exemplares. Para cada classe, são apresentadas caracterizações com as principais estruturas morfológicas de importância taxonômica, seguida das diagnoses das espécies registradas na ESB. Dentro de cada classe, as espécies foram organizadas por família e depois alfabeticamente de acordo com o gênero e a espécie. Para cada espécie foram incluídas fotos, diagnoses, distribuição geográfica e hábitat quando disponíveis em literatura. Esse trabalho é o primeiro guia ilustrado de equinodermos no Brasil e complementa de forma consistente o conhecimento da biodiversidade do grupo, gerando subsídios para futuras intervenções, tomadas de decisões e manutenção da diversidade deste incrível grupo de animais marinhos.

Palavras chave: Equinodermos, sul do Brasil, diversidade, Sudoeste Atlântico, Taxonomia.

\section{Illustrated guide of Echinodermata of the southern portion of the South Brazilian Embankment}

Abstract: The present guide describes 57 species of Echinodermata Bruguière, 1791 [ex Klein, 1734] from the southern portion of the Brazilian South Estuary (BSE), which includes the following coasts: the Southern of the State of São Paulo, entire of the State of Paraná and Northern of the State of Santa Catarina. We designed this guide for students and researchers providing a valuable resource for the identification and appreciation of shallow-water echinoderms. The guide describes the general features of the phylum Echinodermata, has a brief presentation of the study area and the techniques of collection and preservation of the specimens. For each class, the main morphological structures are illustrated, followed by the diagnoses of the species recorded in the BSE. Within each class, the species are organized by family, then alphabetically according to genus and species. For each species, we provide diagnoses, photos, geographic distribution and habitat when available in the literature. This work is the first illustrated guide 
of echinoderms in Brazil and complements the knowledge of biodiversity this group and provide support for future interventions, management and maintenance of the diversity of this wonderful group of marine animals.

Key words: Echinoderms, Southern Brazil, diversity, Southwest Atlantic, Taxonomy.

\section{Introdução}

Os Echinodermata são organismos diversos e facilmente reconhecíveis nos ambientes marinhos. O filo compreende cinco classes viventes: Crinoidea, Ophiuroidea, Asteroidea, Echinoidea e Holothuroidea. Os equinodermos vivem em diversos habitats, desde a zona entremarés até grandes profundidades, em substratos de fundo arenoso, lodoso, rochoso e biológico. As diferentes classes são frequentemente encontradas em uma mesma área (Hendler et al. 1995; Stöhr et al. 2012).

Echinodermata constitui um grupo monofilético apresentando um conjunto de características exclusivas: simetria radial pentâmera nos adultos, sistema hidrovascular formado por canais e apêndices da parede corporal, esqueleto interno constituído por ossículos calcários e um celoma espaçoso que aloja um trato digestivo bem desenvolvido. Não existe sistema excretor diferenciado e os mecanismos para as trocas gasosas parecem ter se originado independentemente dentro das classes. A maior parte dos membros do grupo é dióica e não apresenta dimorfismo sexual (Hendler et al. 1995; Hickman 1998).

"Esse nobre grupo especialmente concebido para intrigar zoólogos" (Hyman 1955) tem despertado interesse dos pesquisadores. Isso porque possui uma ampla quantidade de registros fósseis (13000 espécies), grande importância ecológica, características morfológicas e biomecânicas peculiares e por serem organismos-modelo para estudos de embriologia, ecotoxicologia e biotecnologia (Petzelt 2005; Pawson 2007; Benavides-Serrato et al. 2011).

Existem cerca de 7000 espécies viventes de equinodermos em todo o mundo (Pawson 2007). Destas, aproximadamente 300 são registradas para os $8000 \mathrm{~km}$ de extensão do litoral brasileiro (Ventura et al. 2013), e 83 já foram registrados no Embaiamento Sul Brasileiro.

Neste guia são apresentadas espécies identificadas para todas as classes, das quais 10 espécies são de Asteroidea, 2 espécies de Crinoidea, 9 espécies de Echinoidea, 2 espécies de Holothuroidea e 34 espécies de Ophiuroidea.

\section{Material e Métodos}

Área de estudo

O Embaiamento Sul Brasileiro (ESB) situa-se na porção norte da costa sudeste do Brasil, estende-se do município de Cabo Frio no Rio de Janeiro $\left(23^{\circ} \mathrm{S}\right)$ ao norte até o Cabo de Santa Marta em Santa Catarina $\left(28^{\circ} \mathrm{S}\right)$ ao sul. A área de estudo compreende todo o litoral sul do estado de São Paulo, litoral do Paraná e norte de Santa Catarina, entre as latitudes $24^{\circ}$ e $28^{\circ} \mathrm{S}$ e longitudes $49^{\circ}$ e $45^{\circ} \mathrm{W}$ (Figura 1).

O estado do Paraná insere-se em um largo embaiamento (ESB) composto por um litoral retificado de longos arcos de praia, extensas planícies costeiras e importantes estuários como o Complexo Estuarino-Lagunar de Cananéia (São Paulo), Complexo Estuarino de Paranaguá (Paraná), Baía de Guaratuba (Paraná) e Baía de Babitonga (Santa Catarina). Pode ser caracterizado pela presença de fundos não consolidados quase que na sua totalidade, sendo a presença de afloramentos rochosos restrita às áreas mais rasas da plataforma interna e estuários (Klein et al. 2001).

Hidrologicamente, toda a região é resultado da mistura da Corrente do Brasil (CB) e a Corrente Costeira Brasileira (CCB). Durante o verão, a região apresenta uma estratificação de massa d'água em duas camadas, causada pela intrusão da massa d'água fria e rica em nutrientes denominada Água Central do Atlântico Sul (ACAS) embaixo da CB e a CCB (Borzone et al. 1999; de Mahiques et al. 2004). No inverno, a coluna d'água fica mais homogênea, devido à presença 
de águas frias e de baixa salinidade, causada pela intrusão de águas frias de origem subantártica (Campos et al. 1996).

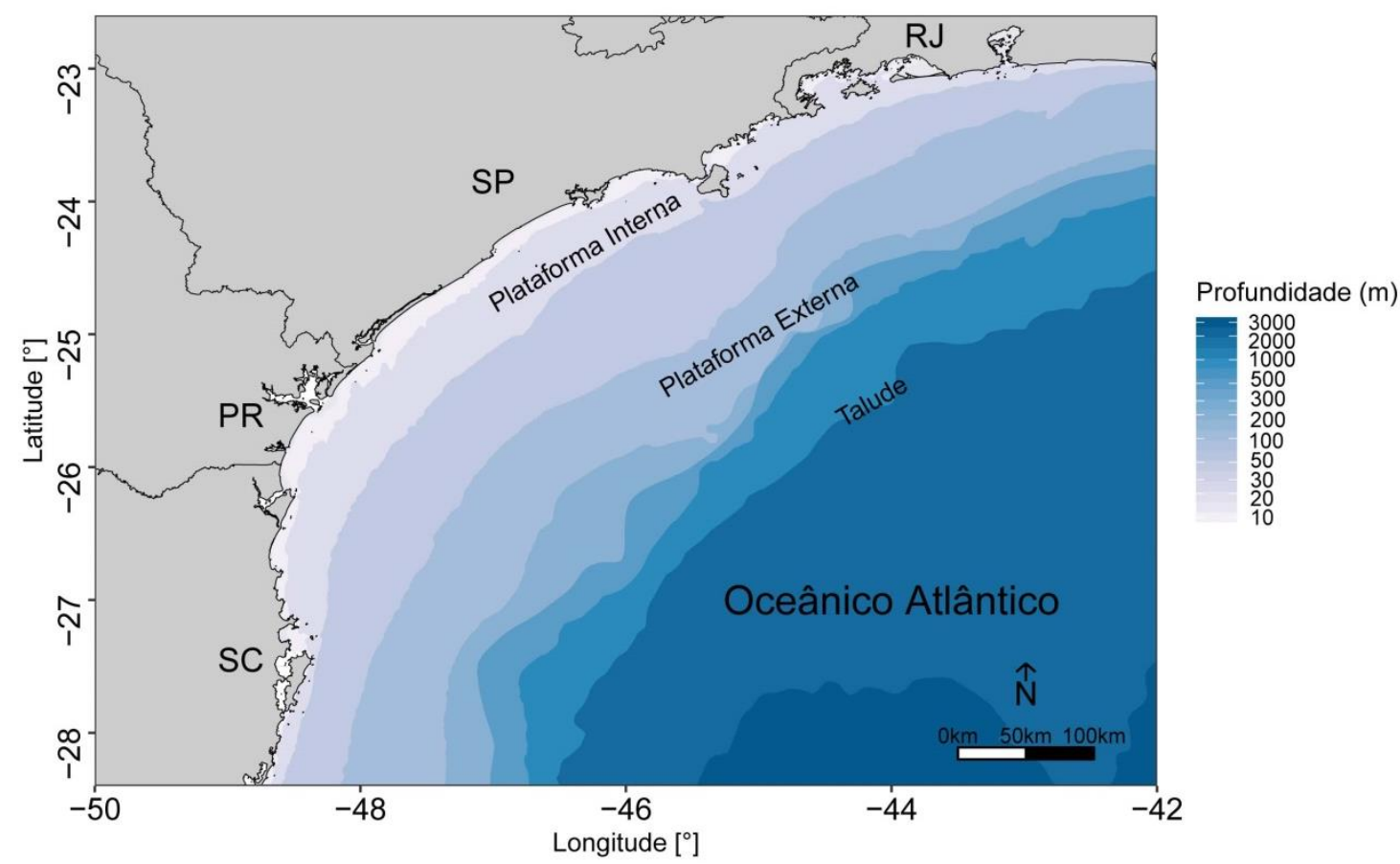

Figura 1. Porção sul do Embaiamento Sul Brasileiro. O gradiente na cor azul indica a variação batimétrica do mais claro, de 0-20 metros de profundidade, ao mais escuro até 4000 metros de profundidade.

\section{Coleta e preservação}

\section{Coleta}

Diferentes equipamentos podem ser utilizados para amostrar equinodermos e variam de acordo com o ambiente e a profundidade de coleta. Em águas profundas são utilizados equipamentos como dragas ou pegadores de fundo, instalados em embarcações apropriadas. Em águas rasas, as coletas podem ser manuais, por mergulho livre ou autônomo na maré baixa, ou podem ser com redes de arrasto ou amostrador cilíndrico (Eleftheriou \& McIntyre 2008).

Asteroides e equinoides irregulares são encontrados expostos em praias arenosas ou enterrados superficialmente. Equinoides regulares são facilmente encontrados em costões rochosos e recifes onde escavam a rocha formando tocas. Holoturoides e crinoides ficam geralmente em fendas de costões rochosos. Ofiuroides podem ser encontrados nos mais variados substratos (consolidado ou inconsolidado), embaixo de pedras ou substrato biológico, como algas e esponjas (Hendler et al. 1995). A Figura 2 mostra as formas corporais das cinco classes de Echinodermata.

Durante a coleta é aconselhável manter cada amostra isolada em um saco ou recipiente para evitar a reação antagônica entre os indivíduos, acondicionar os animais em baldes com água do mar e ter um cuidado especial com os pepinos-do-mar que podem eviscerar devido a estresse (Ditadi 1987).

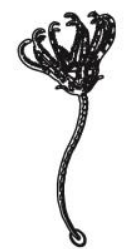

lírios-do-mar (Crinoidea)

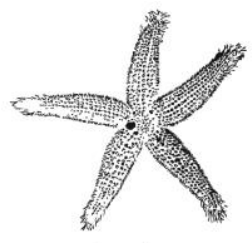

estrelas-do-mar (Asteroidea)

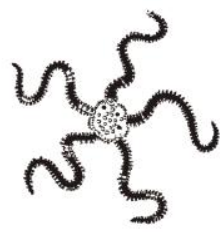

serpentes-do-mar ou ofiúros (Ophiuroidea)

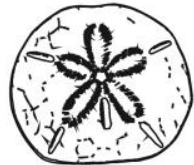

ouriços-do-mar e bolachas-da-praia (Echinoidea)

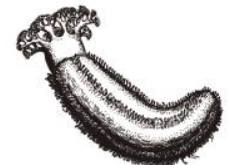

pepinos-do-mar ou holotúrias (Holothuroidea)

Figura 2. Formas corporais das cinco classes de Echinodermata. 


\section{Anestesia, fixação, preservação e acondicionamento}

Para anestesiar os espécimes podem ser utilizados: cloreto de potássio, sulfato de magnésio, mentol, água doce para dar um choque osmótico ou câmara fria. Devem-se colocar os animais em recipientes de fundo chato, contendo água do mar suficiente apenas para cobri-los e adicionar o anestésico escolhido gradualmente. As amostras devem permanecer na solução anestésica até o momento em que os animais não reagem ao estímulo mecânico ou químico (Hendler et al. 1995; Darrigran et al. 2007).

O espécime deve ser imerso a um fixador líquido, a depender da finalidade do estudo a ser realizado. Tendo em vista a existência de um endoesqueleto de carbonato de cálcio, os equinodermos não devem ser mantidos em fixadores ácidos (Ditadi 1987).

Para estudos histológicos são recomendados fixadores como formalina (10\%) ou Bouin (mistura de $750 \mathrm{ml}$ de ácido pícrico com $250 \mathrm{ml}$ de formalina e $50 \mathrm{ml}$ de ácido cético glacial) (Humason 1962; Brogger et al. 2013).

Para estudos moleculares, são retiradas amostras de tecidos, cerca de $1-2 \mathrm{~mm}^{3}$, as quais devem ser mantidas em álcool absoluto e refrigeradas para evitar degradação. Os tecidos podem ser dos tentáculos, pódios, músculos ou gônadas (Uthicke \& Benzie 2003). No caso de ofiuroides, em decorrência do tamanho, aconselha-se a retirada de um a quatro braços para extração do DNA.

Para estudos taxonômicos utiliza-se comumente formalina (10\%) neutralizada por cerca de $48 \mathrm{~h}$ e posteriormente substituído por álcool (70\%). Em organismos grandes é importante injetar o álcool ou formol na cavidade celômica (Ditadi 1987; Hendler et al. 1995). Além disso, durante o processo de fixação o organismo deve ser arrumado de forma a ocupar o menor espaço possível, deixando à mostra os caracteres mais importantes para o estudo taxonômico.

Depois de fixados, os espécimes são transferidos para potes de vidro transparentes com álcool $(70 \%)$ até cobrir todo o corpo. Os espécimes podem ser acondicionados individualmente ou em lotes (se forem da mesma espécie e procedência). Cada exemplar ou lote deve receber uma etiqueta com todas as informações de campo, como data e local de coleta, coletor, coordenadas geográficas, profundidade, substrato, salinidade, entre outras (Ditadi 1987; Papavero 1994).

A preservação a seco é uma alternativa para o caso de não se dispor de vidraria adequada para guardar os animais. Depois de fixados no formol os espécimes devem ser secados à sombra em local arejado, durante 1 a 3 semanas (Ditadi 1987). Holoturoides não devem ser mantidos em via seca devido ao seu reduzido esqueleto, formado apenas pelos ossículos calcários dispersos na parede corporal.

\section{Preparação do endoesqueleto}

Para observação das placas ou ossículos calcários que formam o endoesqueleto é necessária a retirada do tecido que o recobre. Para isso, imerge-se uma parte do corpo que se deseja observar em solução de hipoclorito de sódio $(\mathrm{NaClO})$ a $2.5 \%$ até que toda área esteja limpa (no caso de Asteroidea e Echinoidea) (Serafy 1979; O’Loughlin \& Waters 2004) ou até que os ossículos se desprendam do tecido (no caso de Holothuroidea e Ophiuroidea) (Prata et al. 2014; Alitto et al. 2018).

Em seguida, lava-se em água destilada (cinco vezes) e depois em álcool 70\% (uma vez) (Rowe \& Doty 1977). A observação dos ossículos pode ser feita em estereomicroscópio para a maioria dos grupos ou podem ser montados em lâminas e observados por meio de microscópio óptico. Para um estudo mais detalhado, é preferível que os ossículos sejam montados em suporte de metal (stubs) portando uma fita de carbono dupla face, metalizados em ouro e estudados por meio do microscópio eletrônico de varredura.

\section{Índice de confiabilidade de ocorrência no ESB}


Para garantir a qualidade das informações de ocorrência das espécies aqui apresentadas, criamos um índice de confiabilidade, utilizando como critério o número de ocorrências no ESB, material coletado, material consultado em coleção científica, material consultado em museus e citações por especialistas na área. $\mathrm{O}$ índice foi subdividido em três categorias:

Muito confiável — Material validado que teve sua identificação confirmada por consulta em Museu ou Coleção Científica ou foi coletado.

Confiável - Material não validado, mas com grande número de ocorrências (> 10). Embora o material não tenha sido consultado, foi confirmado por especialista da área ou tratando especificamente de questões taxonômicas do grupo Echinodermata em artigos científicos.

Pouco confiável - Material não validado e com poucas ocorrências $(<3)$. Refere-se a um material que não teve sua identificação confirmada por especialista ou provém de trabalhos não derivados de estudos de cunho sistemático ou taxonômico (Exemplo: Inventários de macrofauna, consultorias, etc.).

\section{Fontes consultadas}

A compilação de dados foi realizada com registros da literatura disponíveis nos sites de busca: Google Scholar, plataforma Capes, Scientific Electronic Library Online (SciELO), banco de dados bibliográficos da Universidade de São Paulo (Dedalus), Sistema de Bibliotecas da Universidade Federal do Paraná (Portal UFPR) e Sistema de Bibliotecas da Universidade Federal do Rio de Janeiro (Minerva), incluindo resumos, artigos, monografias, dissertações, teses, anais de congressos e relatórios técnicos. Dados das plataformas Global Biodiversity Information Facility (GBIF) e a Ocean Biogeographic Information System (OBIS) e da rede colaborativa de museus speciesLink foram extraídos e listados.

Os dados de plataforma continental externa e talude foram extraídos dos relatórios técnicos do Programa de Recursos Vivos na Zona Econômica Exclusiva (REVIZEE), Score Sul/Bentos, que realizou coletas com pegadores van Veen, Box Core e draga de arrasto entre as isóbatas de 60-808 m de profundidade, no período de 13 de dezembro de 1997 e 20 de abril de 1998.

O material reexaminado está depositado nas coleções: Laboratório de Praias Arenosas no Centro de Estudos do Mar, Universidade Federal do Paraná (LEPA-CEM-UFPR) (Curadoria: Carlos Alberto Borzone); Laboratório de Biologia Marinha da Universidade Estadual do Paraná (Curadoria: Yara A. Garcia Tavares); Museu de História Natural Capão da Imbuia (MHNCI) (Curadoria: Odete Lopes Lopez); Museu de Zoologia da Universidade Católica do Paraná (MZPUC/PR) (Curadoria: Acir José da Silva Franco); Museu de Zoologia da Universidade Estadual de Campinas (ZUEC) (Curadoria: Michela Borges); Museu de Zoologia da Universidade de São Paulo (MZUSP) (Curadoria: Marcos Tavares); e Museu Nacional no Rio de Janeiro (MNUFRJ) (Curadoria: Carlos Renato Rezende Ventura).

Em todas as fontes consultadas foram extraídas informações como classificação taxonômica, local de coleta, tipo de substrato, profundidade e coordenadas geográficas. Nos trabalhos onde a localização geográfica não estava disponível, utilizamos a descrição da localidade para obter as coordenadas a partir do software Google Earth versão: 7.1.2.2041.

\section{Confecção de fotos e mapas de distribuição}

Espécimes adultos e mais bem preservados de cada espécie foram escolhidos para serem fotografados por meio de uma vídeo-câmera (ZEISS TK 1270) acoplada a um estereomicroscópio ou por meio de câmera fotográfica Canon EOS 7d.

Foi confeccionado um mapa de distribuição para cada uma das espécies detectadas no presente estudo. Foram utilizadas as coordenadas de cada localidade coletada e sobrepostas a linha de costa brasileira proveniente do Banco de Dados das Áreas Administrativas Globais 
(GADM, https://gadm.org/) e as linhas batimétricas categorizadas por profundidade oriundo do projeto "Batimetria" da Agencia Nacional do Petróleo (http:/www.cprm.gov.br/publique/Geologia/Geologia-Marinha/Projeto-Batimetria-3224.html). Os mapas foram montados em linguagem $\mathrm{R}$, através dos pacotes "rdgal" e "raster" para os dados cartográficos. Para a manipulação, organização e apresentação gráfica foi utilizado a coleção de pacotes "tidyverse".

\section{Abreviações}

EQMN-UFRJ

LABMAR-FAFIPAR

LEPA-GEM-UFPR

MHNGI

MZPUC/PR

MZUSP

ZUEC AST

ZUEC GRI

ZUEC ECH

ZUEC HOL

ZUEC OPH
Coleção de Echinodermata do Museu Nacional do Rio de Janeiro.

Laboratório de Biologia Marinha e Zoologia da Faculdade Estadual de Filosofia Ciências e Letras de Paranaguá.

Laboratório de Praias Arenosas no Centro de Estudos do Mar, Universidade Federal do Paraná.

Museu de História Natural Capão da Imbuia.

Museu de Zoologia da Universidade Católica do Paraná.

Museu de Zoologia da Universidade de São Paulo.

Coleção de Asteroidea do Museu de Zoologia da Universidade Estadual de Campinas.

Coleção de Crinoidea do Museu de Zoologia da Universidade Estadual de Campinas.

Coleção de Echinoidea do Museu de Zoologia da Universidade Estadual de Campinas.

Coleção de Holothuroidea do Museu de Zoologia da Universidade Estadual de Campinas.

Coleção de Ophiuroidea do Museu de Zoologia da Universidade Estadual de Campinas.

\section{Resultados}

\section{Asteroidea de Blainville, 1830}

Considerações: Os Asteroidea, conhecidos popularmente como estrelas-do-mar, são sem dúvida, um dos grupos animais mais emblemáticos do ambiente marinho (Hendler et al. 1995). Caracterizam-se pela forma corporal tipicamente estrelada com um disco central, do qual partem braços (raios) simetricamente projetados. O número e o comprimento destes raios são extremamente variáveis, sendo as formas com cinco braços as mais comuns (Hendler et al. 1995; Benavides-Serrato et al. 2011).

O corpo de uma estrela-do-mar é geralmente achatado ou abaulado (Hyman 1955) e está dividido em superfície aboral e oral. Na região aboral próximo ao centro podem estar presentes um pequeno ânus, o madreporito, pápulas e paxilas (Figura 3A-B).

No centro da região oral está localizada a boca, de onde parte um sulco ambulacral na linha mediana de cada raio, delimitado por placas adambulacrais, que podem ou não conter 
espinhos (Figura 3C). Nestes sulcos projetam-se de 2-4 fileiras de pés ambulacrais, que apresentam ou não ventosas na extremidade. As mandíbulas situam-se ao redor da boca, portando espinhos orais e suborais (Figura 3D) (Clark \& Downey 1992).

O esqueleto dos raios é formado por numerosas placas calcárias e, em alguns asteroides, pode-se distinguir claramente uma série dupla de placas marginais conhecidas como supero e inferomarginais (Figura 3E), as quais estão alinhadas nas bordas dos braços e diferem das demais placas das superfícies aboral e oral, respectivamente (Benavides-Serrato et al. 2011).

Estruturas calcárias conhecidas como pedicelárias podem estar presentes em alguns asteroides tanto na região oral (ao redor dos espinhos ou sob as placas abactinais) quanto aboral (sob as placas actinais) e possuem formato variado (Clark \& Downey 1992).

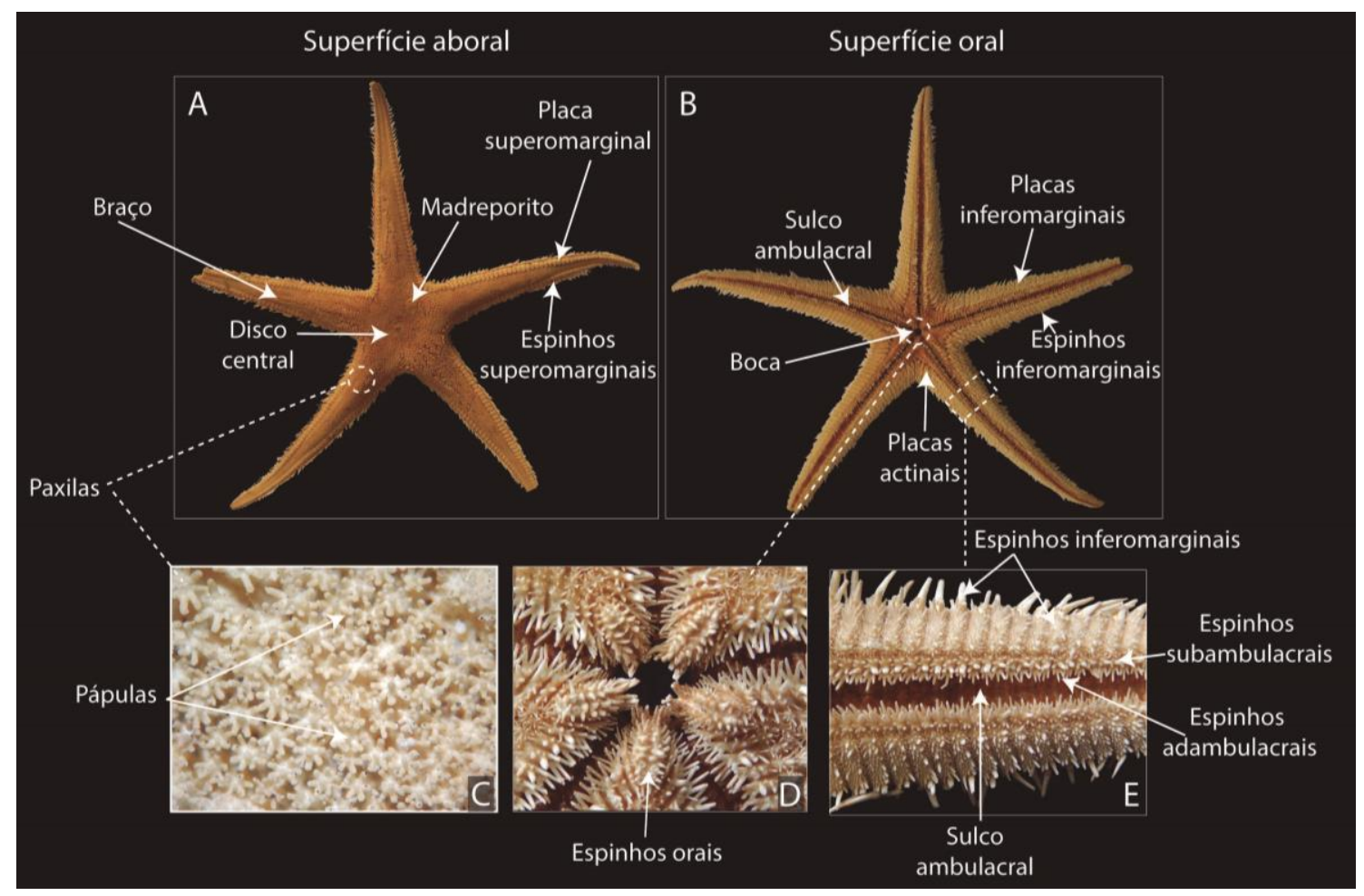

Figura 3. Principais características usadas para a identificação de espécies de Asteroidea. Morfologia externa: A. Vista aboral, B. Detalhe das paxilas, G. Vista oral, D. Detalhe da boca, E. Detalhe do braço - vista ventral.

\section{Astropectinidae Gray, 1840 \\ Astropecten Gray, 1840}

\section{Astropecten articulatus (Say, 1825) \\ Figura 4}

Diagnose: Braços moderadamente longos e estreitos. Paxilas granulosas no disco e braços. Presença de um espinho curto e ereto nas placas superomarginais distais. Placas inferomarginais com dois espinhos marginais alongados, achatados e pontudos. Três espinhos adambulacrais divergentes, mediano maior (Clark \& Downey 1992; Gondim et al. 2014).

Coloração: Superfície aboral azul escuro ou roxo. Placas superomarginais brancas ou alaranjadas. Superfície oral branca ou bege (Tommasi 1970a; Hendler et al. 1995).

Hábitat: Substrato arenoso, na profundidade de $35 \mathrm{~m}$. 
Distribuição geográfica: Oceano Atlântico: Estados Unidos até o Uruguai (Clark \& Downey 1992; Alvarado 2011). Brasil: Piauí, Ceará (Lima-Verde 1969), Rio de Janeiro (Tommasi 1970a), São Paulo (Netto et al. 2005) e Paraná (Klein et al. 2001).
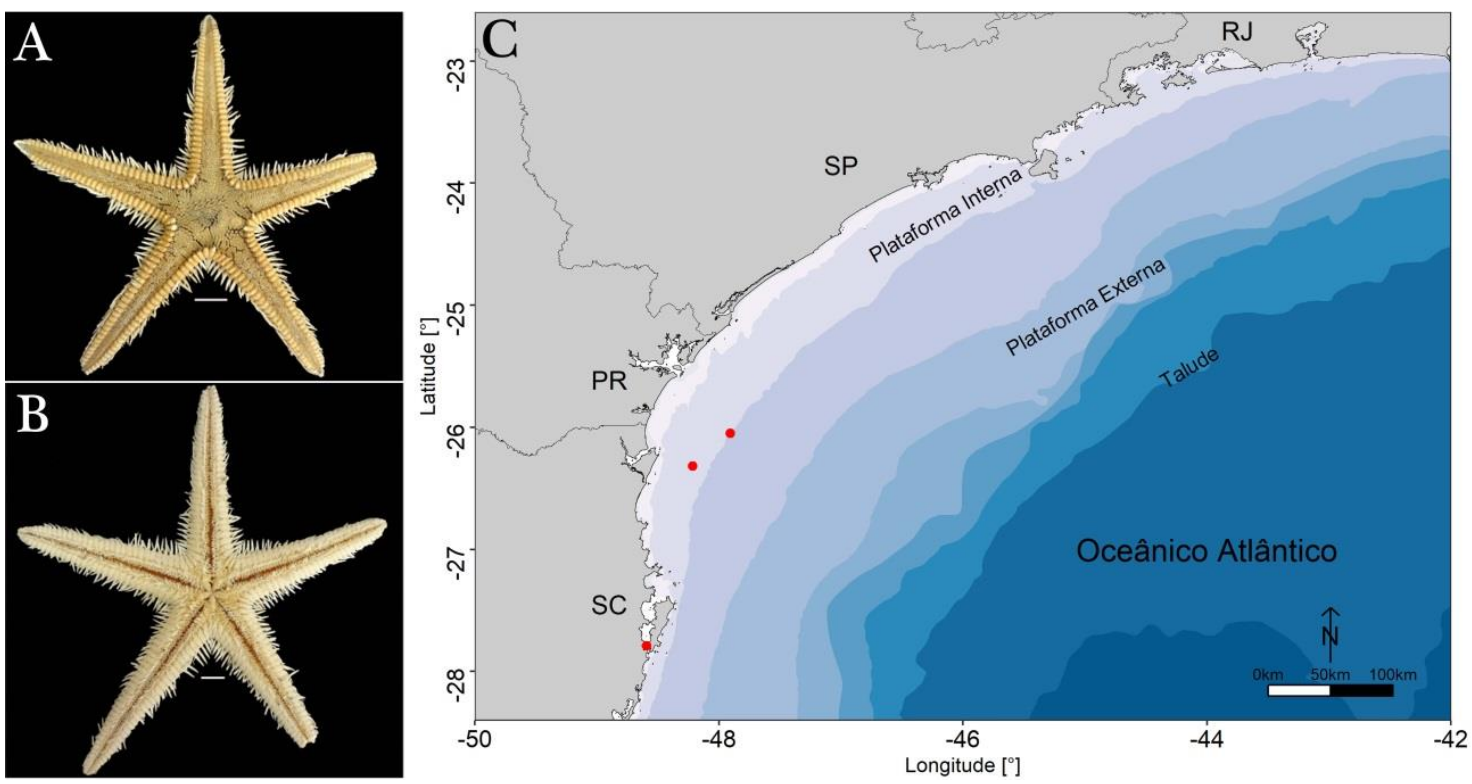

Figura 4. Astropecten articulatus - LABMAR-FAFIPAR: A. Vista aboral, B. Vista oral, C. Ocorrência de $A$. articulatus na plataforma continental interna. Escala: $10 \mathrm{~mm}$.

\section{Astropecten brasiliensis Müller \& Troschel, 1842}

Figura 5

Diagnose: Placas superomarginais mais longas que largas com dois espinhos (raramente um). Paxilas formadas por espineletes paxilares longos e numerosos. Três espinhos ambulacrais, dos quais o interno é um pouco maior que os outros (Bernasconi 1957; Tommasi 1970a; Clark \& Downey 1992).
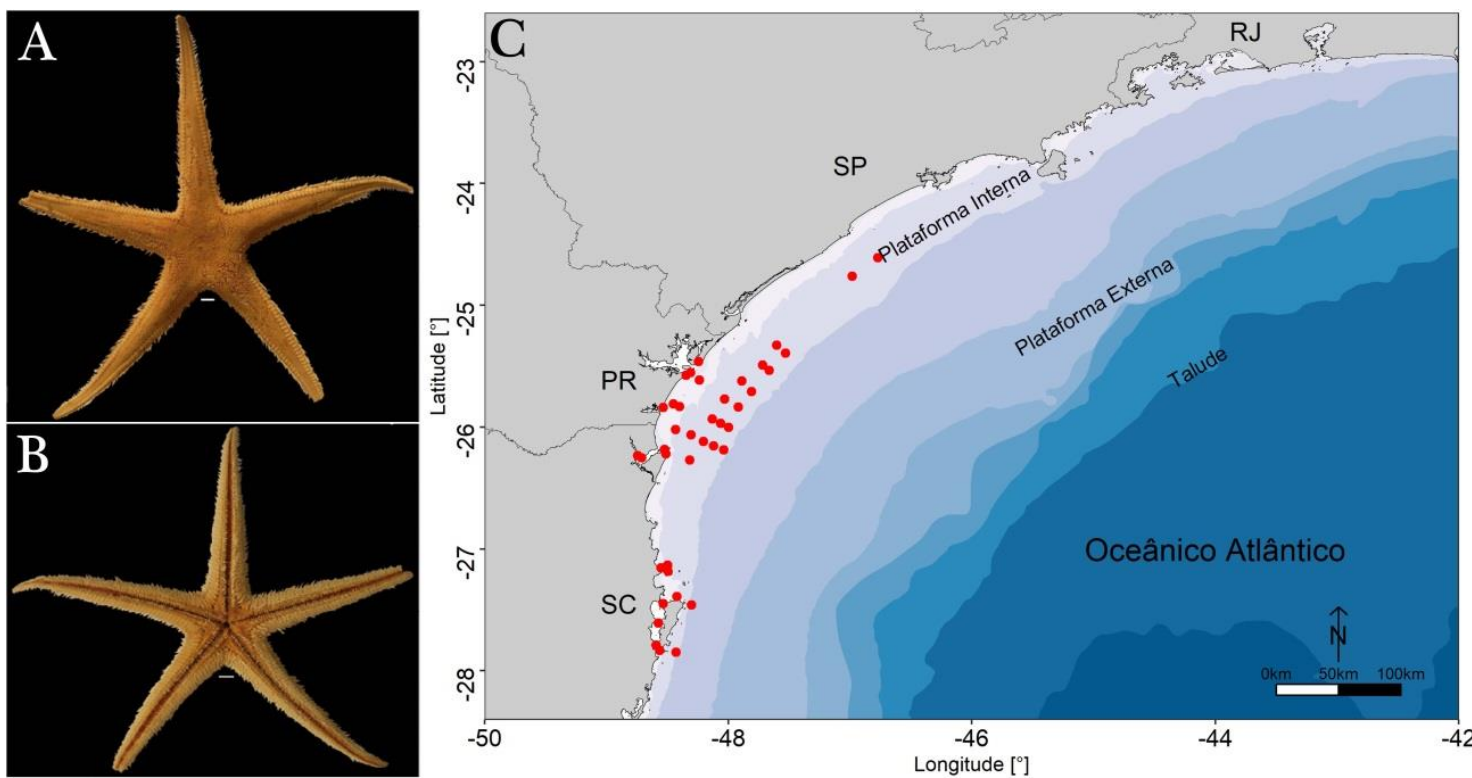

Figura 5. Astropecten brasiliensis - LEPA-CEM-UFPR: A. Vista aboral, B. Vista oral, G. Ocorrência de $A$. brasiliensis na plataforma continental interna e estuário. Escala: $10 \mathrm{~mm}$. 
Coloração: Superfície aboral violeta. Espinhos da franja marginal amarelados ou rosados. Superfície oral salmão claro (Tommasi 1970a; Clark \& Downey 1992).

Hábitat: Substrato arenoso, registrada em profundidades de até $50 \mathrm{~m}$.

Distribuição geográfica: Oceano Atlântico: Honduras, Panamá, Suriname (Clark \& Downey 1992; Alvarado et al. 2008), Brasil (Tommasi 1958, 1970a; Gondim et al. 2014; Alitto et al. 2016), Uruguai e Argentina (Bernasconi 1957).

\section{Astropecten marginatus Gray, 1840 \\ Figura 6}

Diagnose: Cinco braços largos e triangulares. Paxilas pequenas com 6-8 espineletes centrais e 12 marginais. Sem espinhos nas placas superomarginais. Placas inferomarginais destacando-se nitidamente sob as superomarginais e apresentando espinhos inferomarginais afilados e achatados (Clark \& Downey 1992; Gondim et al. 2014).

Coloração: Superfície aboral pode ser azulada ou alaranjada, mas geralmente a coloração varia entre creme e acinzentado (Tommasi 1970a; Hendler et al. 1995).

Hábitat: Substrato arenoso, em profundidades de até $15 \mathrm{~m}$.

Distribuição geográfica: Oceano Atlântico: Costa Rica, Porto Rico, Colômbia, Venezuela, Guiana e Brasil (Benavides-Serrato et al. 2005; Alvarado et al. 2008). Brasil: Ceará até Rio Grande do Sul (Tommasi 1970a; Gondim et al. 2014).
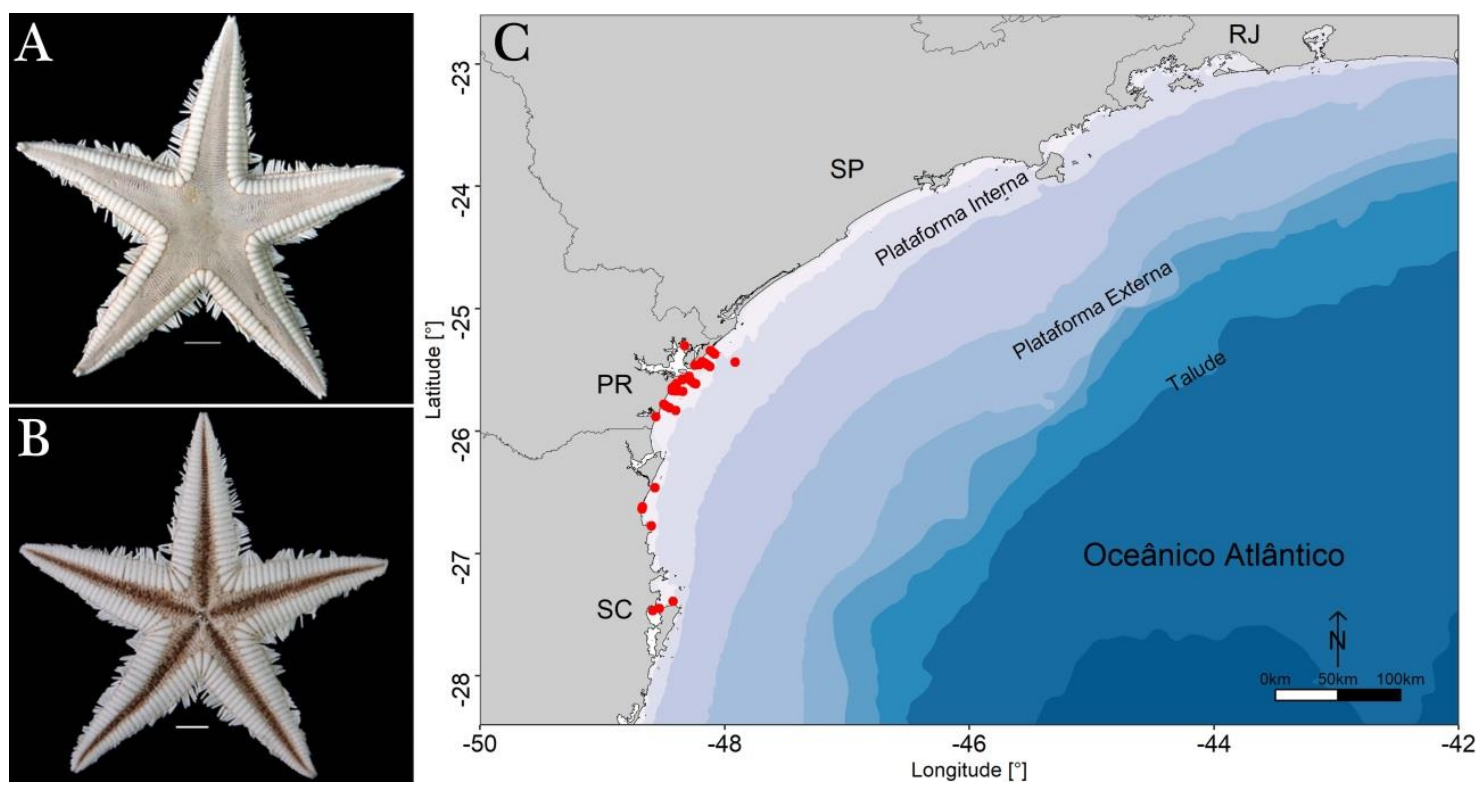

Figura 6. Astropecten marginatus - LABMAR-FAFIPAR: A. Vista aboral, B. Vista oral, C. Ocorrência de $A$. marginatus na plataforma continental interna e estuário. Escala: $10 \mathrm{~mm}$.

Thethyaster Sladen, 1889

Thethyaster vestitus vestitus (Say, 1825)

Figura 7 
Diagnose: Poucos espinhos marginais. Placas superomarginais lateralmente alinhadas, maiores que as inferomarginais, cobertas por muitos espinhos curtos, superficialmente granuliformes e poligonais. Um espinho grande truncado e retangular em cada placa actinal intermediária. Espinhos inferomarginais truncados e pontudos (Clark \& Downey 1992; Benavides-Serrato et al. 2011).

Coloração: Superfície oral e aboral amarelo-alaranjado (Benavides-Serrato et al. 2011).

Hábitat: Substrato arenoso, na profundidade de $46 \mathrm{~m}$.

Distribuição geográfica: Oceano Atlântico: Estados Unidos (Clark \& Downey 1992), Golfo do México, Panamá, Colômbia, Guiana Francesa, Venezuela (Benavides-Serrato et al. 2005) e Brasil (Tommasi 1970a): Rio de Janeiro até Rio Grande do Sul (Carrera-Rodríguez \& Tommasi 1977).
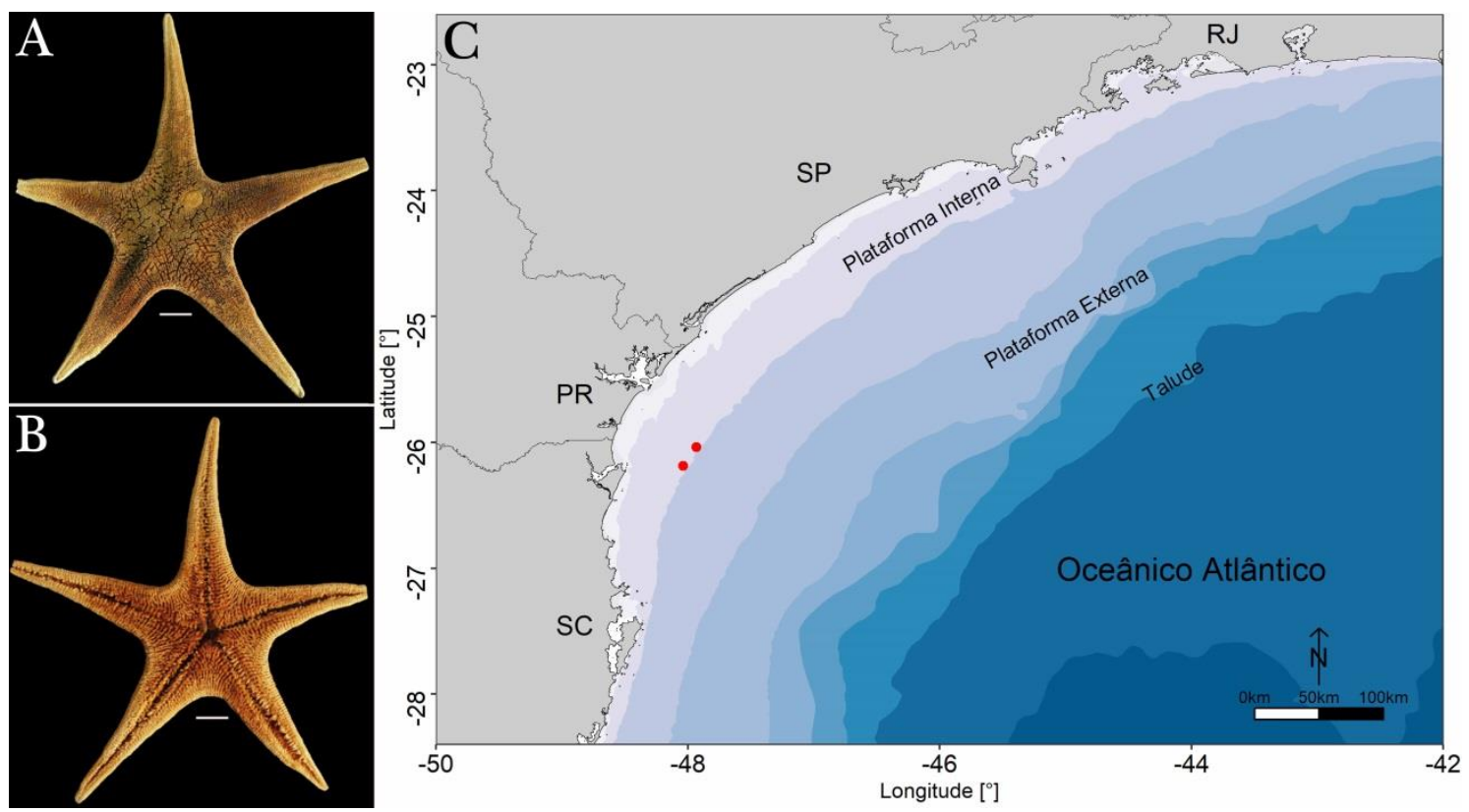

Figura 7. Thethyaster vestitus vestitus - LEPA-CEM-UFPR: A. Vista aboral, B. Vista oral, G. Ocorrência de Thethyaster vestitus vestitus na plataforma continental interna. Escala: $50 \mathrm{~mm}$.

\section{Luidiidae Sladen, 1889}

Luidia Forbes, 1839

\section{Luidia clathrata Lamarck, 1816}

Figura 8

Diagnose: Cinco braços, estreitos e longos. Paxilas da região central do disco pequenas e arredondadas. Paxilas marginais grandes e retangulares. Placas inferomarginais com dois espinhos pontudos (Clark \& Downey 1992; Hendler et al. 1995; Gondim et al. 2014).

Coloração: Superfície aboral pode variar de cinza azulado, marrom, rosa ou salmão. Alguns espécimes apresentam uma linha mais escura no braço e disco. Superfície oral branca ou creme (Clark \& Downey 1992; Hendler et al. 1995; Gondim et al. 2014).

Hábitat: Substrato arenoso ou lamoso, em profundidades de até $46 \mathrm{~m}$. 
Distribuição geográfica: Oceano Atlântico: Estados Unidos até o Brasil (Bernasconi 1943; Tommasi 1958, 1970a; Benavides-Serrato et al. 2005; Alvarado et al. 2008). Brasil: Paraíba até Santa Catarina (Tommasi 1970a; Gondim et al. 2014).
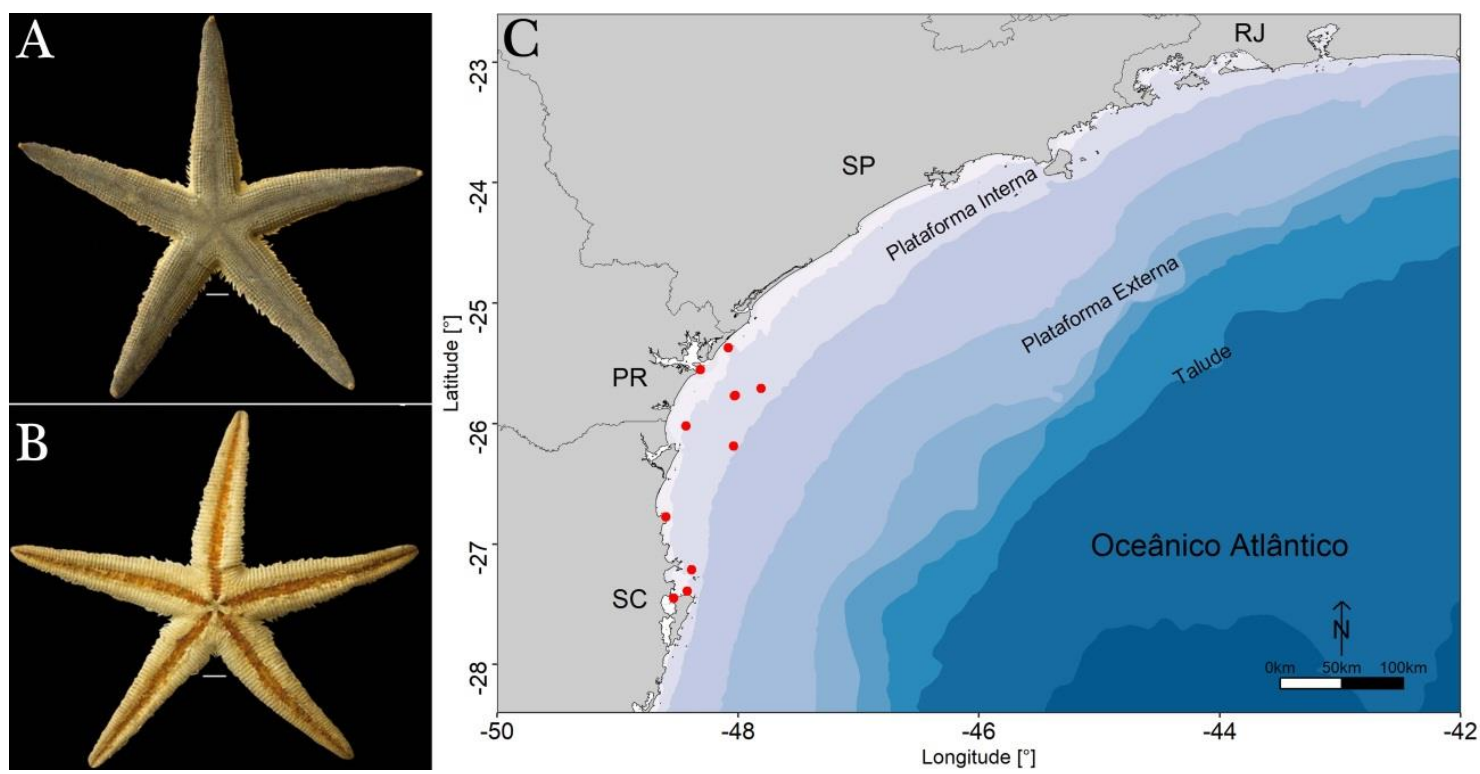

Figura 8. Luidia clathrata - LEPA-CEM-UFPR: A. Vista aboral, B. Vista oral, G. Ocorrência de L. clathrata na plataforma continental interna. Escala: $10 \mathrm{~mm}$.

Luidia ludwigi scotti Bell, 1917

Figura 9

Diagnose: Cinco braços. Nas placas superomarginais as paxilas abactinais formam fileiras transversais. Placas adambulacrais com quatro espinhos. Com pedicelárias nas placas orais. Um espinho inferomarginal (Clark \& Downey 1992; Gondim et al. 2014).

Coloração: A maioria apresenta braços com manchas brancas e marrons, mas podem apresentar manchas negras, esbranquiçadas ou pardas avermelhadas. Superfície oral apresenta coloração branca ou creme (Clark \& Downey 1992; Gondim et al. 2014).
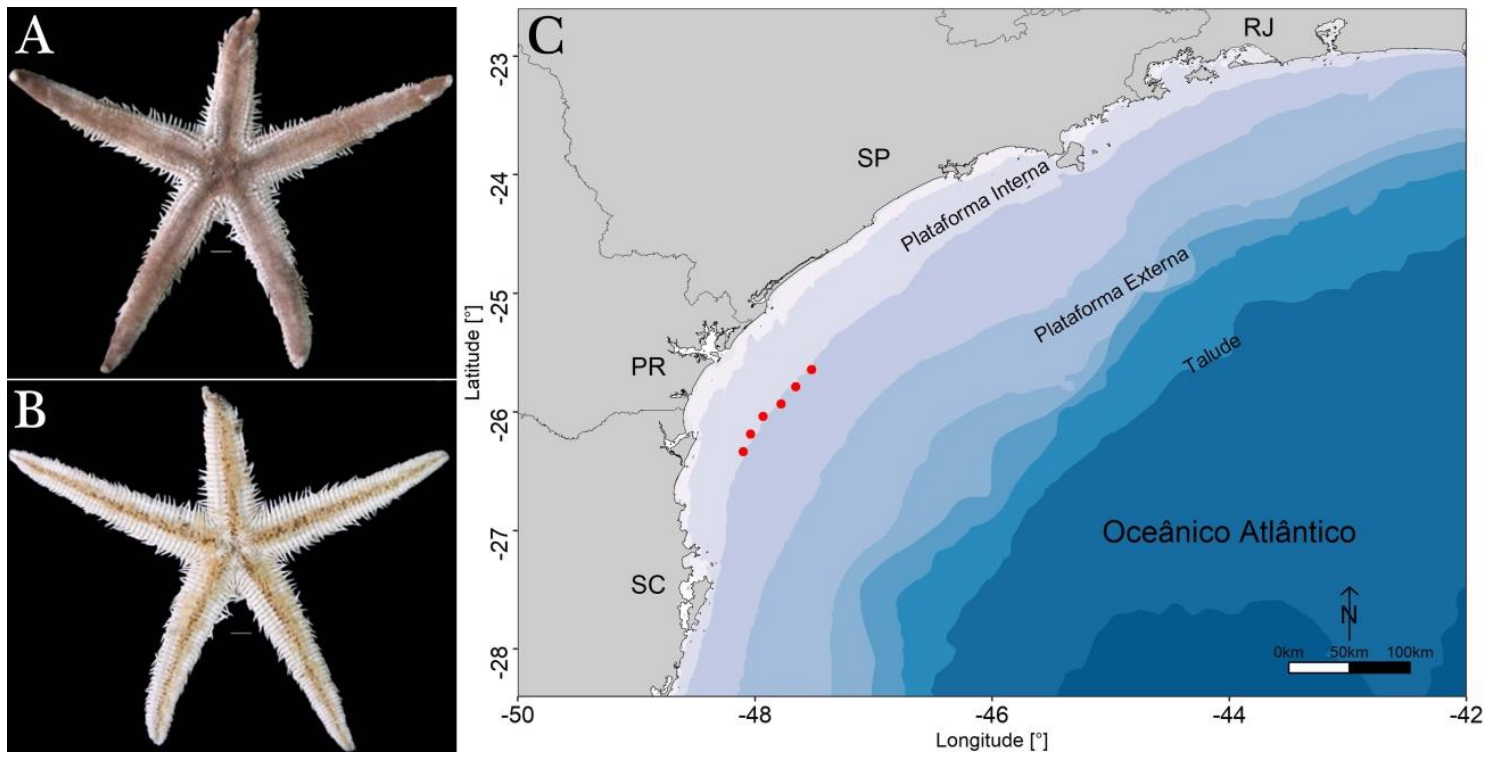

Figura 9. Luidia ludwigi scotti - ZUEC AST 29: A. Vista aboral, B. Vista oral, C. Ocorrência de Luidia ludwigi scotti na plataforma continental interna. Escala: $3 \mathrm{~mm}$. 
Hábitat: Substrato arenoso ou lamoso, em profundidades de até $50 \mathrm{~m}$.

Distribuição geográfica: Oceano Atlântico: Estados Unidos até Argentina (Bernasconi 1943; Pawson et al. 2009; Benavides-Serrato et al. 2011). Brasil: Paraíba (Gondim et al. 2014), Rio de Janeiro até Rio Grande do Sul (Carrera-Rodríguez \& Tommasi 1977).

\section{Luidia senegalensis (Lamarck, 1816)}

Figura 10

Diagnose: Sete a nove braços. Duas fileiras regulares de paxilas quadrangulares laterais. Placas inferomarginais com dois espinhos pequenos, sendo o superior o mais curto. Placas adambulacrais com quatro espinhos (Clark \& Downey 1992; Hendler et al. 1995; Gondim et al. 2014).

Coloração: Superfície aboral cinza azulado ou esverdeado com uma linha escura nos braços e disco. Superfície oral apresenta coloração branca ou creme (Hendler et al. 1995; Gondim et al. 2014).

Hábitat: Substrato arenoso, lamoso ou areno-lamoso, em profundidades de até $32 \mathrm{~m}$.

Distribuição geográfica: Oceano Atlântico: Estados Unidos até o Brasil (Clark \& Downey 1992; Alvarado et al. 2008). Brasil: Piauí até Santa Catarina (Tommasi 1970b; Gondim et al. 2014; Alitto et al. 2016).
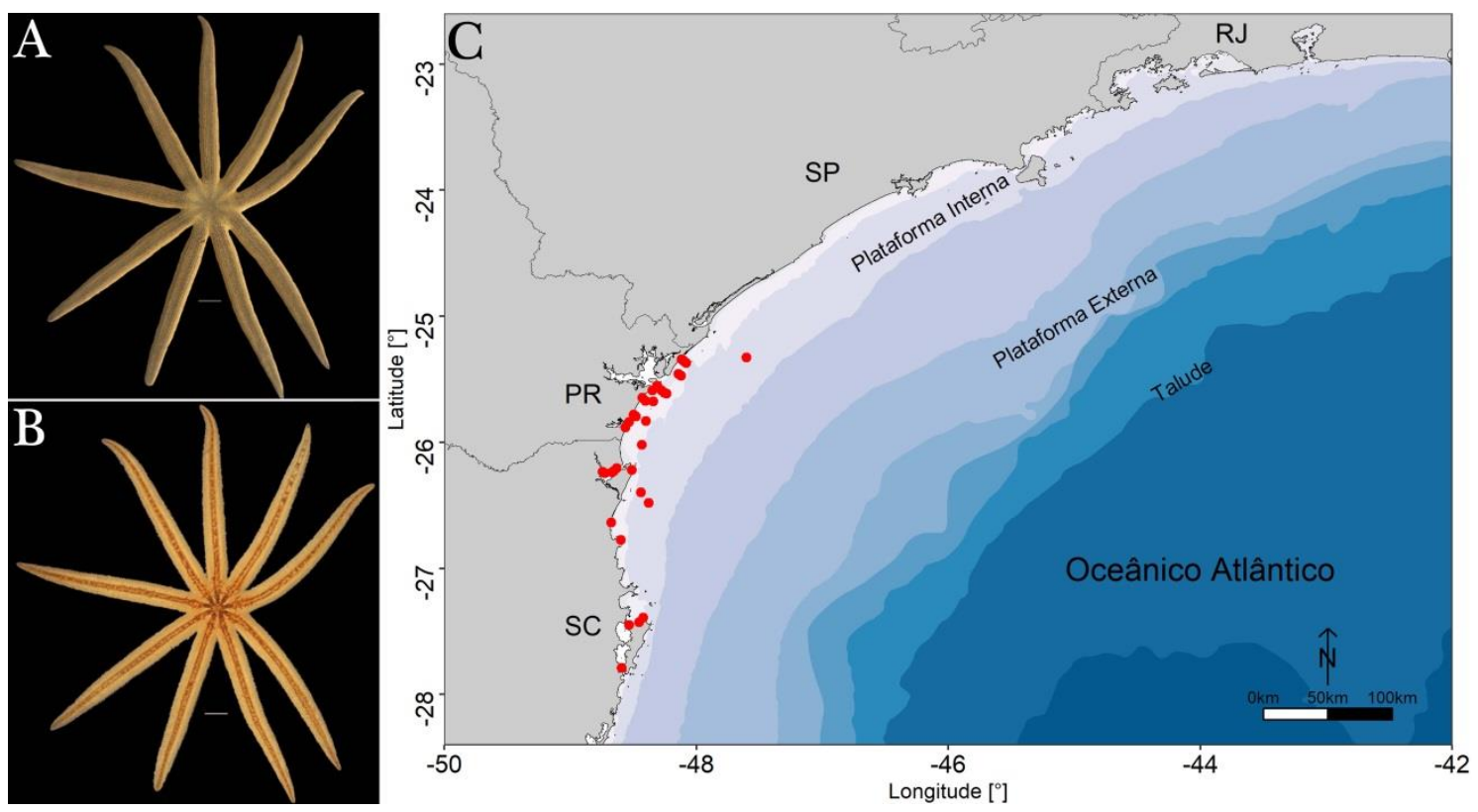

Figura 10. Luidia senegalensis - LEPA-CEM-UFPR: A. Vista aboral, B. Vista oral, C. Ocorrência de $L$. senegalensis na plataforma continental interna e estuário. Escala: $50 \mathrm{~mm}$.

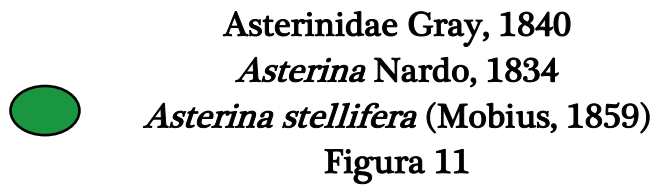

Diagnose: Cinco braços. Áreas papulares diferenciadas. Placas dorsais lobuladas com arcos curvados ou lunulados que apresentam pequenos espinhos. Pedicelárias nas placas dorsais (Tommasi 1970a; Clark \& Downey 1992). 
Coloração: Superfície aboral pode ser cinza, azul a esverdeado com manchas alaranjadas a avermelhadas (Tommasi 1970a; Clark \& Downey 1992).

Hábitat: Substratos arenosos e rochosos, em profundidades de até $6 \mathrm{~m}$.

Distribuição geográfica: Oceano atlântico: Antilhas a Argentina, a leste de Senegal até a Namíbia (Tommasi 1970a; Clark \& Downey 1992). Brasil: Rio de Janeiro (Carvalho \& Ventura 2002) até Santa Catarina (Xavier 2010).
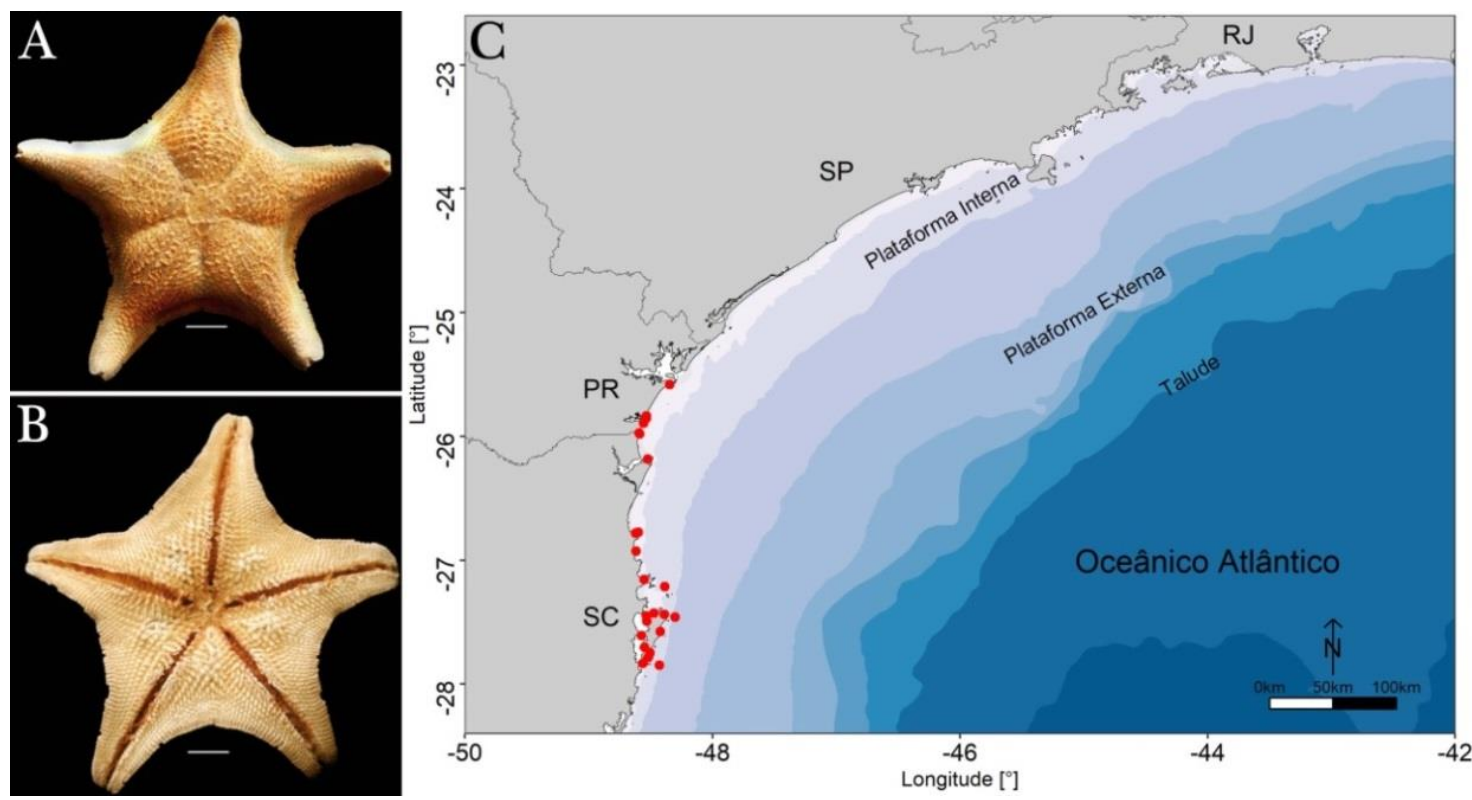

Figura 11. Asterina stellifera - LEPA-CEM-UFPR: A. Vista aboral, B. Vista oral, G. Ocorrência de $A$. stellifera nos costões rochosos da plataforma continental interna. Escala: $10 \mathrm{~mm}$.

Diplasteria Perrier, 1891

\section{Diplasterias brandti (Bell, 1881)}

Figura 12
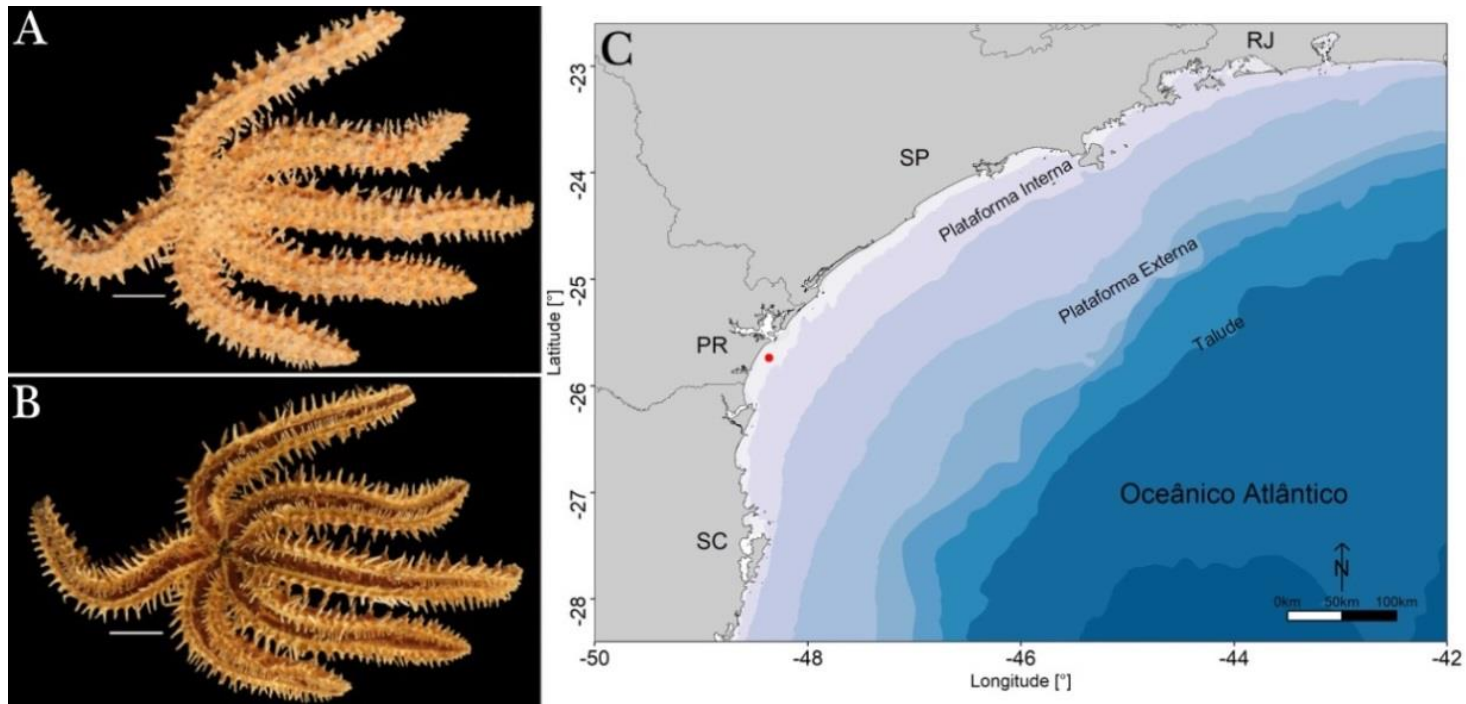

Figura 12. Diplasteria brandti - LEPA-CEM-UFPR: A. Vista aboral, B. Vista oral, G. Ocorrência de $D$. brandti próximo à Ilha dos Currais, plataforma continental interna. Escala: $10 \mathrm{~mm}$. 
Diagnose: Seis braços. Placas dos braços dispostas em séries longitudinais. Placa superomarginal e inferomarginal com dois espinhos com um colar de pedicelárias. Placas adambulacrais com dois espinhos seriais finos e sem pedicelárias (Tommasi 1970a; Clark \& Downey 1992).

Coloração: Superfície aboral castanho avermelhado alternada com faixas castanhas e claras (Tommasi 1970a; Clark \& Downey 1992).

Hábitat: Substrato arenoso ou lamoso, em profundidades de até $5 \mathrm{~m}$.

Distribuição geográfica: Oceano Atlântico: Brasil a Península Antártica (Tommasi 1970a; Clark \& Downey 1992). Brasil: São Paulo, Paraná e Rio Grande do Sul (Tommasi 1970a; CarreraRodríguez \& Tommasi 1977).

\section{Echinasteridae Verrill, 1867}

Echinaster Müller \& Troschel, 1840

\section{Echinaster (Othilia) brasiliensis (Müller \& Troschel, 1842) Figura 13}

Diagnose: Cinco braços que tendem a afilar rapidamente na extremidade. Aboralmente apresenta de 9-15 fileiras longitudinais de espinhos. Placas abactinais mameolares e placas adambulacrais com quatro espinhos, dos quais três são desenvolvidos e um é rudimentar (Clark \& Downey 1992; Gondim et al. 2014).

Coloração: Superfície aboral pode variar de marrom claro, marrom avermelhado, vermelho escuro ou vermelho amarelado (Tommasi 1970a; Clark \& Downey 1992; Gondim et al. 2014).

Hábitat: Substrato arenoso, areno-lamoso e rochoso, em profundidades de até $10 \mathrm{~m}$.

Distribuição geográfica: Oceano Atlântico: Estados Unidos até Argentina (Tommasi 1970a; Clark \& Downey 1992; Alvarado et al. 2008; Benavides-Serrato et al. 2011). Brasil: Rio Grande do Norte até Santa Catarina (Tommasi 1970a; Gondim et al. 2014; Alitto et al. 2016).
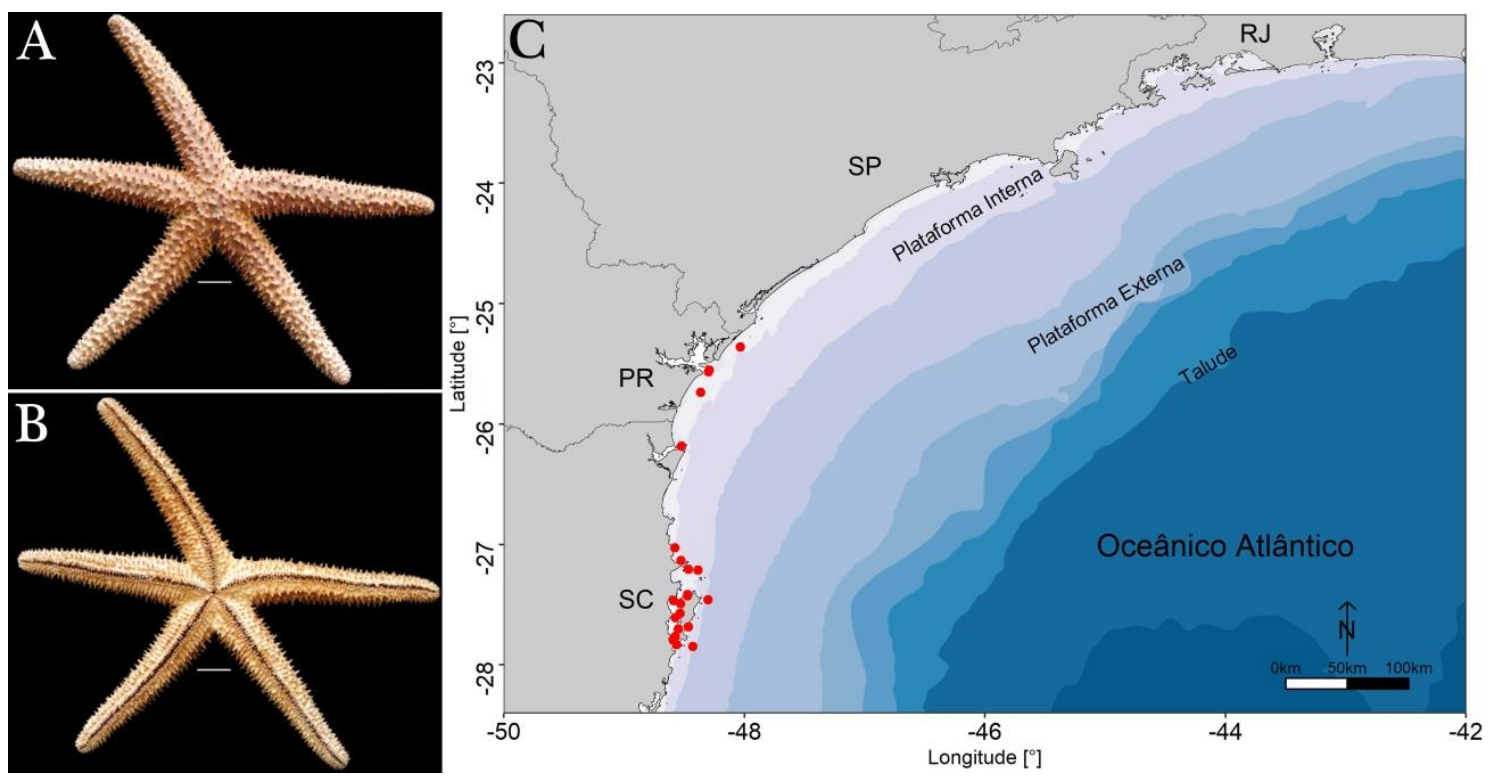

Figura 13. Echinaster (Othilia) brasiliensis — LEPA-CEM-UFPR: A. Vista aboral, B. Vista oral, G. Ocorrência de Echinaster (Othilia) brasiliensis na plataforma continental interna. Escala: $10 \mathrm{~mm}$. 


\section{Crinoidea Miller, 1821}

Considerações: Os Crinoidea, conhecidos popularmente como lírios-do-mar, formam o grupo ainda vivo que preserva a maior quantidade de caracteres ancestrais dentre os equinodermos (Hess et al. 1999), pois algumas espécies apresentam pedúnculo de fixação e todas possuem superfície oral voltada para cima, características que sugerem o hábito séssil original do grupo e a captação do alimento de forma passiva (observado em diversos fósseis). No entanto, as espécies mais recentes pertencem a subclasse Articulata (Hess 2011), sendo a maioria (80\%) da ordem Comatulida (Hemery et al. 2013; Rouse et al. 2013), a qual tem como característica principal a perda do pedúnculo no estágio juvenil, assumindo um hábito não séssil (Haig \& Rouse 2008). Essa classe exibe grande plasticidade morfológica, o que gera dificuldades taxonômicas, indicando uma diversificação contínua (Messing 1997).

Um típico lírio-do-mar consiste em uma haste segmentada que suporta um pequeno corpo central (teca) do qual se projetam braços cilíndricos e ramificados (Figura 14A).

$\mathrm{Na}$ maioria das espécies, numerosos cirros projetam-se da região centrodorsal. Eles são constituídos de uma série de ossículos, sendo o último modificado em forma de gancho, que auxilia na fixação do mesmo no substrato (Figura 14B-C) (Messing 1997).

A superfície oral é voltada para cima, localiza-se na teca onde estão presentes a boca, o ânus e os sulcos ambulacrais (Figura 14D) (Messing 1997; Roux et al. 2002). O pedúnculo, quando presente, origina-se no cálice.

Cerca de $80 \%$ do corpo de um crinoide é formado por ossículos calcários mantidos juntos por ligamentos ou músculos. Podem apresentar entre 10 e 200 braços ramificados, formados por pínulas semelhantes a penas. As pínulas são classificadas conforme sua posição e função (Messing 1997).

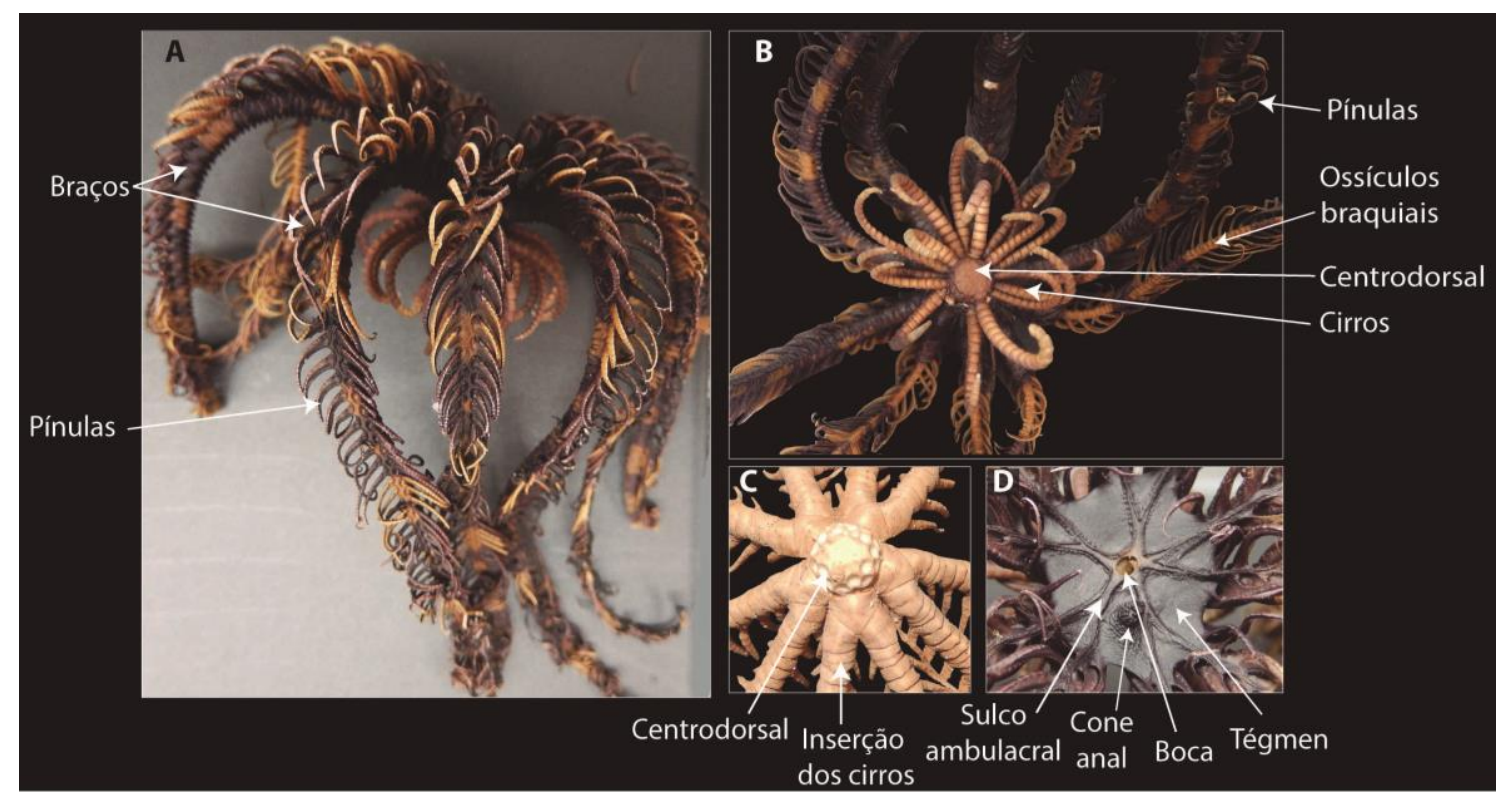

Figura 14. Principais características a serem observadas para a identificação de espécies. Morfologia externa - comatulídeo: A. Corpo central - vista lateral, B. Corpo - vista aboral, G. Detalhe da parte aboral, D. detalhe da parte oral.

Bourgueticrinidae Loriol, 1882

Democrinus Perrier, 1883

Democrinus conifer (AH Clark, 1909)

Figura 15 
Diagnose: Cinco braços. Comprimento do pedúnculo pode alcançar $280 \mathrm{~mm}$ e a coroa no mínimo $78 \mathrm{~mm}$. Sutura entre os ossículos basais normalmente visíveis, exceto em espécimes maiores. Suturas dos ossículos radiais completamente visíveis. Cálice geralmente largo e cônico (Tommasi 1965; Benavides-Serrato et al. 2011).

Coloração: Amarelo ou amarelo-alaranjado (Tommasi 1965; Benavides-Serrato et al. 2011).

Hábitat: Substrato arenoso, na profundidade de $184 \mathrm{~m}$.

Distribuição geográfica: Oceano Atlântico: Estados Unidos até o Brasil (Messing 1997; Roux et al. 2002). Brasil: Rio de Janeiro, São Paulo e Paraná (Tommasi 1969b).
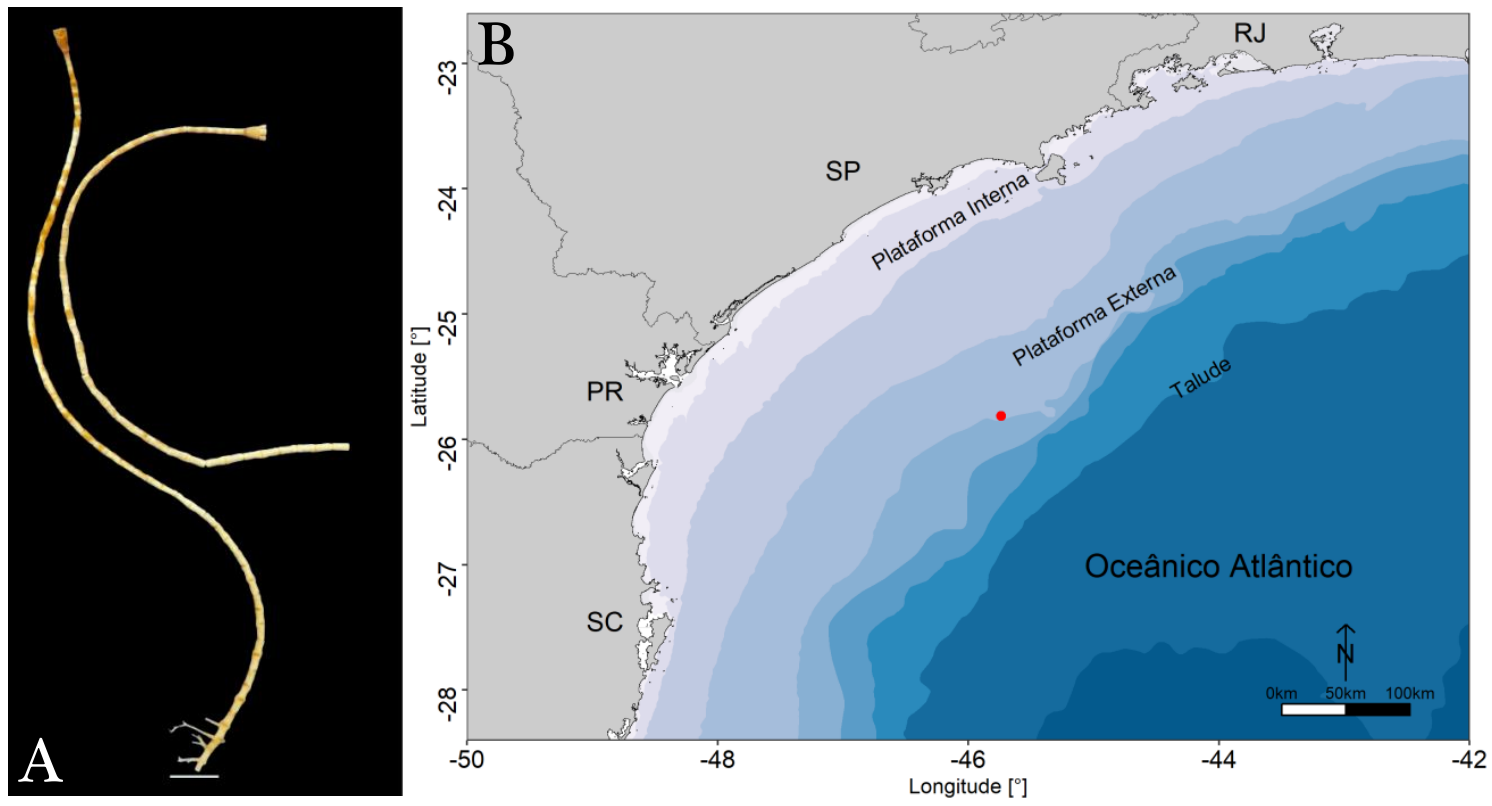

Figura 15. Democrinus conifer - MZUSP, Revizee Score Sul \#6659: A. Vista lateral de dois espécimes, B. Ocorrência de $D$. conifer na plataforma continental externa. Escala: $10 \mathrm{~mm}$.

\section{Tropiometridae AH Clark, 1908 \\ Tropiometra AH Clark, 1907}

Tropiometra carinata Clark, 1907 Figura 16

Diagnose: Dez braços. Apresentam quilhas e carenação dorsal mediana conspícua (comprimento máximo $180 \mathrm{~mm}$ ). De 19 a 27 cirros com 15-27 mm de comprimento. Segmentos dos cirros uniformes, mais largos que longos (Tommasi 1965; Benavides-Serrato et al. 2011).

Coloração: Cor variando do castanho-avermelhado até totalmente amarelo (Tommasi 1965; Benavides-Serrato et al. 2011).

Hábitat: Substrato arenoso e rochoso, em profundidades de 2 a $16 \mathrm{~m}$.

Distribuição geográfica: Oceano Atlântico: da Colômbia até o Brasil (Tommasi 1965). Oceano Índico: África, desde a Somália até o cabo da Boa Esperança incluindo Seychelles, Ilha de Comoros, Ilhas Mascarenas, Cargados e Carajos, Zanzibar e Madagascar (Larrauri 1978; Benavides-Serrato et al. 2011). 

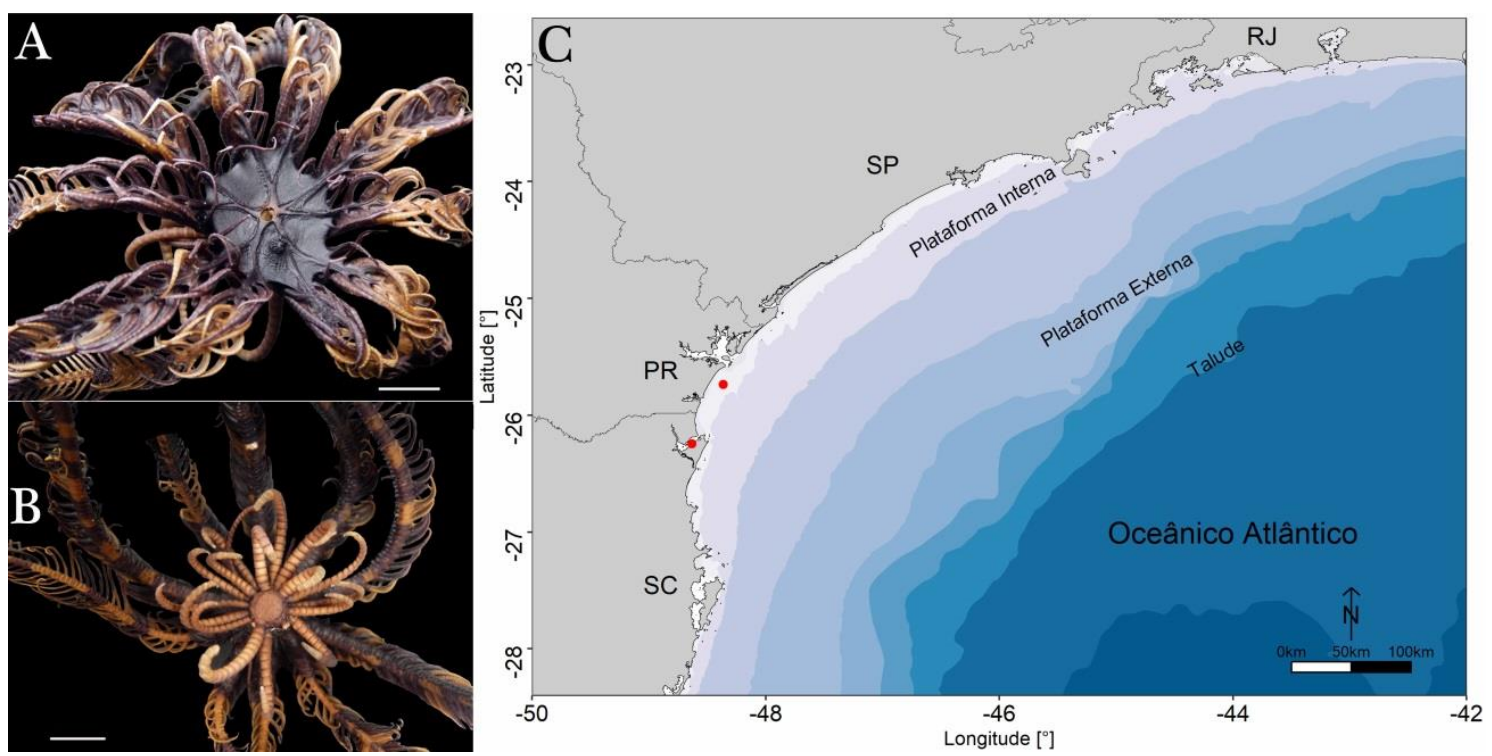

Figura 16. Tropiometra carinata - ZUEC CRI 01: A. Vista oral, B. Vista aboral, C. Ocorrência de T. carinata no Arquipélago de Currais (Paraná) e Baía de Babitonga (Santa Catarina). Escala: 5 mm.

\section{Echinoidea Leske, 1778}

Considerações: A classe Echinoidea, formada pelos mais conhecidos como ouriços-do-mar e bolachas-da-praia, é atualmente dividida em duas subclasses Cidaroidea Smith, 1984 e Euechinoidea Bronn, 1860 (Hendler et al. 1995; Kroh \& Smith 2010). Cidaroidea compreende as espécies pertencentes à ordem Cidaroida Claus, 1880, e a subclasse Euechinoidea compreende todas as demais ordens, tanto de ouriços regulares quanto irregulares (Pawson 2007).

\section{Ouriços regulares}

Considerações: Os equinoides regulares são caracterizados morfologicamente por apresentar um corpo globóide, formado por 20 colunas de placas justapostas, as quais estão organizadas em ambulacrais (zona ambulacral) intercaladas com interambulacrais (zona interambulacral). Nestas placas estão presentes tubérculos onde se articulam os espinhos primários e secundários. Na região aboral encontra-se o periprocto, que também pode estar recoberto por placas, e o ânus, posicionado próximo ou no centro do sistema apical (Hendler et al. 1995; Borrero-Pérez et al. 2012) (Figura 17A).

Ao redor da boca há a membrana peristomial, que pode estar recoberta por placas (Figura 17B). O sistema apical é constituído por cinco placas genitais e cinco ocelares, sendo uma das placas genitais maior, portando o madreporito (Figura 17C). $\mathrm{O}$ arranjo das placas deste sistema é um caráter taxonômico importante e pode ser classificado em: monocíclico, hemicíclico e dicíclico (Hendler et al. 1995; Borrero-Pérez et al. 2012).

\section{Ouriços irregulares}

Considerações: Os ouriços irregulares são divididos em dois grupos: as bolachas-de-praia e ouriços cordiformes. Os primeiros possuem corpo achatado e o ânus deslocado do sistema apical, podendo estar posicionado na margem da carapaça ou no interior da lúnula anal. As lúnulas são fendas encontradas na testa de algumas espécies de bolachas-da-praia (Hyman 1955).

Bolachas-da-praia

Apresentam na superfície aboral o petalóide, o qual é formado por cinco pétalas, das quais os inferiores são denominados bívio e as superiores trívio (Figura 17D). No centro deste petalóide está o madreporito e entre as pétalas os gonóporos. Na região oral são encontrados sulcos ramificados, denominados filódios, que partem da boca em direção à margem da carapaça 
(Figura 17E-F). O padrão de suas ramificações é utilizado na taxonomia das espécies (Hendler et al. 1995; Gondim 2012).

\section{Ouriços cordiformes}

Considerações: Apresentam externamente um corpo globoso, bilateralmente simétrico, composto por pares de colunas, interambulacrais e ambulacrais. $\mathrm{O}$ sistema apical é constituído por cinco placas ocelares e cinco genitais. A disposição e o grau de desenvolvimento das pétalas do petalóide variam de acordo com a espécie.

Ventralmente está a boca que, em geral, tem a forma de um “D” invertido e está posicionada na região mais anterior da carapaça (Figura 17G). Possuem espinhos curtos, geralmente de ponta espatulada que recobrem densamente todo corpo. Algumas espécies podem ter faixas distintas de pequenos espinhos de ponta mucosa, as quais são denominadas fascíolos.

$\mathrm{Na}$ região oral há um conjunto de placas interambulacrais alargadas denominadas plastrão e entre estas e a boca encontra-se o labrum (Figura 17H-I) (Hendler et al. 1995; Borrero-Pérez et al. 2012; Gondim 2012). Os equinoides de um modo geral apresentam um aparelho dental denominado Lanterna de Aristóteles, que são ossículos ambulacrais modificados e espinhos orais fundidos (Fernandes et al. 2002).

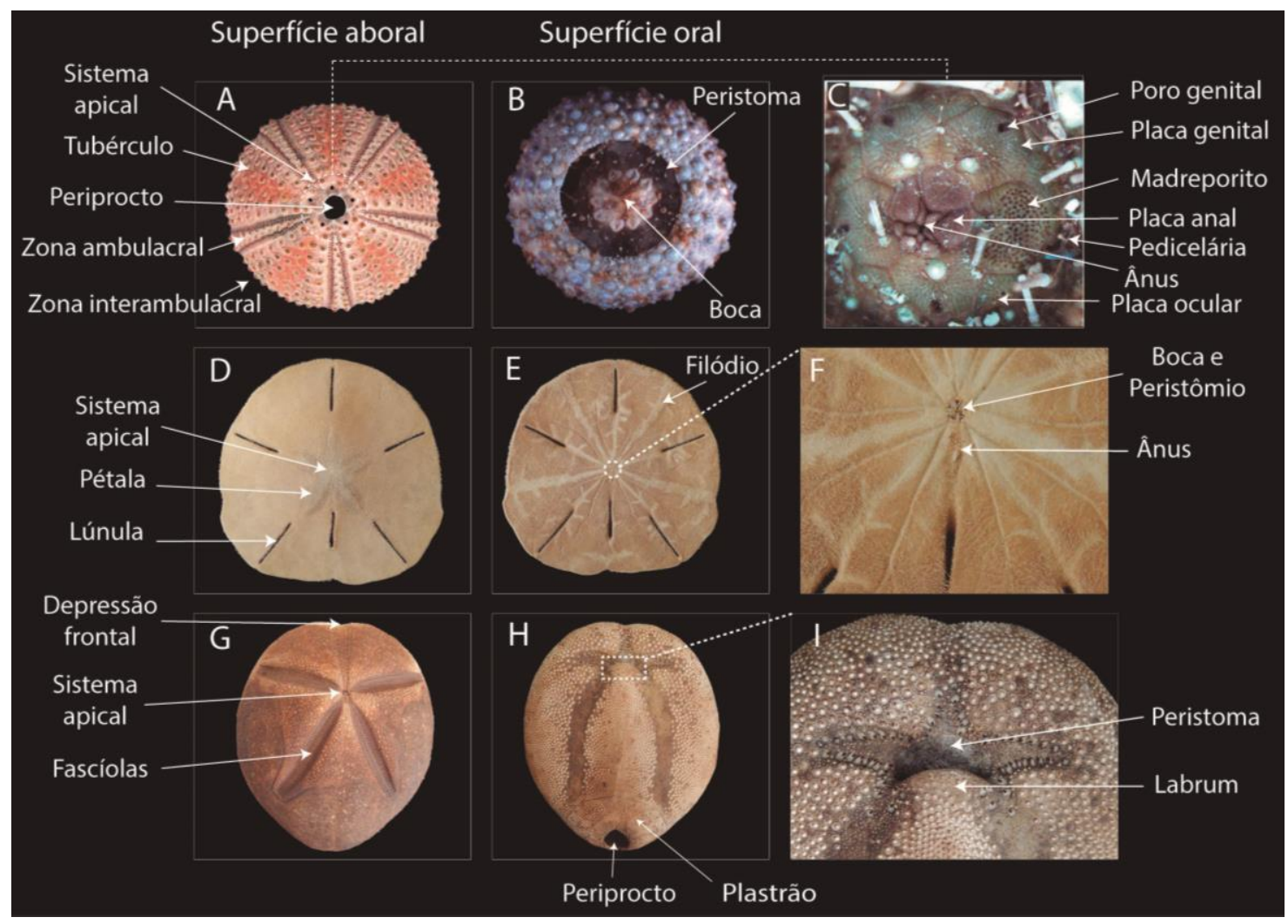

Figura 17. Principais características a serem observadas para a identificação de espécies de Echinoidea. Morfologia externa: Ouriço regular: A. Vista aboral, B. Vista oral, G. Detalhe do sistema apical. Bolacha-dapraia: D. Vista aboral, E. Vista oral, F. Detalhe da boca. Ouriço cordiforme: G. Vista aboral, H. Vista oral, I. Detalhe da boca.

Cidaridae Gray, 1825

Eucidaris Pomel, 1883

Eucidaris tribuloides (Lamarck, 1816)

Figura 18 
Diagnose: Carapaça globular, pouco achatada nas faces oral-aboral. Espinhos primários grossos, cilíndricos e às vezes afilados, terminando em uma coroa de dentículos. Sistema apical dicíclico, tuberculado. Espinhos secundários menores e achatados. Pedicelárias globíferas sem dente terminal (Tommasi 1966; Hendler et al. 1995; Borrero-Pérez et al. 2012).

Coloração: Testa marrom-clara a marrom-avermelhada. Espinhos juvenis primários têm bandas alternadas brancas e castanho avermelhadas, nos adultos são esbranquiçados com as pontas levemente pintadas de marrom (Hendler et al. 1995; Borrero-Pérez et al. 2012).

Hábitat: Substrato não consolidado, em profundidades de até $6 \mathrm{~m}$.

Distribuição geográfica: Oceano Atlântico: Estados Unidos até o Brasil (Hendler et al. 1995; Kroh \& Mooi 2018). Brasil: Paraíba até Santa Catarina (Tommasi 1958; Xavier 2010; Gondim 2012).
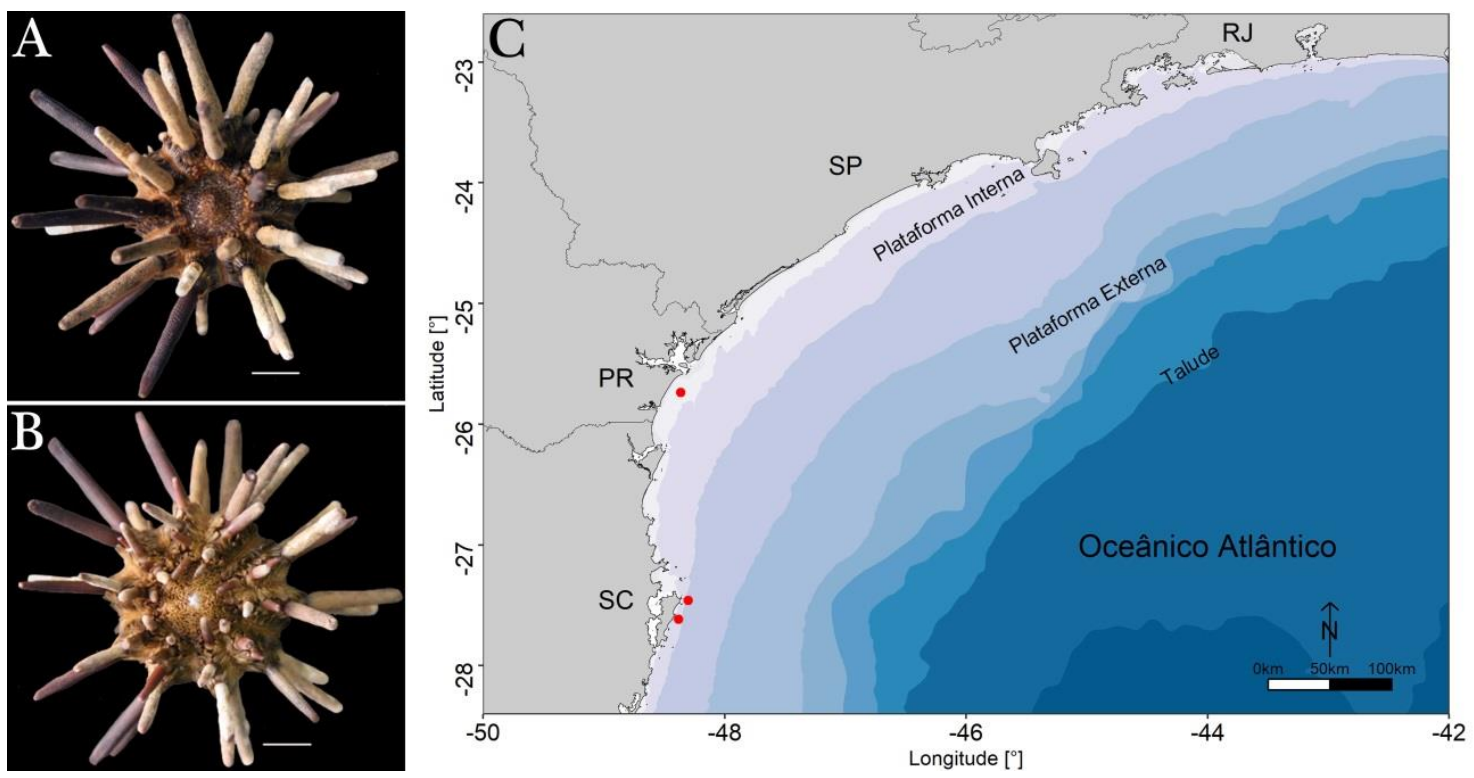

Figura 18. Eucidaris tribuloides - ZUEC ECH 07: A. Vista aboral, B. Vista oral, G. Ocorrência de $E$. tribuloides na plataforma continental interna. Escala: $10 \mathrm{~mm}$.

\section{Echinometridae Gray, 1855 \\ Echinometra Gray, 1825}

\section{Echinometra lucunter (Linnaeus, 1758) Figura 19}

Diagnose: Carapaça variando de elíptica até arredondada. Sistema apical hemicíclico. Placa ocular "V" comumente estendida para fora do sistema apical. Placas do periprocto densamente cobertas de espinhos. Placas ambulacrais poligeminadas, com 4-8 pares de poros dispostos em arco em cada placa composta. Um tubérculo primário grande em cada placa ambulacral e interambulacral. Pedicelárias globíferas com um dente lateral. Espinhos grossos (Serafy 1979; Hendler et al. 1995).

Coloração: Espinhos da superfície aboral variam de verde-oliva na base e verde, roxo ou violeta no ápice, os demais espinhos podem ser negros ou vermelhos (Hendler et al. 1995).

Hábitat: Preferencialmente substrato rochoso, em profundidades de até $6 \mathrm{~m}$. 
Distribuição geográfica: Oceano Atlântico: Estados Unidos até o Brasil e oeste da África (Pawson et al. 2009). Brasil: Ceará até Santa Catarina (Tommasi 1966; Gondim 2012).
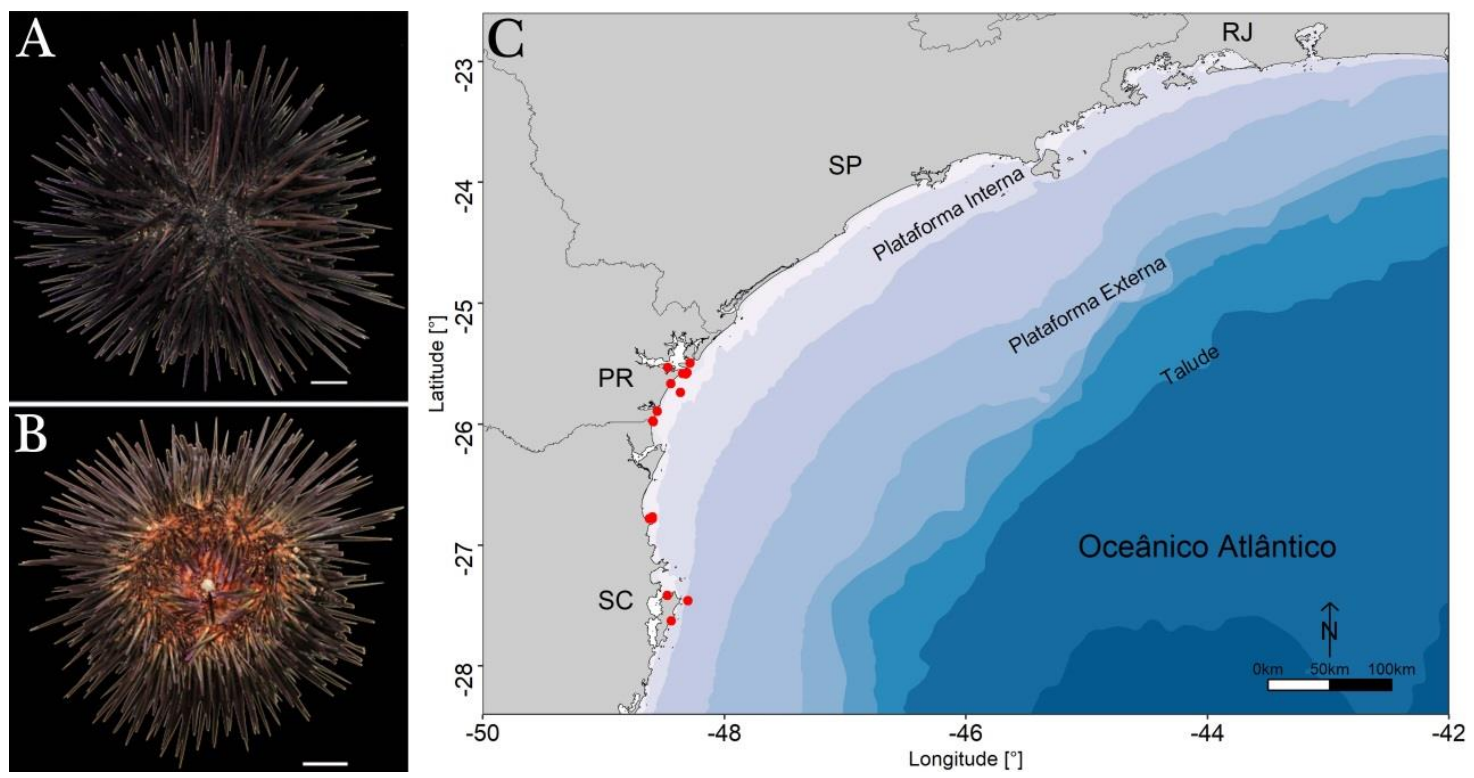

Figura 19. Echinometra lucunter - ZUEC ECH 29: A. Vista aboral, B. Vista oral, C. Ocorrência de $E$. lucunter na plataforma continental interna e estuário. Escala: $10 \mathrm{~mm}$.

\section{Toxopneustidae Troschel, 1872 \\ Lytechinus A. Agassiz, 1863}

\section{Lytechinus variegatus (Lamarck, 1816) \\ Figura 20}

Diagnose: Carapaça hemisférica achatada na região oral. Sistema apical hemicíclico, com oculares I e V inseridas. Placas do sistema apical com poucos tubérculos. Peristômio densamente coberto por placas hexagonais. Placas ambulacrais com três pares de poros. Espinhos cobrindo uniformemente a carapaça, exceto nas áreas interambulacrais (Tommasi 1966; Hendler et al. 1995; Borrero-Pérez et al. 2012).
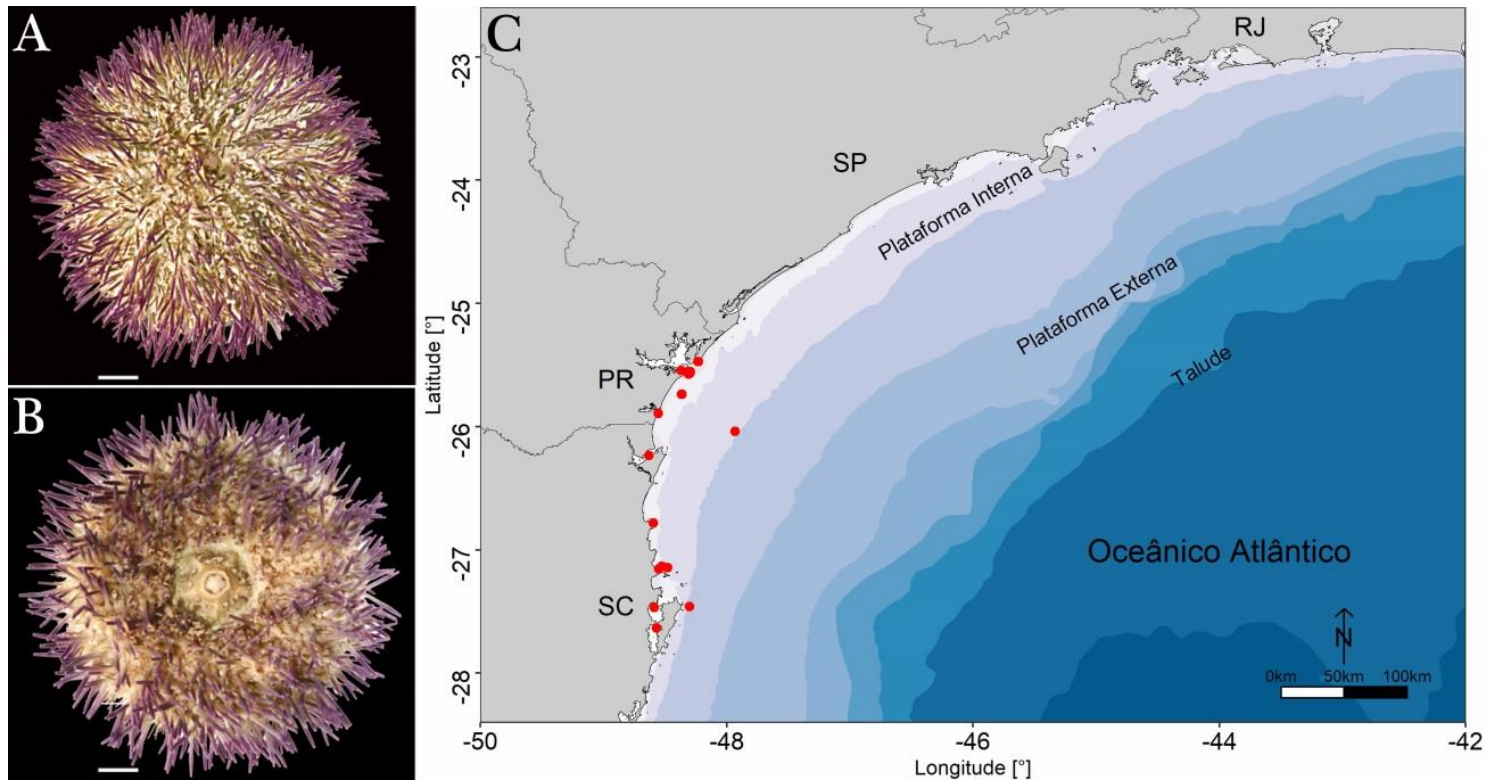

Figura 20. Lytechinus variegatus - ZUEC ECH 34: A. Vista aboral, B. Vista oral, C. Ocorrência de $L$. variegatus na plataforma continental interna e estuário. Escala: $10 \mathrm{~mm}$. 
Coloração: Carapaça esverdeada. Espinhos verdes com extremidade arroxeada, podendo ainda apresentar-se amarelados, azulados ou avermelhados (Tommasi 1966; Hendler et al. 1995).

Hábitat: Preferencialmente substrato rochoso, em profundidades de até $46 \mathrm{~m}$.

Distribuição geográfica: Oceano Atlântico: Bermudas, Estados Unidos até o Brasil (Tommasi 1966; Hendler et al. 1995; Alvarado \& Solís-Marín 2013).

\section{Arbaciidae Gray, 1855 \\ Arbacia Gray, 1835 \\ Arbacia lixula (Linnaeus, 1758) \\ Figura 21}

Diagnose: Carapaça hemisférica, sistema apical dicíclico nu. Quatro placas anais bem desenvolvidas. Pedicelárias tridentadas alongadas. Zona ambulacral formada por placas trigeminadas. Zona interambulacral com numerosos tubérculos dispostos em séries regulares (Bernasconi 1955; Tommasi 1966).

Coloração: Carapaça avermelhada ou negra. Espinhos com as pontas esbranquiçadas. Jovens apresentam faixas transversais coloridas nos espinhos (Tommasi 1966).

Hábitat: Substrato rochoso, em profundidades de até $10 \mathrm{~m}$.

Distribuição geográfica: Oceano Atlântico: a oeste Venezuela até Argentina, a leste toda costa Africana e ao norte Galícia (Besteiro \& Ugorri 1988), nas Ilhas Canárias, Madeira e Açores; Mar Mediterrâneo (Tommasi 1966). Brasil: Rio de Janeiro até Santa Catarina (Netto et al. 2005; Xavier 2010; Alitto et al. 2016).
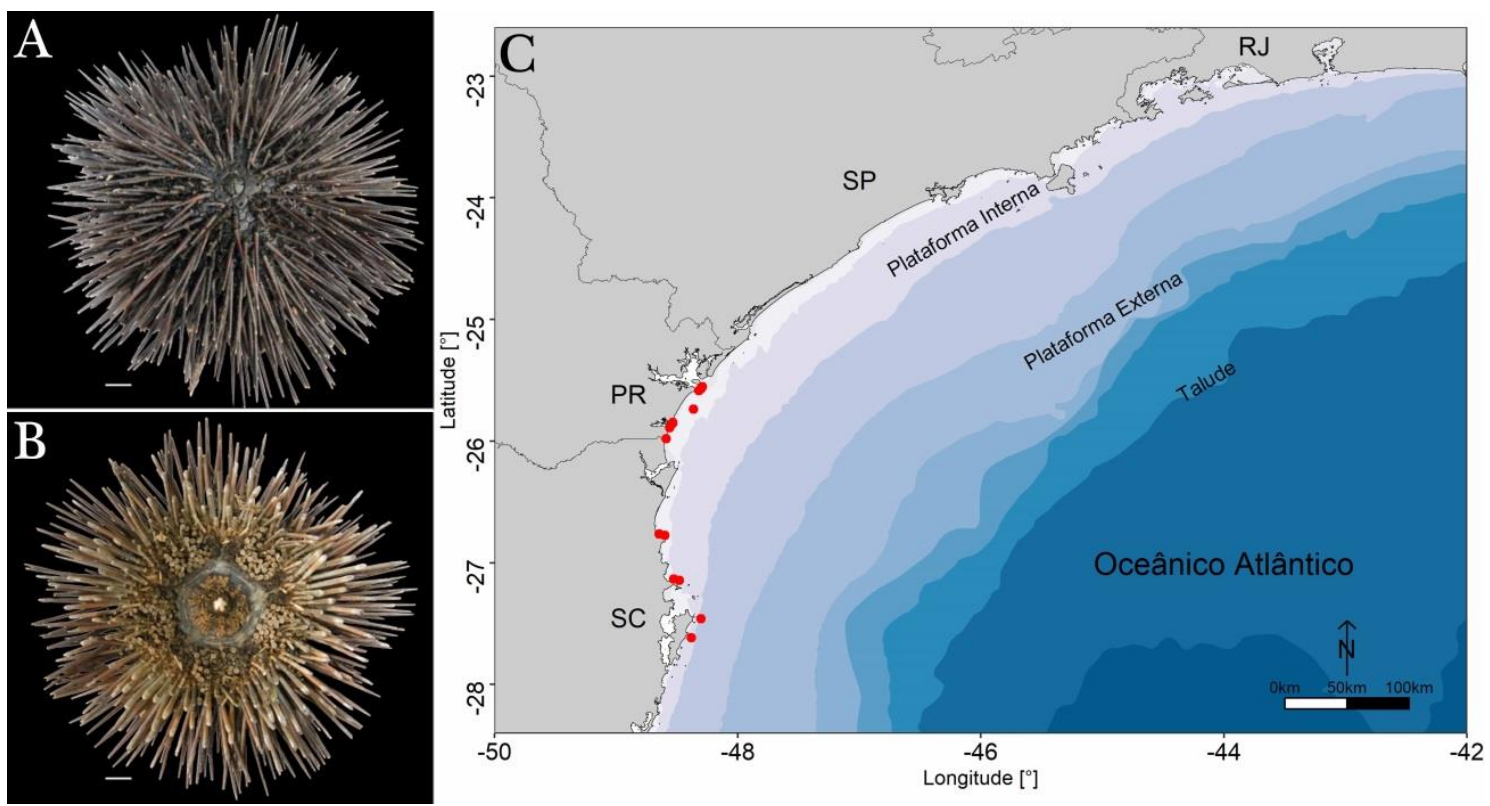

Figura 21. Arbacia lixula - ZUEC ECH 27: A. Vista aboral, B. Vista oral, G. Ocorrência de $A$. lixula na plataforma continental interna. Escala: $10 \mathrm{~mm}$. 
Paracentrotus gaimardi (Blainville, 1825)

Figura 22

Diagnose: Carapaça hemisférica, âmbito circular. Sistema apical dicíclico. Placas apicais estriadas no sentido radial. Placas genitais com poucos tubérculos secundários no seu bordo interno. Dois tipos de pedicelárias tridentadas. Espinhos uniformemente distribuídos, maiores que a altura da carapaça, delgados com estrias longitudinais finas (Netto 2006).

Coloração: Varia do verde, branco, azul, roxo ou avermelhado (Tommasi 1966).

Hábitat: Substrato rochoso, comum em profundidades de até $5 \mathrm{~m}$ (Tommasi 1966).

Distribuição geográfica: Oceano Atlântico: Brasil, Angola e Golfo de Guiné (Tommasi 1966; Netto et al. 2005).
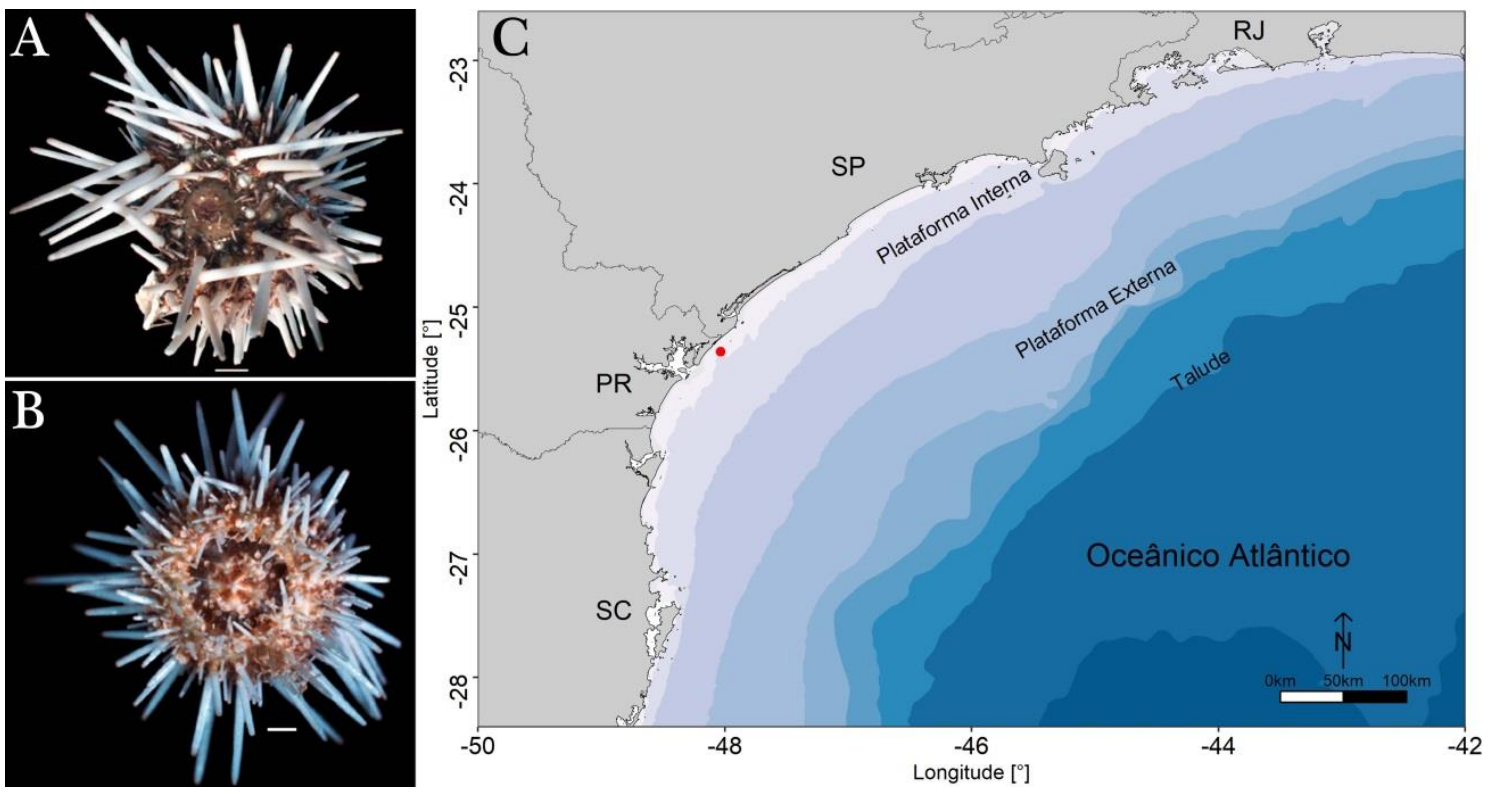

Figura 22. Paracentrotus gaimardi - MZUSP 01112: A. Vista aboral (escala: $2 \mathrm{~mm}$ ), B. Vista oral (escala: 1 $\mathrm{mm})$, G. Ocorrência de $P$. gaimardi na plataforma continental interna.

\section{Mellitidae Stefanini, 1912 \\ Mellita L. Agassiz, 1841}

\section{Mellita quinquiesperforata (Leske, 1778)}

Figura 23

Diagnose: Carapaça elíptica, achatada, com uma pequena elevação na região anterior. Periprocto coberto por placas grandes. Pedicelárias bidentadas. Quatro gonóporos. Cinco lúnulas, uma interambulacral, maior e mais larga e quatro ambulacrais, estreitas e do mesmo tamanho (Tommasi 1966; Francisco \& Pauls 2008).

Coloração: Varia do marrom escuro ao claro (Tommasi 1966).

Hábitat: Substrato arenoso, em profundidades de até $20 \mathrm{~m}$.

Distribuição geográfica: Oceano Atlântico: Estados Unidos até Argentina (Tommasi 1966; Brito 1968; Pomory 2004; Alvarado et al. 2008; Kroh \& Mooi 2018). 

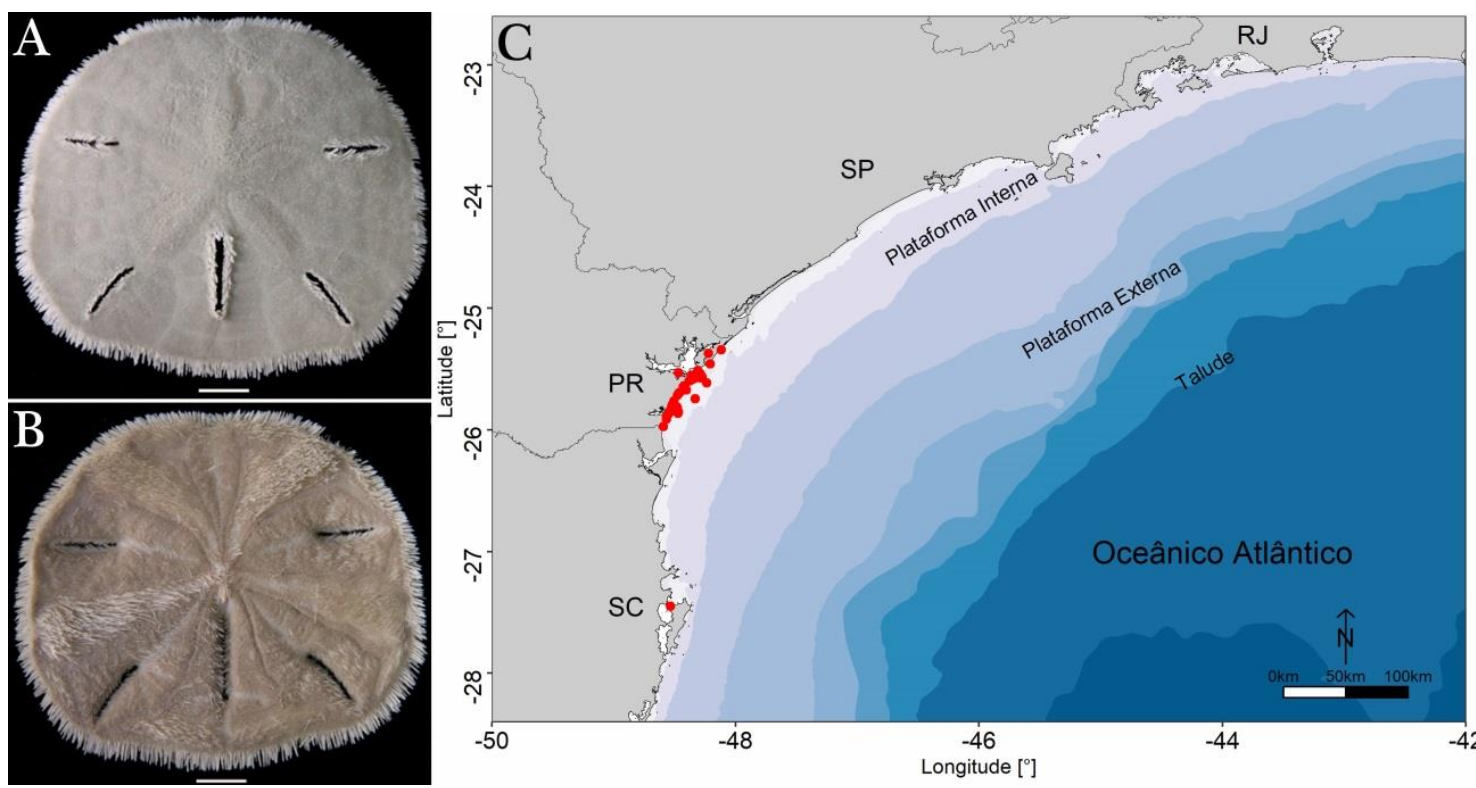

Figura 23. Mellita quinquiesperforata - LEPA-UFPR-CEM: A. Vista aboral, B. Vista oral, C. Ocorrência de M. quinquiesperforata na plataforma continental interna e estuário. Escala: $10 \mathrm{~mm}$.

\section{Leodia Gray, 1851}

\section{Leodia sexiesperforata (Leske, 1778) Figura 24}

Diagnose: Carapaça elíptica, elevada na região mediana. Quatro gonóporos. Seis lúnulas estreitas e alongadas, uma interambulacral menor e cinco ambulacrais do mesmo tamanho. Pedicelárias bivalves. Petalóide pequeno com pétalas posteriores um pouco maior que as anteriores (Tommasi 1966; Francisco \& Pauls 2008).
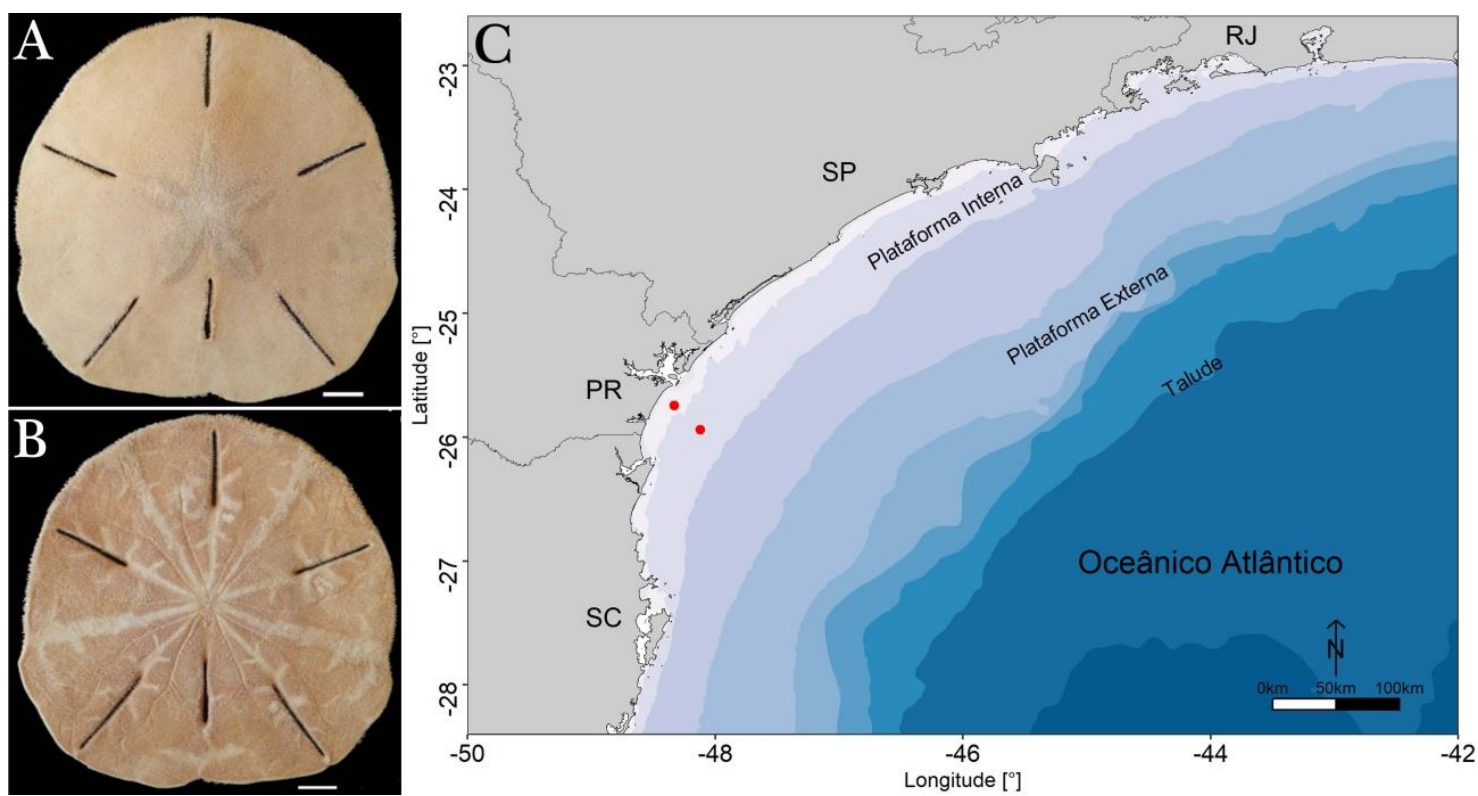

Figura 24. Leodia sexiesperforata - LEPA-UFPR-CEM: A. Vista aboral, B. Vista oral, G. Ocorrência de $L$. sexiesperforata na plataforma continental interna. Escala: $10 \mathrm{~mm}$.

Coloração: Varia do marrom-amarelado a castanho claro (Hendler et al. 1995).

Hábitat: Substrato arenoso, em profundidades de até $17 \mathrm{~m}$. 
Distribuição geográfica: Oceano Atlântico: Estados Unidos até o Uruguai (Tommasi 1966; Hendler et al. 1995).

\section{Encope L. Agassiz, 1840}

\section{Encope emarginata (Leske, 1778)}

Figura 25

Diagnose: Carapaça ovalada, elevada na região apical ou na região mediana. Superfície oral plana. Cinco gonóporos. Pétalas do bívio maiores do que as do trívio. Seis lúnulas, posteriores maiores que as anteriores. Espinhos claviformes que cobrem uniformemente a superfície aboral (Brito 1960; Tommasi 1966; Francisco \& Pauls 2008).

Coloração: Marrom claro ou esverdeada (Brito 1960).

Hábitat: Substrato arenoso, em profundidades de até $50 \mathrm{~m}$.

Distribuição geográfica: Oceano Atlântico: Estados Unidos, Belize, Guatemala, Panamá, Colômbia, Venezuela, Argentina e Brasil (Bernasconi 1955; Tommasi 1966; Francisco \& Pauls 2008; Alvarado 2011; Alitto et al. 2016; Kroh \& Mooi 2018).

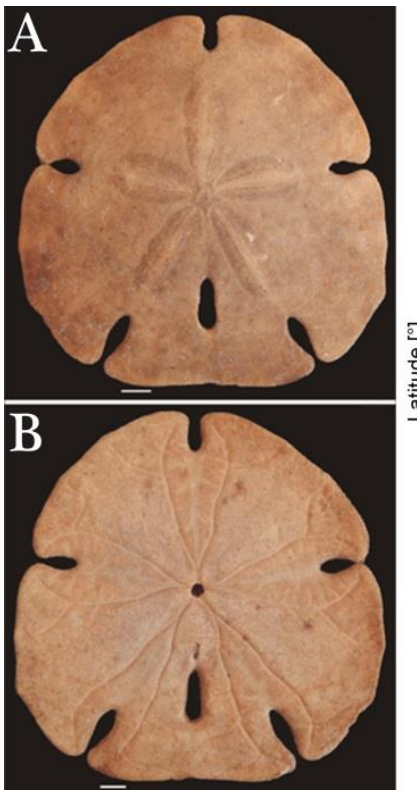

Figura 25. Encope emarginata - ZUEC ECH 30: A. Vista aboral, B. Vista oral, G. Ocorrência de $E$. emarginata na plataforma continental interna e estuários. Escala: $0.5 \mathrm{~mm}$.

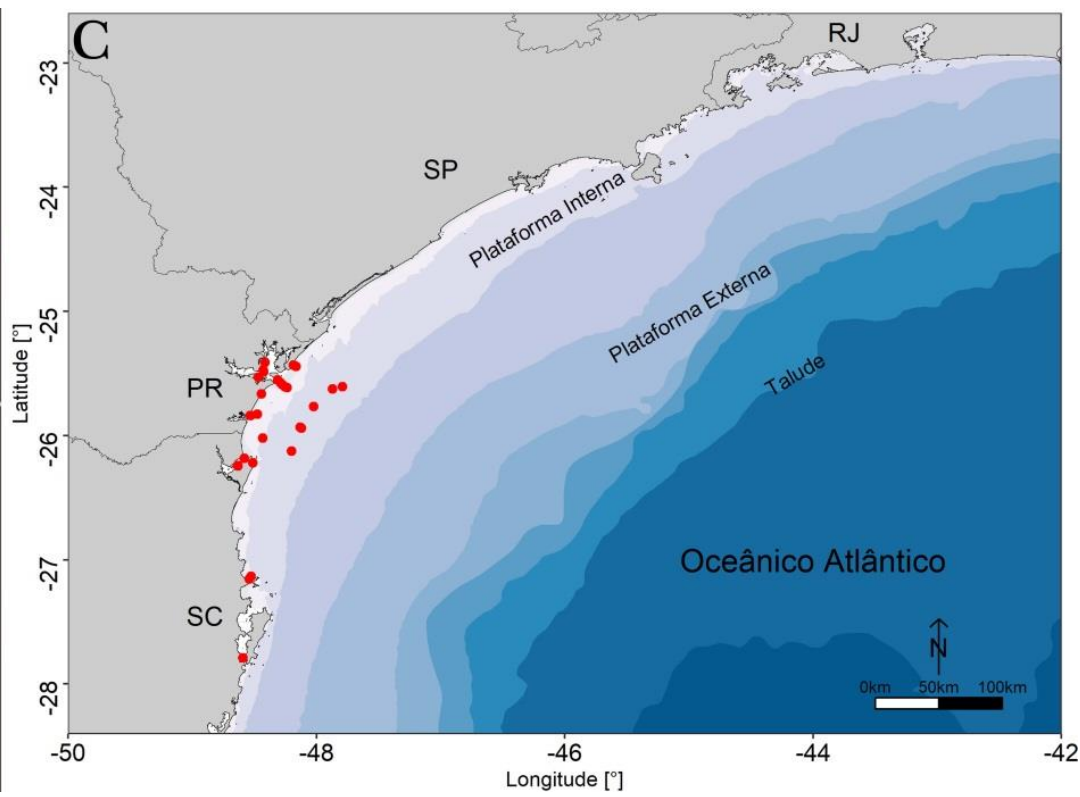

Brissidae Gray, 1855

Brissopsis L. Agassiz, 1840

\section{Brissopsis atlantica Mortensen, 1907}

Figura 26

Diagnose: Carapaça elevada na região posterior. Área do petalóide não muito desenvolvida. Fascíolo subanal bem desenvolvido e reniforme. Quatro poros genitais. Labrum curvado. Cinco placas ambulacrais no plastrão subanal. Pétalas posteriores proximalmente convergentes e distalmente divergentes. A $6^{\mathbf{0}}$ placa ambulacral é a primeira a entrar no plastrão subanal (Chesher 1968). 
Coloração: Os jovens são muito pálidos quase branco, mas depois de passar de $40 \mathrm{~mm}$ a cor escurece e adultos podem chegar a até um verde oliva escuro ou marrom intenso (PérezFarfante 1959).

Hábitat: Substrato arenoso, na profundidade de $241 \mathrm{~m}$.

Distribuição geográfica: Oceano Atlântico: Estados Unidos até o Brasil (Serafy 1979; Alvarado \& Solís-Marín 2013). Brasil: Espírito Santo até Rio Grande do Sul (Tommasi 2004).
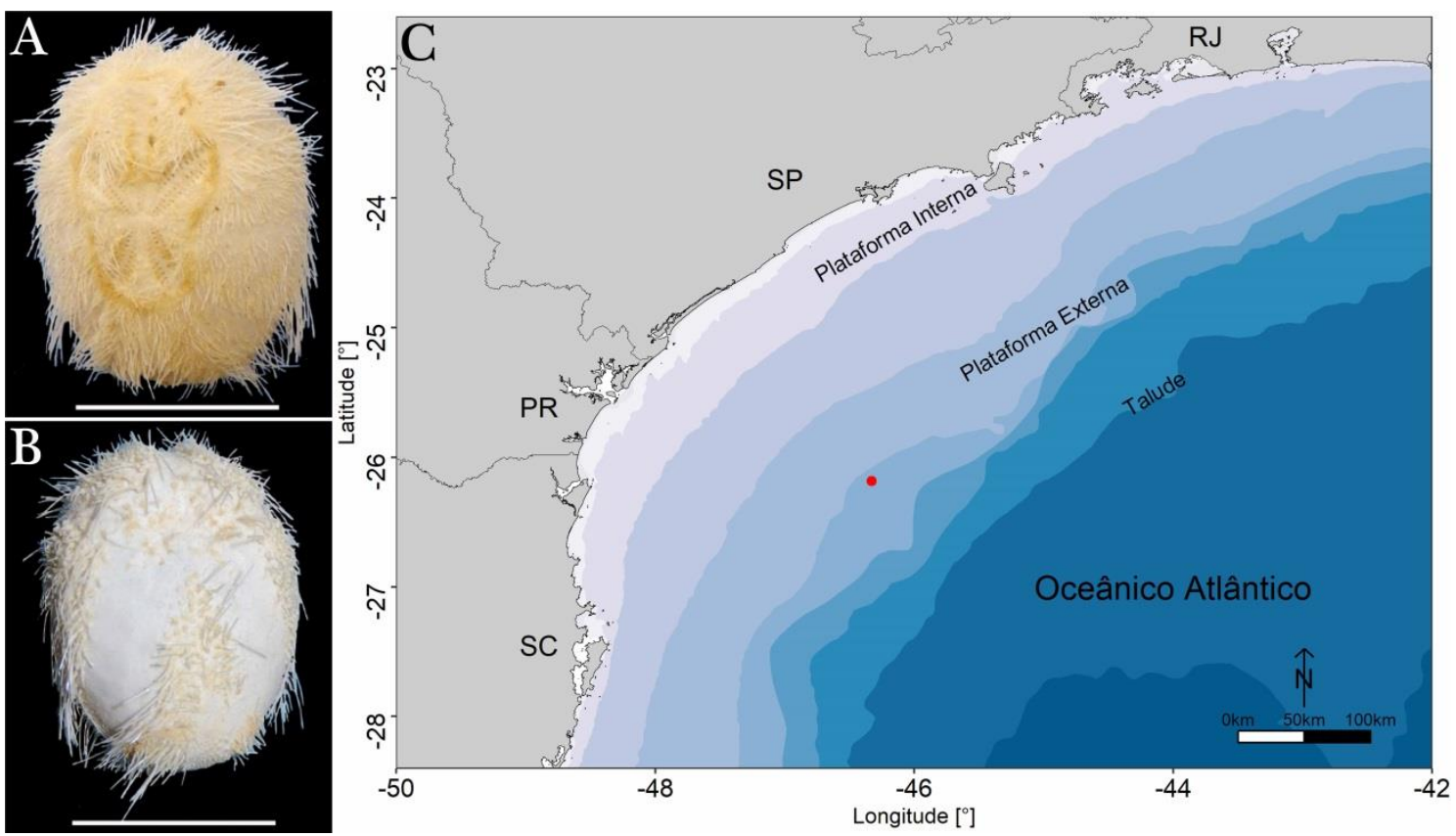

Figura 26. Brissopsis atlantica - MZUSP: A. Vista aboral, B. Vista oral, C. Ocorrência de B. atlantica na plataforma continental externa. Escala: $0.5 \mathrm{~mm}$.

\section{Holothuroidea Blainville, 1834}

Considerações: Os Holothuroidea, conhecidos como holotúrias ou pepinos-do-mar, apresentam simetria bilateral externa. A boca está rodeada por um círculo de numerosos tentáculos na região anterior e o ânus está situado na região posterior distal (Figura 27A) (Samyn et al. 2006). Vivem com um lado do corpo apoiado contra o substrato. Esta superfície "ventral" (trivium) possui três áreas ambulacrais e em algumas espécies pode formar uma sola. Na superfície "dorsal" (bivium) há duas áreas ambulacrais (Pawson et al. 2010). Algumas espécies apresentam estruturas e ornamentações que são utilizadas como caracteres taxonômicos (Pawson 1982).

Os pés ambulacrais e papilas se projetam ao longo dos cinco canais radiais (Figura 27B) e estão ligados ao canal vascular aquífero, o qual possui uma ou mais vesículas de Poli e um ou mais canais pétreos. $\mathrm{O}$ madreporito se localiza na cavidade interna do animal.

$\mathrm{Na}$ maioria das holotúrias o esqueleto está reduzido a um anel calcário perifaríngeo, formado por peças radiais e interradiais macroscópicas, e ossículos calcários microscópicos, embebidos no tegumento (Figura 27C). Essa redução do esqueleto é compensada pela musculatura, constituída por cinco bandas de músculos longitudinais em posição radial, ligadas anteriormente às peças radiais do anel e posteriormente à cloaca, a partir dos músculos retratores da mesma (Samyn et al. 2006).

Os tentáculos que circundam a boca podem ser peltados, pinados, digitados ou dendríticos, além de variar quanto ao número e tamanho (Figura 27D) (Hyman 1955). Há uma série de músculos retratores faríngeos que são usados para a contração dos tentáculos. Durante a alimentação estes são levados para dentro da boca e liberam as partículas alimentares na faringe (Féral \& Massin 1982; Roberts et al. 2000). 
Como estratégia de proteção contra predadores, algumas holotúrias expulsam o trato digestivo posterior através da boca quando são agredidos ou submetidos a estresse, e depois podem regenerar as partes perdidas. Algumas espécies de Aspidochirotida possuem túbulos de Cuvier, estruturas de caráter elástico e pegajoso, às vezes tóxicos, específicas para a defesa (Samyn et al. 2006).

As holotúrias podem ser consideradas um microecossistema por abrigar grande variedade de organismos simbiontes, como turbelários, poliquetas, crustáceos, moluscos e até pequenos peixes (Samyn et al. 2006; Pawson et al. 2010).

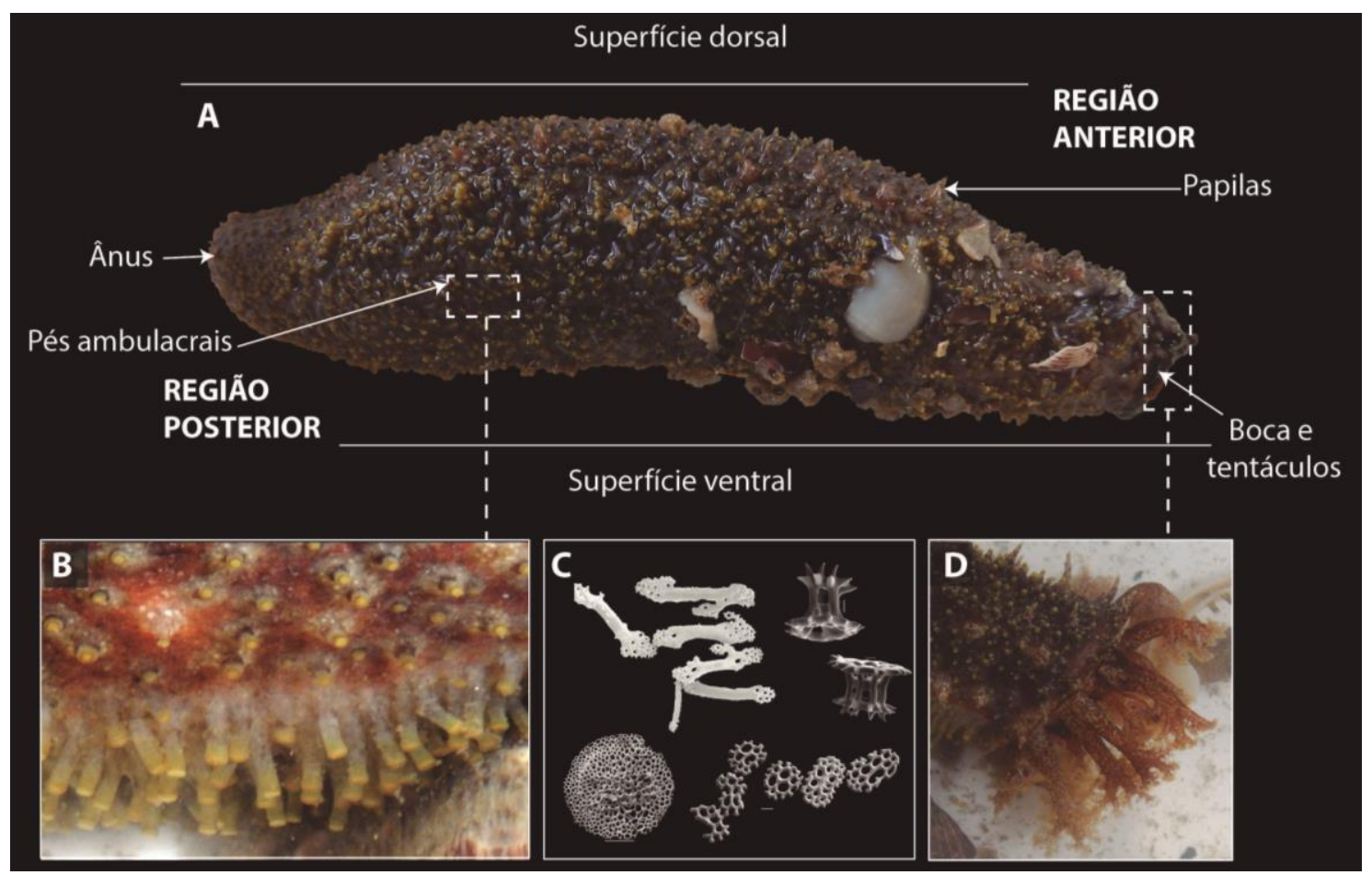

Figura 27. Principais características a serem observadas para a identificação de espécies de Holothuroidea: A. Morfologia externa, B. Detalhe dos pés ambulacrais, C. Tipos de ossículos, D. Tipos de tentáculos orais.

Holothuriidae Gray, 1855

Holothuria Linnaeus, 1767

\section{Holothuria (Halodeima) grisea Selenka, 1867 Figuras 28-29}

Diagnose: Corpo subcilíndrico. A boca está ligeiramente posicionada ventralmente, com 20-25 tentáculos peltados e ramificados. Anel calcário simples, formado por 10 placas. Os ossículos da parede do corpo são torres com aproximadamente 12 espinhos marginais no disco, placas com duas ou quatro perfurações centrais e margeadas com dentes robustos. Tentáculos contém bastões alongados com pequenas projeções e barras curvadas com extremidade ramificada. Pés ambulacrais possuem placas perfuradas e placas terminais (Tommasi 1969a; Pawson et al. 2010).

Coloração: Varia do negro ao cinza esverdeado, com pequenas manchas avermelhadas (Tommasi 1969a).

Hábitat: Preferencialmente substrato rochoso, em profundidades de até $5 \mathrm{~m}$. 
Distribuição geográfica: Oceano Atlântico: a oeste dos Estados Unidos até Brasil, a leste na África e Ilha de Ascensão (Hendler et al. 1995; Pawson et al. 2010; Borrero-Pérez et al. 2012). Brasil: Piauí até Santa Catarina (Tommasi 1969a; Prata et al. 2014).

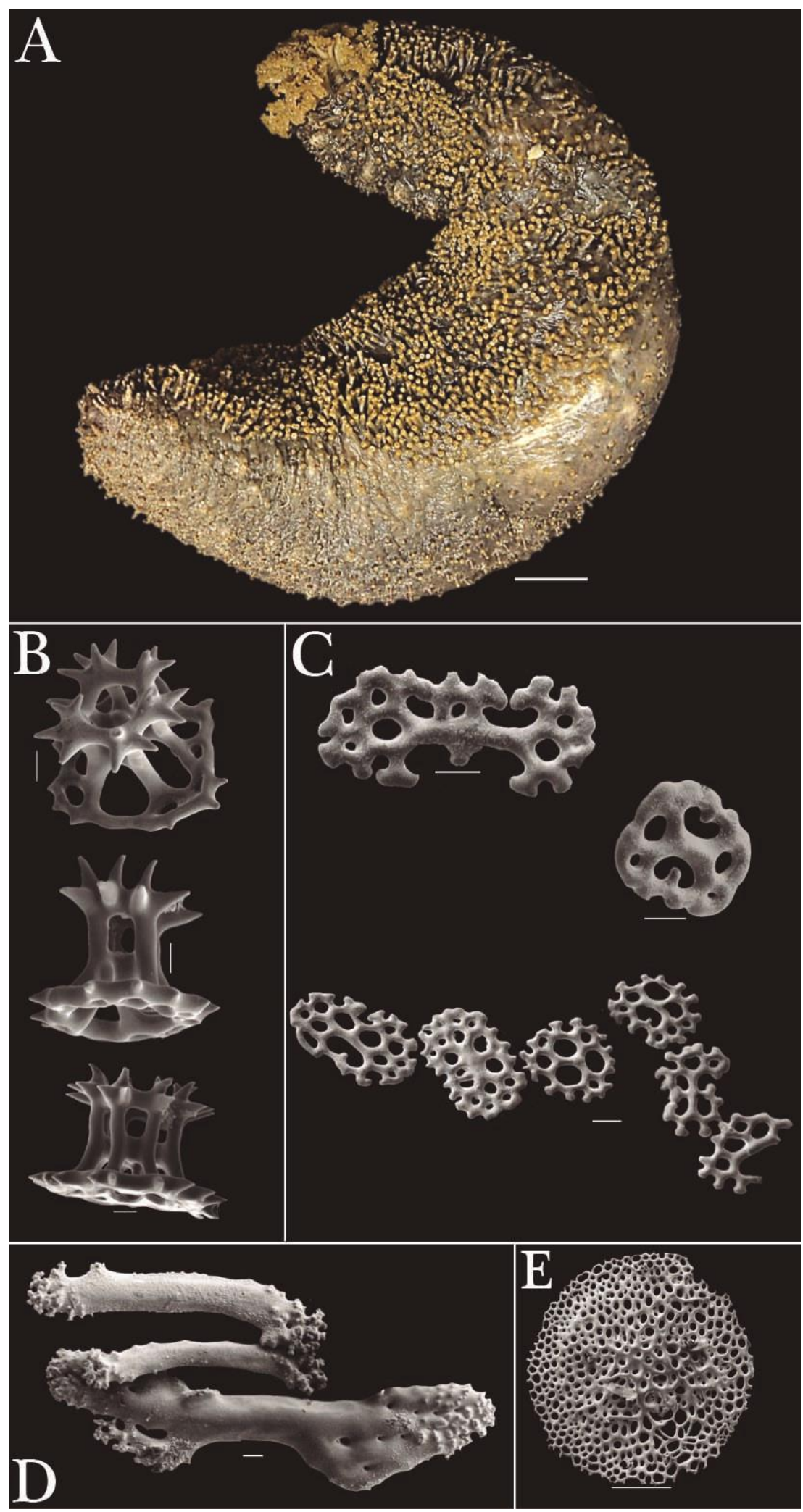

Figura 28. Holothuria (Halodeima) grisea - ZUEC HOL 94: A. Aparência externa (escala: 10 mm). Fotos dos ossículos calcários em MEV: B. Torres da parede do corpo (escala: $10 \mu \mathrm{m}$ ), G. Placas perfuradas da parede do corpo (escala: $10 \mu \mathrm{m}$ ), D. Barras dos tentáculos (escala: $10 \mu \mathrm{m}$ ), E. Placa terminal da porção final da parede do corpo (escala: $50 \mu \mathrm{m}$ ). 


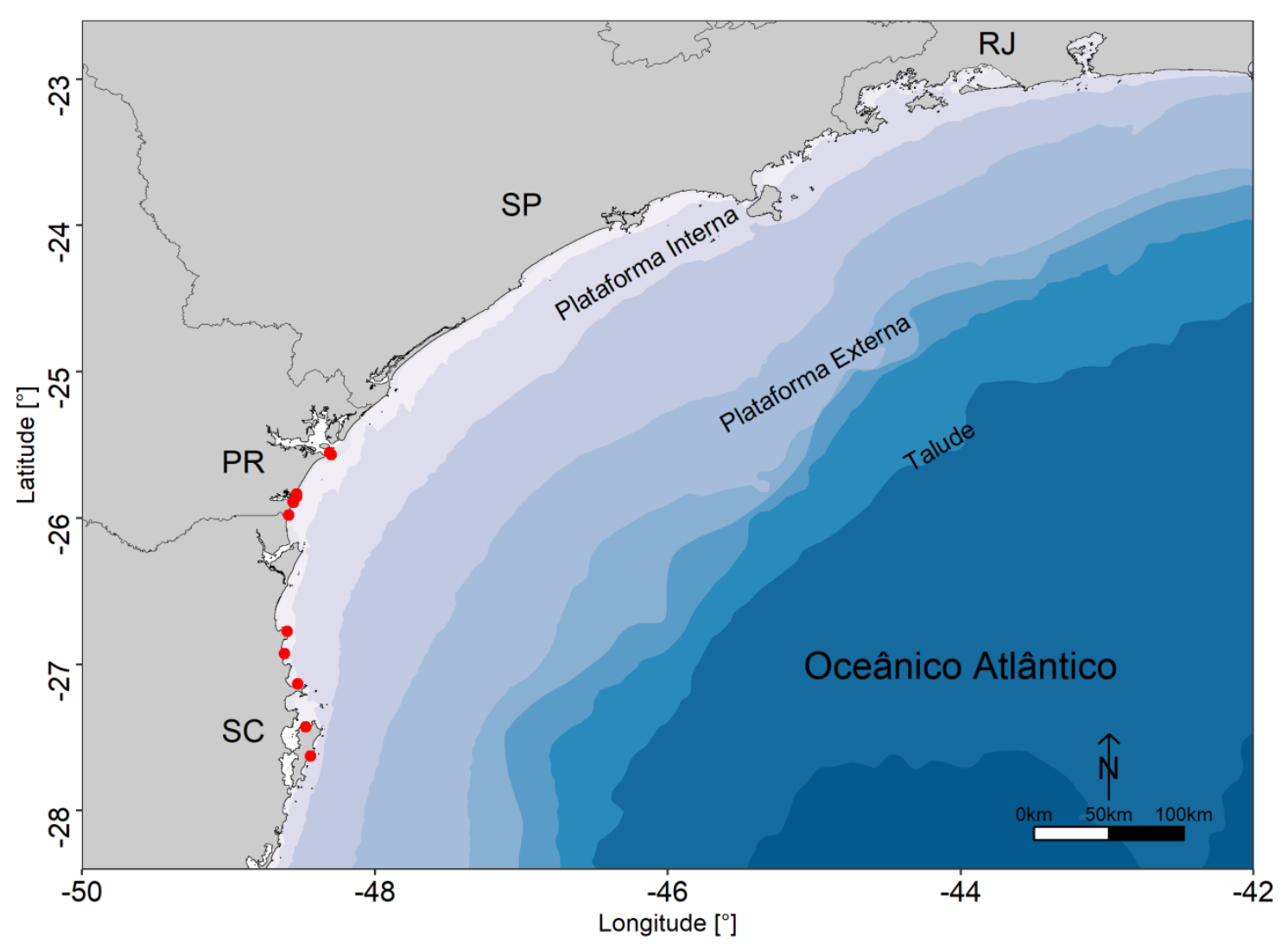

Figura 29. Ocorrência de Holothuria (Halodeima) grisea em costões rochosos da plataforma interna.

\section{Cucumariidae Ludwig, 1894 \\ Trachythyone Studer, 1876}

\section{Trachythyone crassipeda Cherbonnier, 1961 Figuras 30-31}

Diagnose: Corpo globoso afilado em direção ao ânus. Boca contendo 10 tentáculos dendríticos ramificados. Pés ambulacrais terminam em ventosas, distribuídos por todo o corpo, mais abundante no trívio. Ânus cercado por cinco grupos radiais de duas pequenas papilas calcificadas. Ossículos da parede do corpo são placas lisas com quatro perfurações, cestos com 46 perfurações. Nos tentáculos ocorrem barras e rosetas. Nos pés ambulacrais ocorrem barras alongadas com seis ou mais perfurações no ápice de cada extremidade, além de uma placa terminal (Tommasi 1969a; Martins 2012; Oliveira 2013).

Coloração: Marrom acinzentado, tentáculos marrons com manchas brancas e amarelas (Tommasi 1969a; Hendler et al. 1995).

Hábitat: Substrato rochoso, na profundidade de $1 \mathrm{~m}$.

Distribuição geográfica: Oceano Atlântico: Estados Unidos até o Brasil (Hendler et al. 1995). Brasil: Ceará até o Paraná (Tommasi 1969a; Queiroz et al. 2013). 

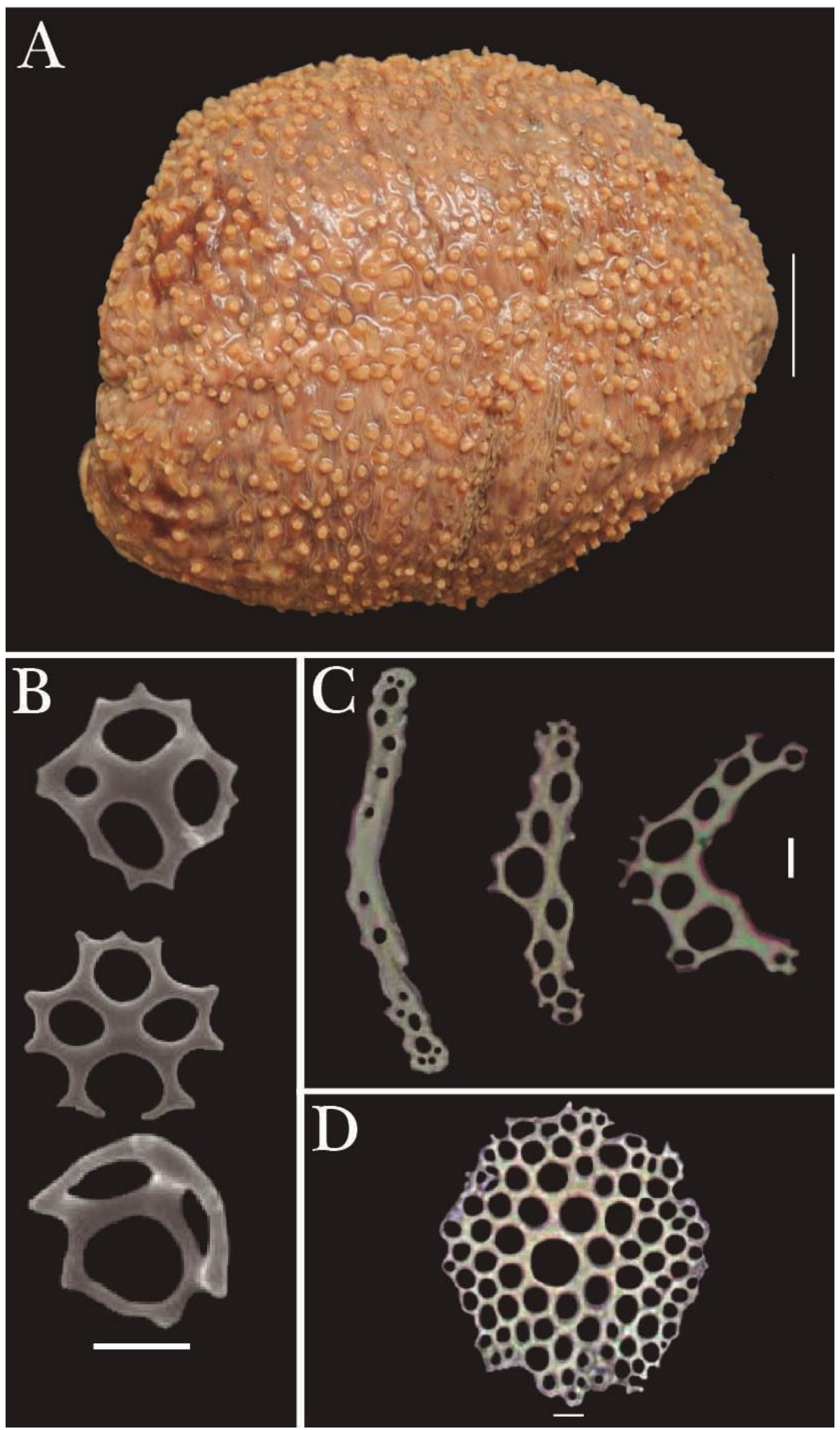

Figura 30. Trachythyone crassipeda - EQMN-UFRJ 814: A. Aparência externa (escala: 10 mm). Fotos dos ossículos calcários em MEV: B. Cestos da parede do corpo (escala: $10 \mu \mathrm{m}$ ), G. Barras dos pés ambulacrais (escala: $20 \mu \mathrm{m}$ ), D. Placa terminal (escala: $50 \mu \mathrm{m}$ ). Fotos B-D: Oliveira (2013). 


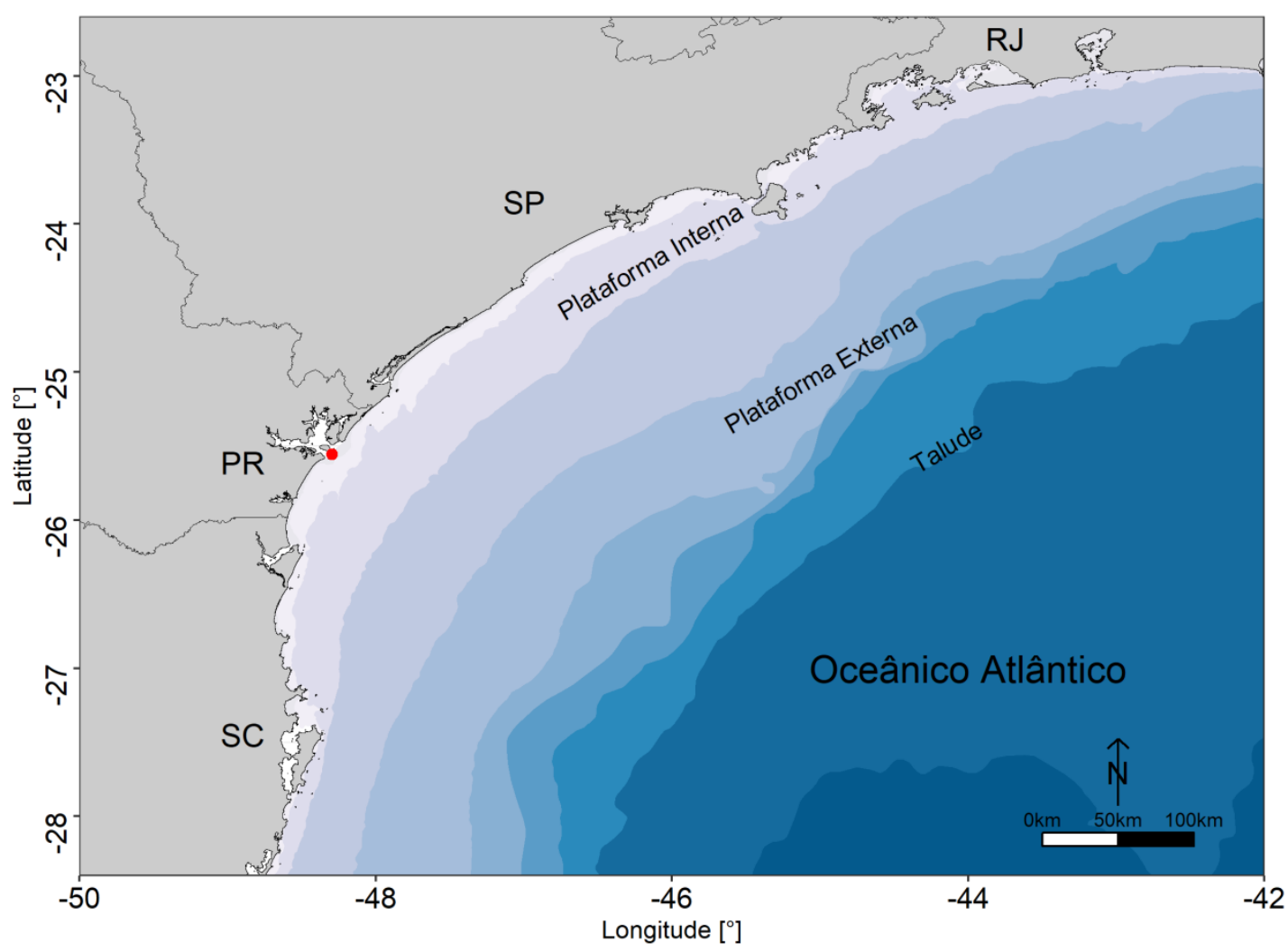

Figura 31. Ocorrência de Trachythyone crassipeda na Ilha do Mel, litoral do Paraná.

\section{Ophiuroidea Gray, 1840}

Considerações: Os Ophiuroidea, conhecidos como ofiuroides, estrelas-cesto ou serpentes-do-mar, são considerados uma das classes mais bem-sucedidas entre os Echinodermata devido à sua mobilidade, diversidade de hábitos alimentares e tamanho reduzido que lhes permite explorar habitats muitas vezes inatingíveis por outros equinodermos (Hendler et al. 1995; BenavidesSerrato et al. 2011).

A esta classe atribui-se tradicionalmente duas ordens: Euryalida Lamarck, 1816 (estrelascesto) e Ophiurida Müller \& Troschel, 1840 sensu O'Hara et al., 2017 (serpente-do-mar) (Pawson 2007). Euryalida contém os ofiuroides que possuem como principal característica ossículos braquiais com articulação estreptospôndila, que permite o movimento de torção espiral do braço. Os ofiuroides da ordem Ophiurida apresentam articulação braquial do tipo zigospôndila, com projeções e depressões nos ossículos que limitam o movimento dos braços ao plano horizontal, porém, permitem maior flexibilidade ao braço e melhor locomoção ao animal (Stöhr et al. 2012).

Ofiuroides apresentam como padrão corporal, um disco central, de onde originam-se os braços (geralmente cinco) que podem estar inseridos ventralmente ao disco ou fusionados lateralmente a ele. $O$ disco é achatado dorsoventralmente e pode ser nu ou, na maioria das vezes, coberto por escamas, espinhos, grânulos, placas ou até mesmo tegumento. Dorsalmente, apresenta cinco pares de escudos radiais localizados na região marginal radial, próximo à base de cada braço (Figura 32A) (Borges \& Amaral 2005; Benavides-Serrato et al. 2011).

Cada braço pode ser simples ou ramificado, contendo duas fileiras de placas laterais, uma de placas dorsais e uma de placas ventrais. Das placas laterais projetam-se espinhos braquiais que variam em número, tamanho e podem conter dentículos. Os pés ambulacrais (tentáculos) estão localizados ao longo dos braços e projetam-se por meio de poros (Borges \& Amaral 2005; Pomory 2007) (Figura 32B-C).

$\mathrm{Na}$ superfície ventral encontram-se placas organizadas em cinco mandíbulas triangulares inter-radiais, com o ápice voltado para o centro do disco (Figura 32D). Cada 
mandíbula contém um escudo oral e dois escudos adorais, além de papilas orais que, quando presentes, projetam-se para o interior da boca, lateralmente ou no ápice das mandíbulas (apicais ou infra-dentais), e variam em número, formato, tamanho e posição. $\mathrm{O}$ madreporito é formado por um escudo oral modificado e não é evidente em todas as espécies (Hendler et al. 1995; Borges \& Amaral 2005; Pomory 2007; Benavides-Serrato et al. 2011; Stöhr et al. 2012).

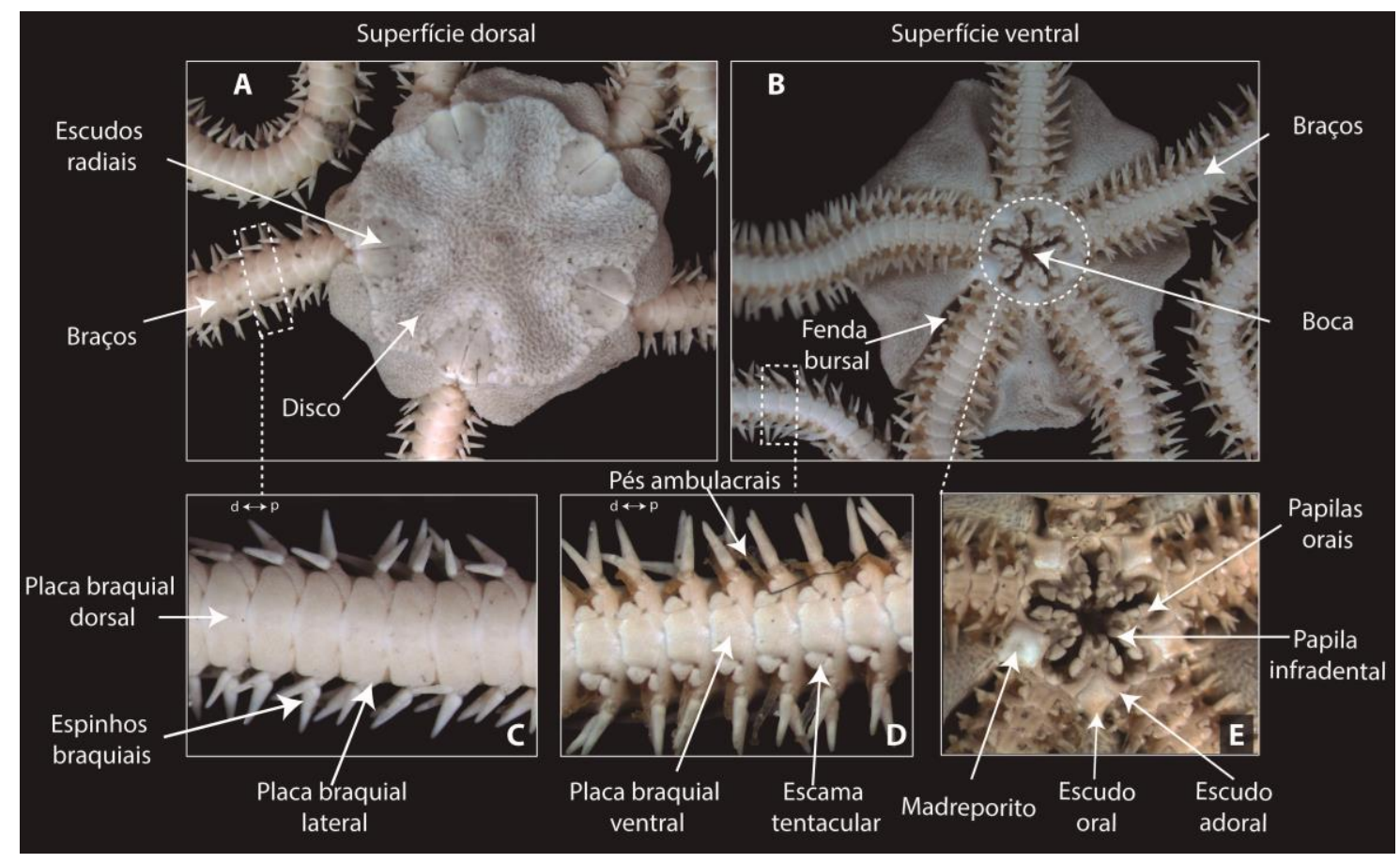

Figura 32. Principais características a serem observadas para a identificação de espécies de Ophiuroidea. Morfologia externa: A. Vista dorsal do disco, B. Vista dorsal do braço, G. Vista ventral do braço, D. vista ventral do disco, E. detalhe da boca. Abreviações: $\mathrm{p}$ = proximal, $\mathrm{d}=$ distal.

Ophiomyxidae Ljungman, 1866

Ophioleptoplax Clark, 1911

\section{Ophioleptoplax brasiliana Tommasi \& Abreu 1974 Figura 33}

Diagnose: Disco pentagonal, escamas e escudos radiais não evidentes. Coberto por uma pele que apresenta corpúsculos calcários alongados, distribuídos irregularmente na região radial do disco. Superfície braquial dorsal revestida por uma pele. Primeira placa braquial ventral triangular, posteriores semi-retangulares com reentrâncias laterais que alojam grandes poros tentaculares. Ausência de escamas tentaculares. Quatro espinhos braquiais afilados e com dentículos marginais (Tommasi \& Abreu 1974; Borges \& Amaral 2005).

Coloração: Superfície dorsal do disco alaranjada e braços amarelados.

Hábitat: Substrato arenoso, na profundidade de $78 \mathrm{~m}$.

Distribuição geográfica: Oceano Atlântico: Brasil: Rio de Janeiro ao Paraná (Tommasi \& Abreu 1974; Borges et al. 2002). 

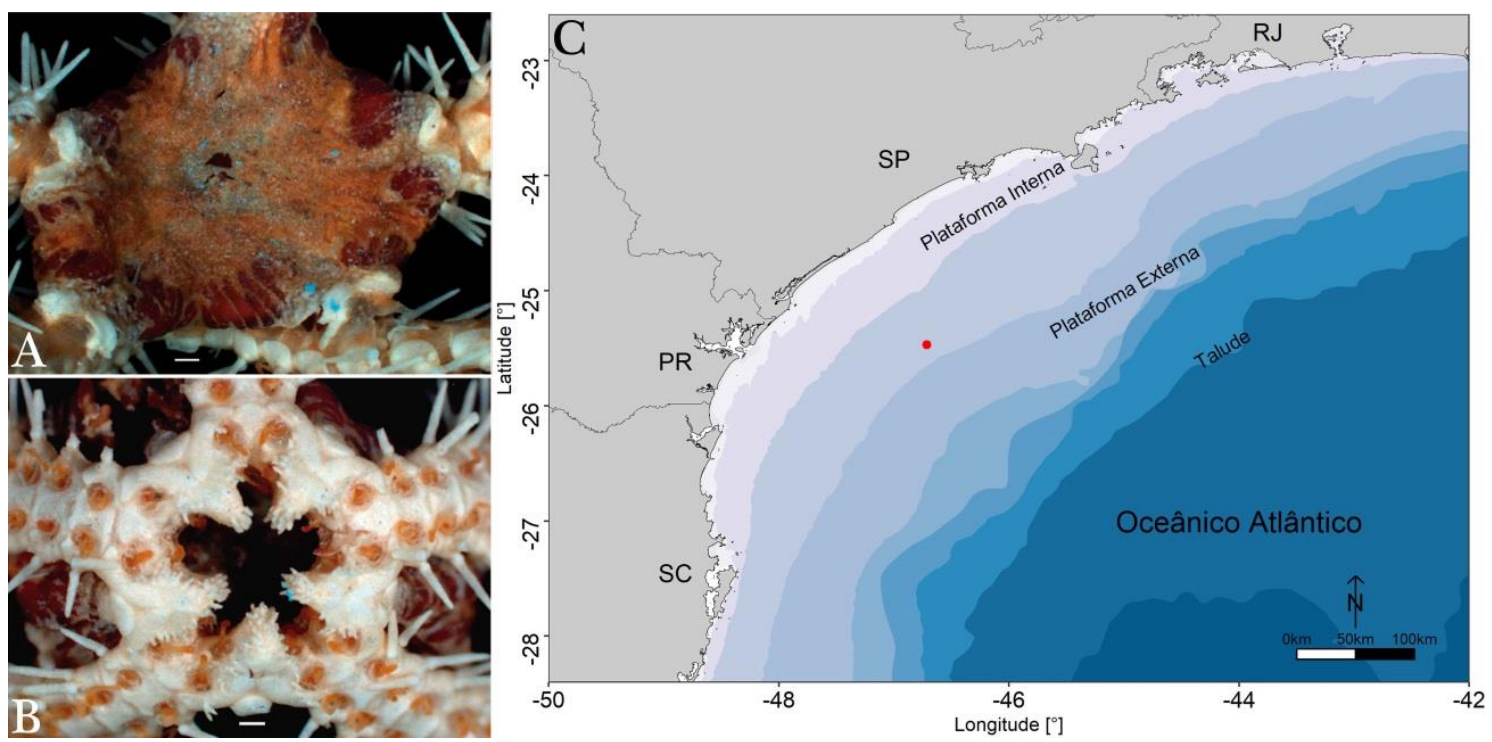

Figura 33. Ophioleptoplax brasiliana - ZUEC OPH 1882: A. Vista dorsal, B. Vista ventral, G. Ocorrência de $O$. brasiliana na plataforma continental externa. Escala: $0.5 \mathrm{~mm}$.

\section{Ophiuridae Müller \& Troschel, 1840 \\ Ophiostriatus Madsen, 1983}

\section{Ophiostriatus striatus (Mortensen, 1933)}

Figura 34

Diagnose: Disco coberto por grânulos na superfície dorsal e ventral. Escudos radiais mais longos que largos. Placa braquial dorsal mais larga que longa com quilha na linha mediana. Placa braquial ventral contígua e pentagonal com uma reentrância na região mediana distal e reentrâncias laterais dos poros tentaculares. Uma escama tentacular. Estrias transversais em todas as placas braquiais. Três espinhos braquiais afilados (Borges et al. 2002).

Coloração: Branca amarelada.

Hábitat: Substrato arenoso, na profundidade de $430 \mathrm{~m}$.
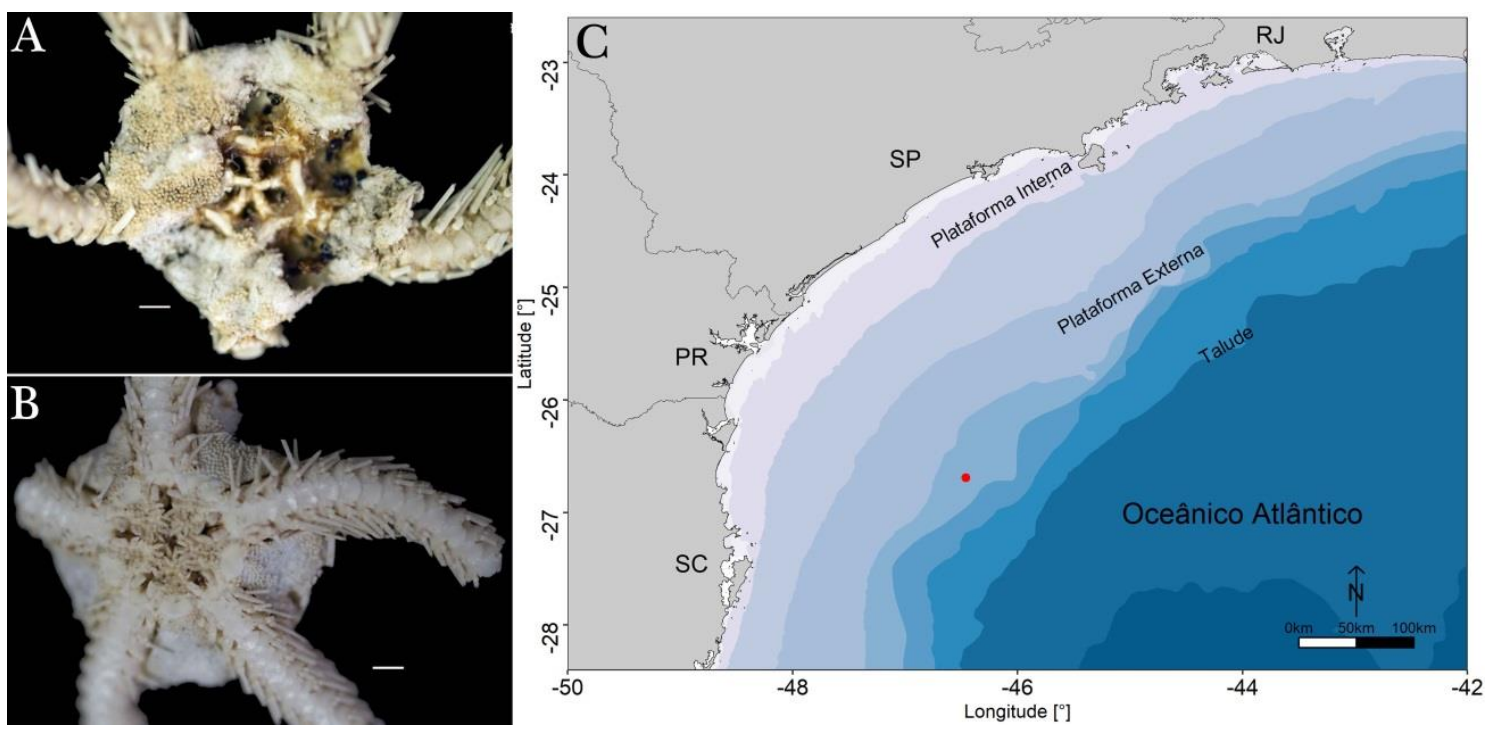

Figura 34. Ophiostriatus striatus - ZUEC OPH 774: A. Vista dorsal, B. Vista ventral, G. Ocorrência de $O$. striatus no talude continental. Escala: $0.5 \mathrm{~mm}$. 
Distribuição geográfica: Oceano Atlântico: Groelândia, Islândia, Brasil (Borges et al. 2002). Oceano Ártico: Rússia (Smirnov et al. 2014). Brasil: Rio de Janeiro até Rio Grande do Sul (Borges et al. 2002; Oliveira et al. 2010).

\section{Ophiomastus Lyman, 1878}

\section{Ophiomastus satelitae Tommasi \& Abreu, 1974 \\ Figura 35}

Diagnose: Disco elevado, coberto por escamas grandes alternadas com pequenas. Placas centrodorsal e primárias evidentes. Escudos radiais subtriangulares, unidos distalmente e separados no bordo proximal. Primeira placa braquial dorsal mais larga que longa, posteriores losangulares, reduzindo de tamanho em direção à extremidade do braço, presentes até o décimo segmento. Placas braquiais ventrais curvas distalmente e afiladas proximalmente, diminuindo de tamanho até a extremidade do braço. Uma escama tentacular arredondada. Um espinho braquial curto e afilado (Tommasi \& Abreu 1974; Borges et al. 2015).

Coloração: Branca.

Hábitat: Substrato não consolidado, nas profundidades de 380 a $430 \mathrm{~m}$.

Distribuição geográfica: Oceano Atlântico: Brasil: Rio de Janeiro ao Rio Grande do Sul (Borges et al. 2002).
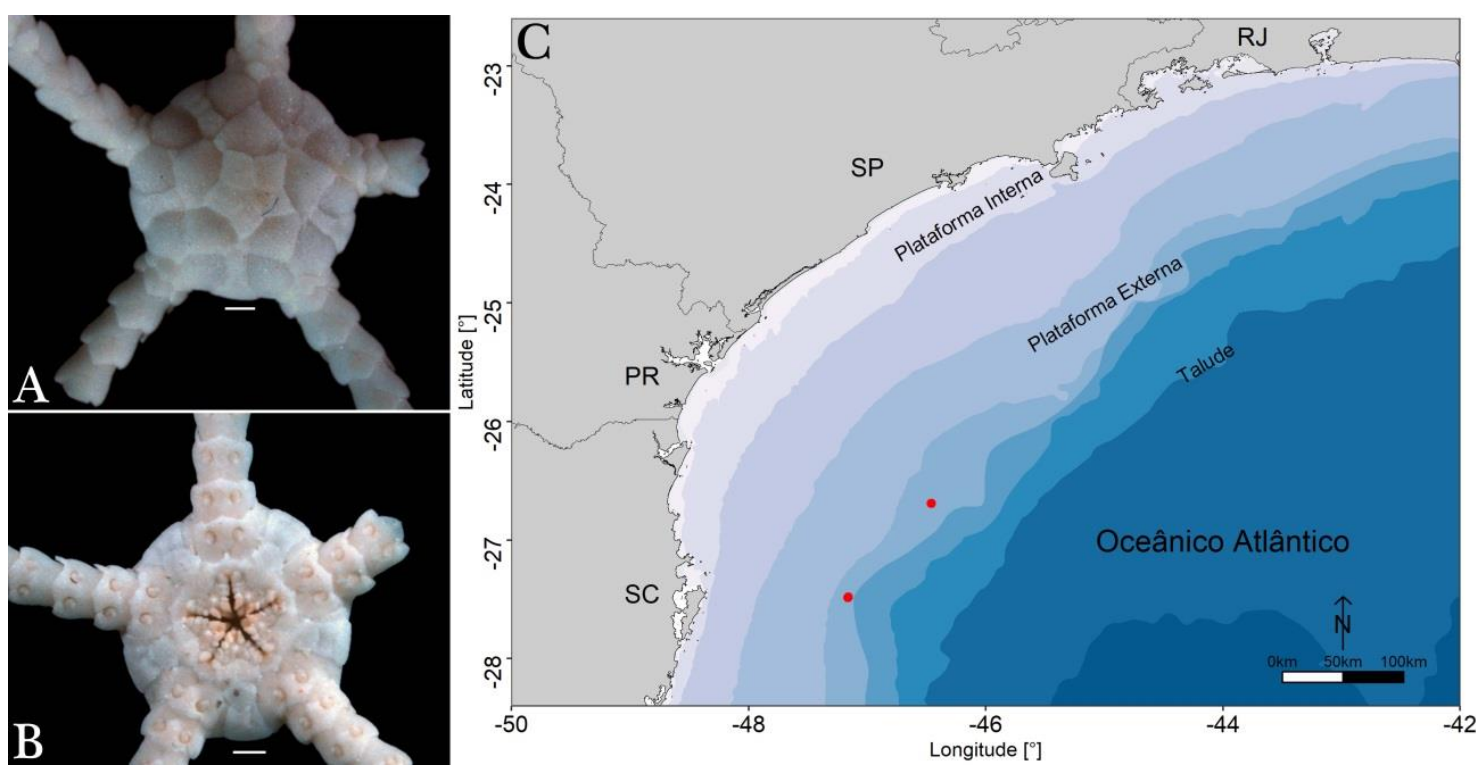

Figura 35. Ophiomastus satelitae - ZUEC OPH 1714: A. Vista dorsal, B. Vista ventral, G. Ocorrência de $O$. satelitae no talude continental. Escala: $0.5 \mathrm{~mm}$.

\section{Ophiomisidium Koehler, 1914}

\section{Ophiomisidium tommasii Borges, Monteiro \& Amaral, 2006 Figura 36}

Diagnose: Disco dorsalmente coberto pelos escudos radiais. Placa centrodorsal pentagonal. Placas primárias subpentagonais. Escudos orais pequenos, semitriangulares. Escudos adorais robustos, maiores que os orais, proximalmente unidos. Ausência de escamas na região interradial ventral. Primeira placa braquial dorsal mais larga que longa, afilada proximalmente; posteriores pequenas e losangulares, presentes até o oitavo segmento. Três pares de poros 
tentaculares em cada braço; uma escama tentacular. Dois espinhos braquiais pequenos e grossos (Borges et al. 2006, 2015).

Coloração: Branca.

Hábitat: Substrato arenoso e areno-lodoso, em profundidades de 380 a $510 \mathrm{~m}$.

Distribuição geográfica: Oceano Atlântico: Brasil: Rio de Janeiro até Rio Grande do Sul (Borges et al. 2006; Oliveira et al. 2010).
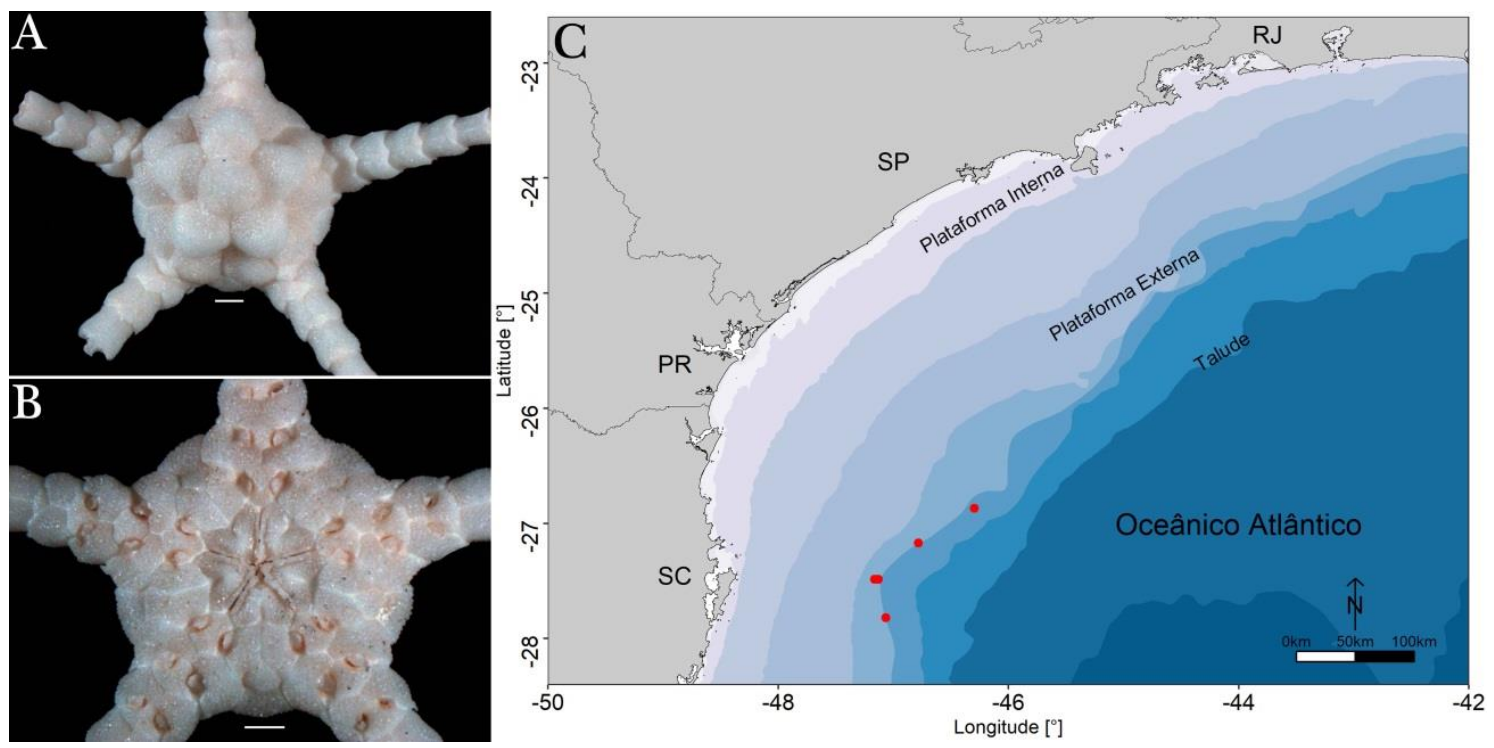

Figura 36. Ophiomisidium tommasii - ZUEC OPH 682: A. Vista dorsal, B. Vista ventral, G. Ocorrência de O. tommasii no talude continental. Escala: $0.5 \mathrm{~mm}$.

\section{Ophiura Lamarck, 1801}

Ophiura clemens (Koehler, 1904) Figura 37

Diagnose: Disco dorsalmente coberto por escamas irregulares. Placas centrodorsal e primárias evidentes. Escudos radiais bem desenvolvidos, cuneiformes e separados por várias escamas. Três primeiros poros tentaculares braquiais amplos com quatro a sete escamas tentaculares; segmentos posteriores com uma escama tentacular. Segundo poro tentacular oral amplo, abrindo fora da fenda oral, ao lado dos escudos adorais. Três espinhos braquiais iguais pequenos; a partir do $20^{\circ}$ segmento braquial o espinho mediano é transformado em gancho com dentículos hialinos (Borges \& Amaral 2007; Borges et al. 2015).

Coloração: Branca.

Hábitat: Substrato arenoso, nas profundidades de 380 a $430 \mathrm{~m}$.

Distribuição geográfica: Oceano Atlântico: ao norte na França (Smirnov et al. 2014) e ao sul na Guiana Francesa e Brasil (Borges \& Amaral 2007). Oceano Indo-Pacífico: Filipinas, Índia (Smirnov et al. 2014). Brasil: Rio de Janeiro até Rio Grande do Sul (Borges \& Amaral 2007). 

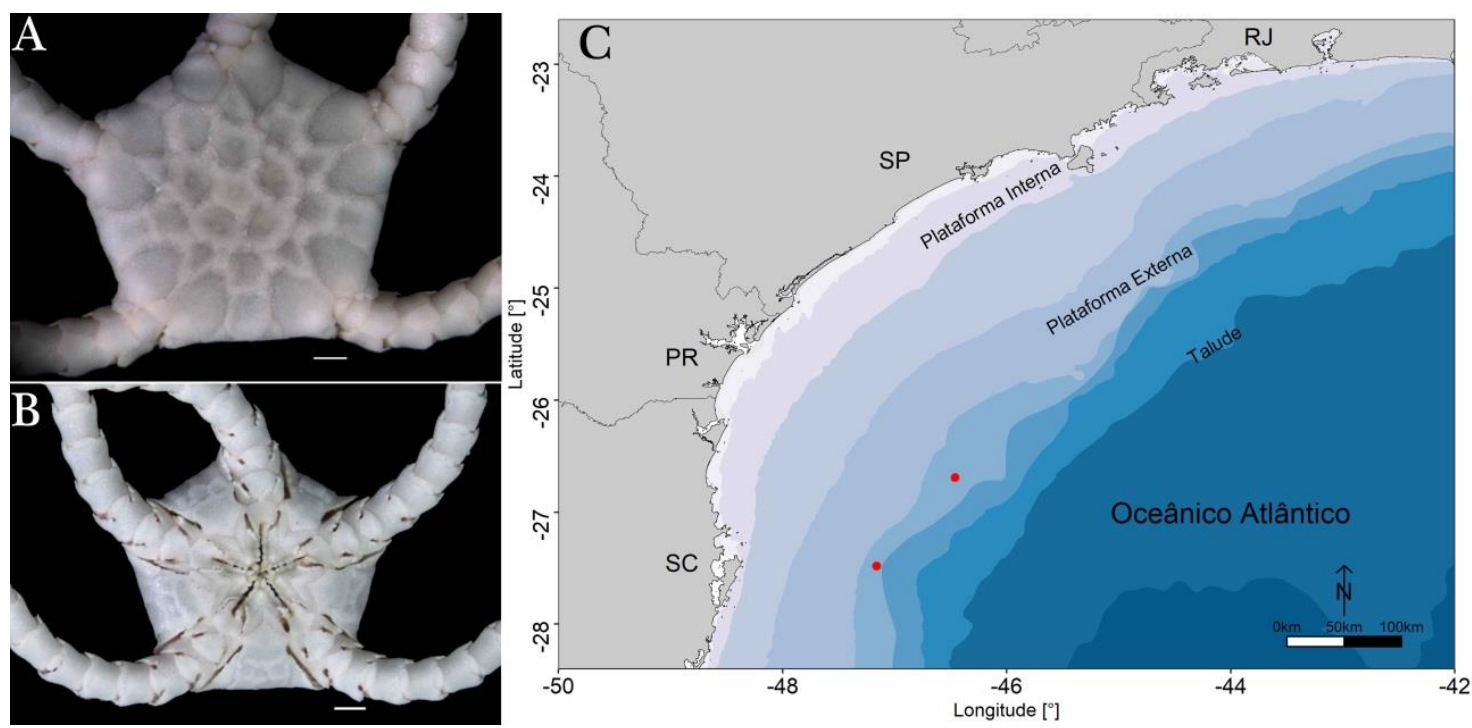

Figura 37. Ophiura clemens - ZUEG OPH 869: A. Vista dorsal, B. Vista ventral, G. Ocorrência de $O$. clemens no talude continental. Escala: $0.5 \mathrm{~mm}$.

\section{Ophiolepididae Ljungman, 1867}

Ophiomusium Lyman, 1869

\section{Ophiomusium eburneum Lyman, 1869}

Figura 38

Diagnose: Disco circular coberto com placas imbricadas. Escudos radiais bem desenvolvidos, ovais e separados. Escama tentacular ovalada presente apenas no $1^{\circ}$ e $2^{\circ}$ segmentos do braço. Primeiros 4-5 segmentos do braço portando dois espinhos braquiais pequenos, aumentando para três espinhos nos segmentos posteriores. Próximo a extremidade do braço, espinho inferior denteado e em gancho (Borges \& Amaral 2007; Borges et al. 2015).

Coloração: Disco alaranjado ou rosado, com escamas centrais num tom mais forte (BenavidesSerrato et al. 2011).

Hábitat: Substrato arenoso, em profundidades de 380 a $808 \mathrm{~m}$.
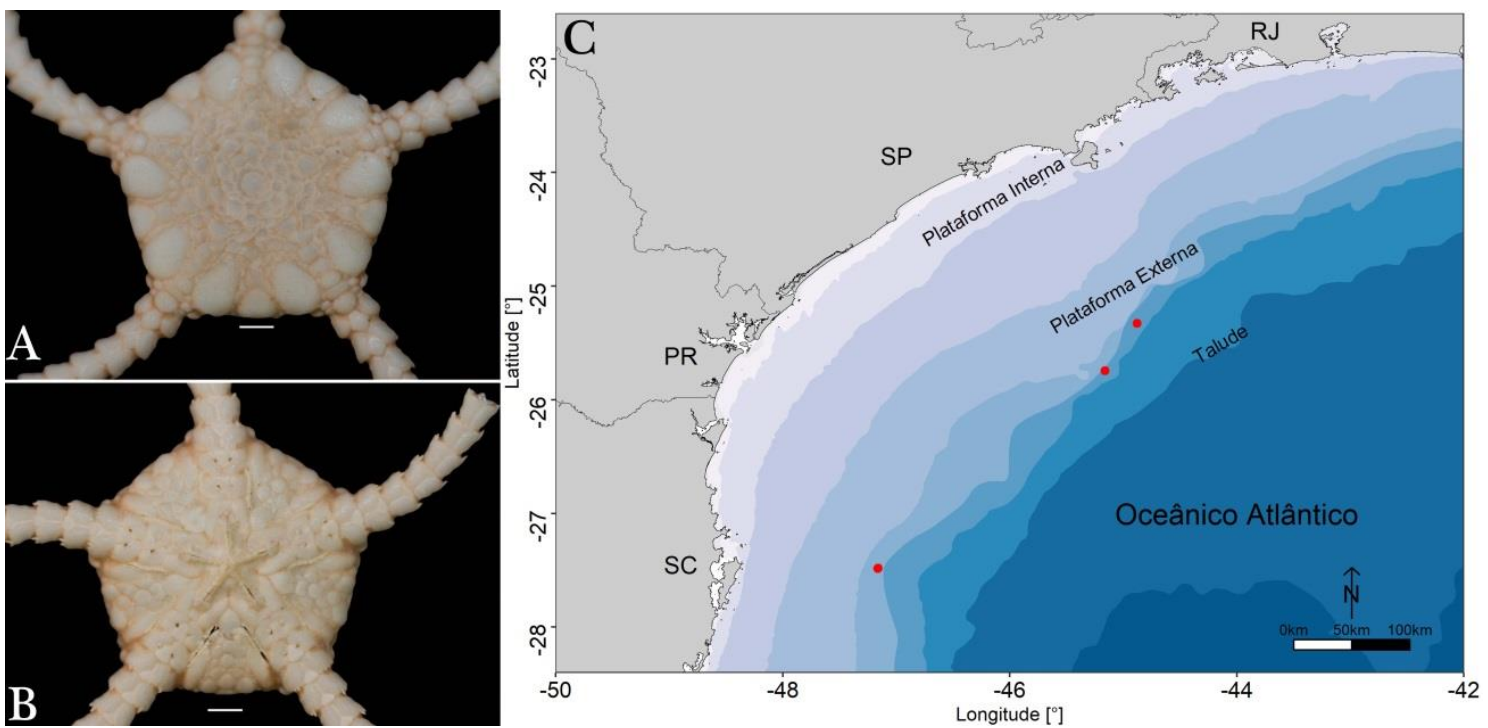

Figura 38. Ophiomusium eburneum - ZUEC OPH 847: A. Vista dorsal, B. Vista ventral, G. Ocorrência de O. eburneum no talude continental. Escala: $0.5 \mathrm{~mm}$. 
Distribuição geográfica: Oceano Atlântico: Estados Unidos, Golfo do México (Benavides-Serrato et al. 2011), Cuba (Laguarda-Figueras et al. 2009) Porto Rico, Colômbia (Borrero-Pérez et al. 2008) e Brasil: São Paulo, Paraná e Santa Catarina (Borges \& Amaral 2007).

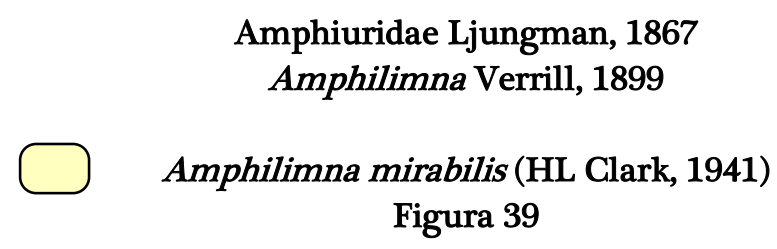

Diagnose: Disco coberto por grânulos dorsal e ventralmente. Escudos radiais estreitos, unidos, situados no sulco radial. Seis a nove espinhos braquiais, sendo os superiores maiores que os inferiores. Espinhos superiores fundem-se a placa genital formando uma estrutura em forma de asa (Borges \& Amaral 2005; Benavides-Serrato et al. 2011).

Coloração: Disco branco acinzentado. Braços na cor bege (Benavides-Serrato et al. 2011).

Hábitat: Substrato arenoso, na profundidade de $241 \mathrm{~m}$.

Distribuição geográfica: Oceano Atlântico: Golfo do México, Cuba, Colômbia e Brasil (Pawson et al. 2009; Benavides-Serrato et al. 2011). Brasil: Rio de Janeiro (Frensel et al. 2010; Barboza 2015), São Paulo, Paraná (Borges et al. 2002; Borges \& Amaral 2005), Santa Catarina (Xavier 2010) e Rio Grande do Sul (Capítoli \& Monteiro 2000).
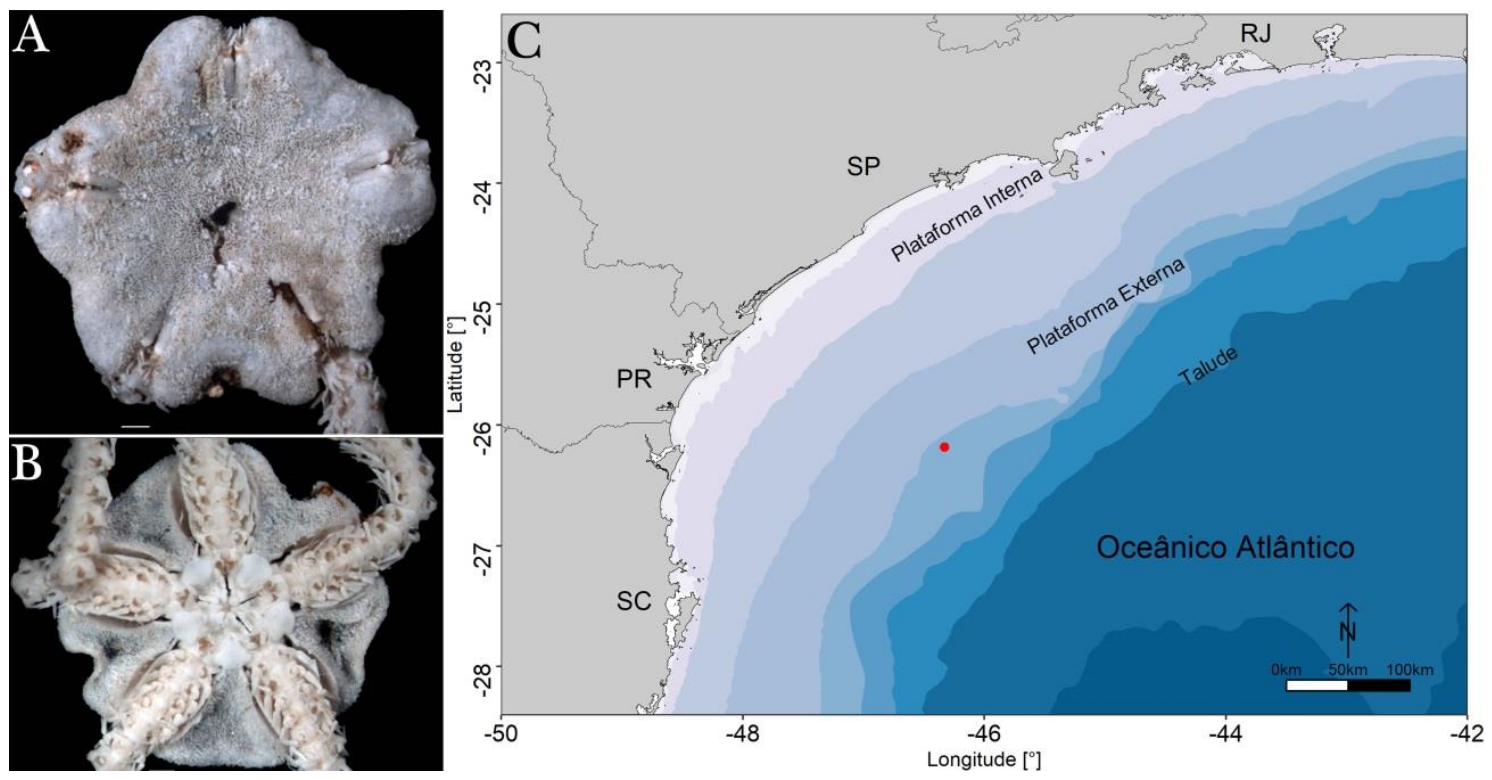

Figura 39. Amphilimna mirabilis - ZUEC OPH 1739: A. Vista dorsal, B. Vista ventral, G. Ocorrência de $A$. mirabilis no talude continental. Escala: $0.5 \mathrm{~mm}$.

\section{Amphilimna olivacea (Lyman, 1869)}

Figura 40

Diagnose: Disco com um sulco na região mediana radial e totalmente coberto por espinhos afilados. Madreporito bem desenvolvido, com grande poro na porção distal. Oito espinhos braquiais, os quatro superiores sub-iguais e os quatro inferiores aumentam de tamanho em direção à região ventral (Tommasi 1970b; Borges \& Amaral 2005; Benavides-Serrato et al. 2011). 
Coloração: Disco pode variar do cinza a marrom claro. Braços rosados ou alaranjados (Tommasi 1970b; Benavides-Serrato et al. 2011).

Hábitat: Substrato não consolidado, em profundidades de 10 e $100 \mathrm{~m}$.

Distribuição geográfica: Oceano Atlântico: a oeste dos Estados Unidos até Uruguai (Tommasi 1970b; González et al. 2002; Laguarda-Figueras et al. 2005; Borrero-Pérez et al. 2008; Pawson et al. 2009) a leste da Libéria até a Angola (Thomas 1967; Borges \& Amaral 2005). Brasil: Rio de Janeiro até o Rio Grande do Sul (Tommasi 1970b; Capítoli \& Monteiro 2000; Borges et al. 2002).
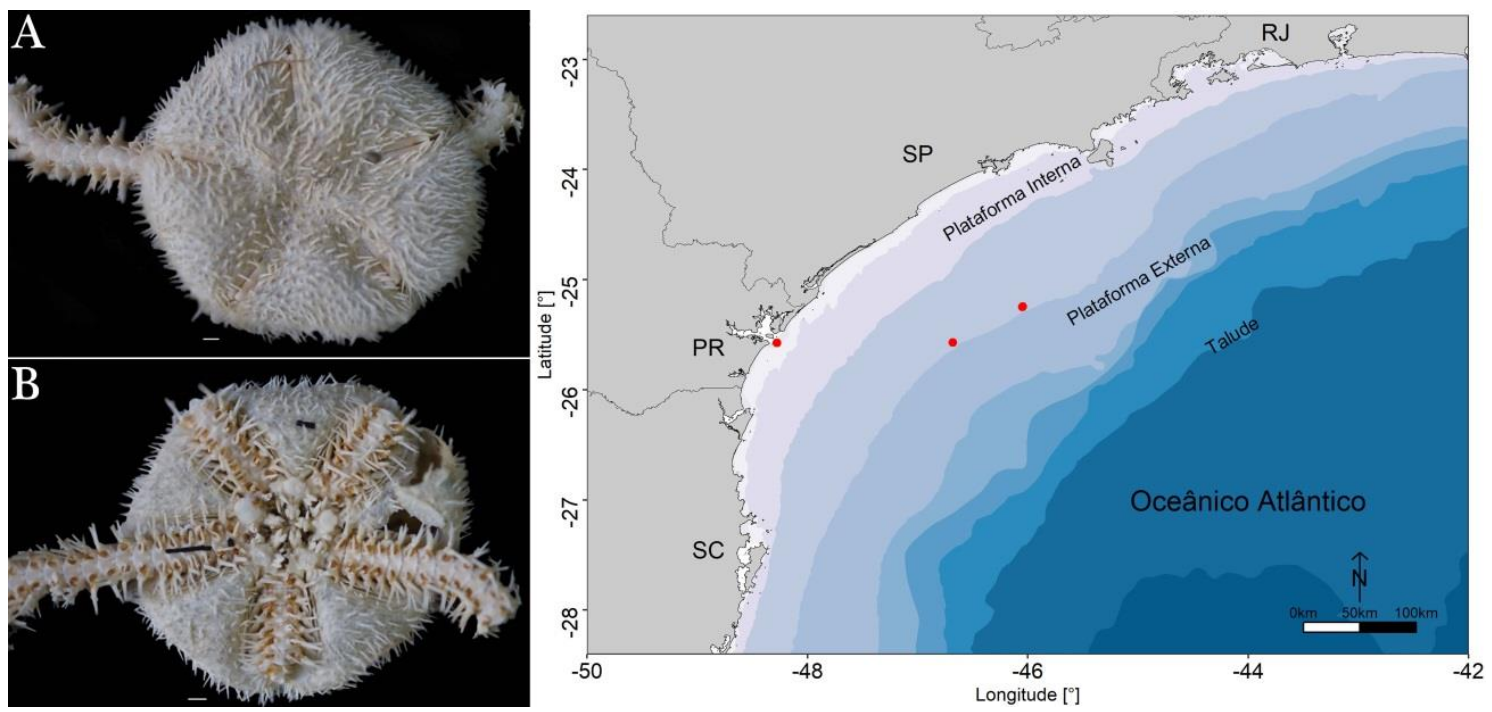

Figura 40. Amphilimna olivacea - ZUEC OPH 801: A. Vista dorsal, B. Vista ventral, G. Ocorrência de $A$. olivacea na plataforma continental interna e externa. Escala: $0.5 \mathrm{~mm}$.

\section{Amphiodia Verrill, 1899}

\section{Amphiodia pulchella (Lyman 1869)} Figura 41

Diagnose: Placas braquiais dorsais com o bordo anterior arredondado e o posterior mais reto. Primeiras 4-5 placas braquiais ventrais contíguas, posteriores separadas pelas placas braquiais laterais. Três espinhos braquiais, mediano mais robusto e com dentículos marginais (Tommasi 1970b; Borges \& Amaral 2005; Alitto et al. 2018).

Coloração: Disco cinza a marrom. Braços muitas vezes cinza pálido com manchas em cinza, marrom ou avermelhado (Hendler et al. 1995).

Hábitat: Substrato arenoso, nas profundidades de 8 e $18 \mathrm{~m}$.

Distribuição geográfica: Oceano Atlântico: Estados Unidos, México, Belize, Antilhas, Brasil e Argentina (Tommasi 1970b; Hendler et al. 1995; Borges \& Amaral 2005; Alvarado et al. 2008). Brasil: Espírito Santo até Rio Grande do Sul (Borges \& Amaral 2005; Netto et al. 2005; Alitto et al. 2018). 

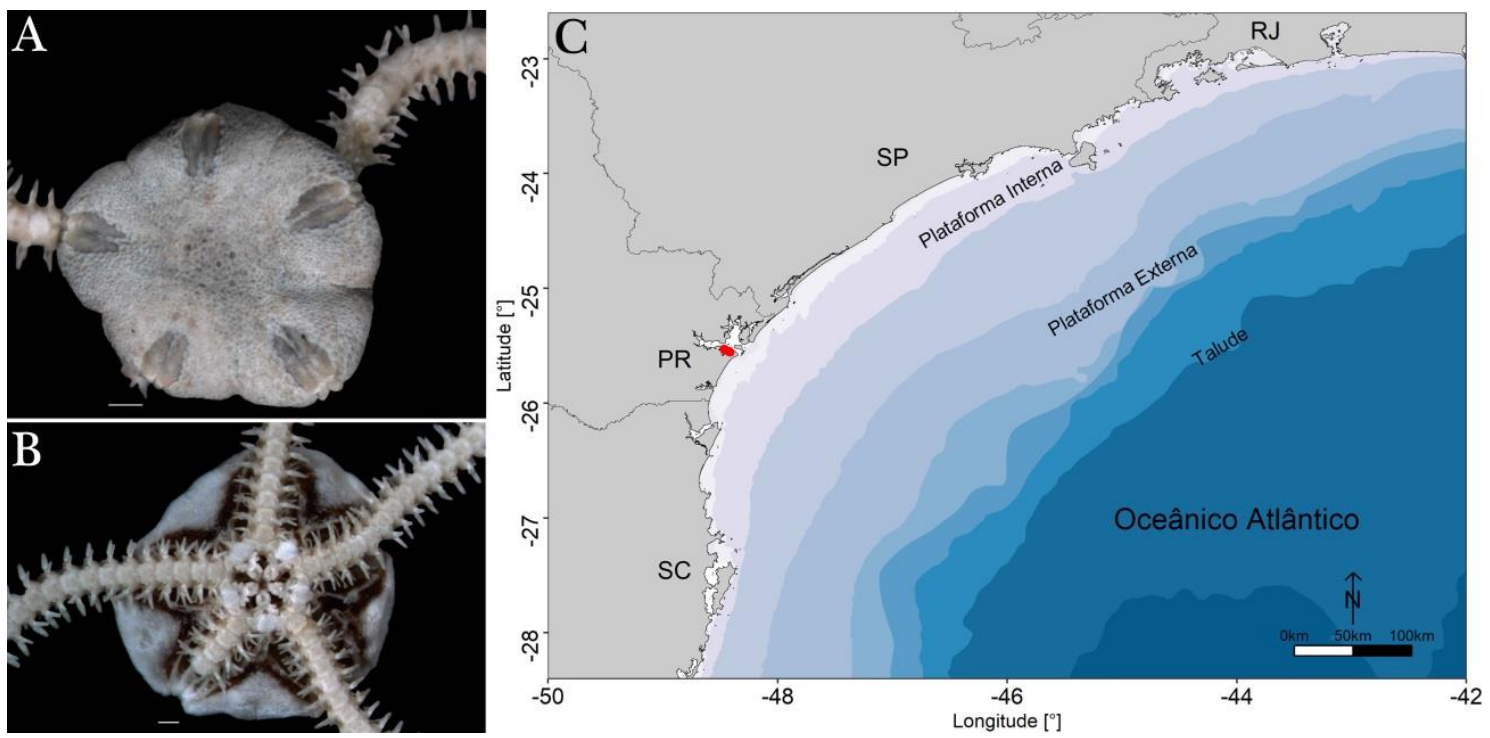

UEC OPH 2276: A. Vista dorsal, B. Vista ventral, C. Ocorrência de $A$. Figura 41. Amphiodia pulchella - ZUEC
pulchella no Complexo Estuarino de Paranaguá (Paraná). Escala: $0.5 \mathrm{~mm}$.

\section{Amphiodia planispina (v. Martens, 1867) Figura 42}

Diagnose: Disco arredondado, coberto por escamas imbricadas. Placas primárias não são evidentes. Escudos radiais mais longos que largos. Três espinhos braquiais rombudos comprimidos lateralmente; o espinho mais dorsal é maior nos segmentos proximais, enquanto o mais ventral é maior nos segmentos distais (Borges et al. 2002; Benavides-Serrato et al. 2011; Gondim et al. 2013).

Coloração: Disco cinza-azulado. Escudos radiais de marrom a cinza escuro com pontas brancas (Hendler et al. 1995; Benavides-Serrato et al. 2011).
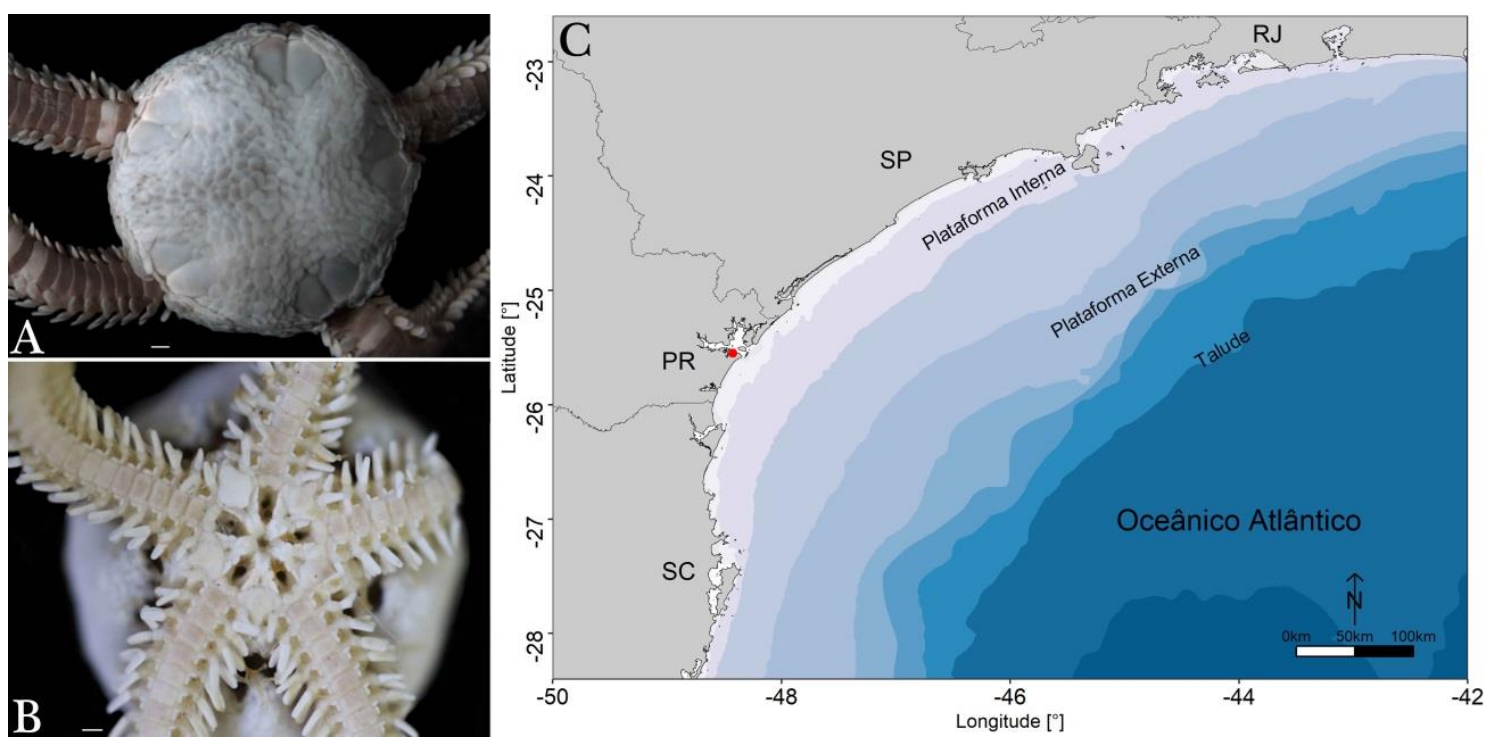

Figura 42. Amphiodia planispina - ZUEC OPH 422: A. Vista dorsal, B. Vista ventral, C. Ocorrência de $A$. planispina no Complexo Estuarino de Paranaguá (Paraná). Escala: $0.5 \mathrm{~mm}$.

Hábitat: Substrato arenoso, na profundidade de $8 \mathrm{~m}$. 
Distribuição geográfica: Oceano Atlântico: Estados Unidos, Panamá, Antilhas (Hendler et al. 1995; Alvarado et al. 2008), Brasil (Tommasi 1970b) e Argentina (Bernasconi \& D'Agostino 1977). Brasil: Maranhão até Rio Grande do Sul (Borges \& Amaral 2005; Gondim et al. 2013).

\section{Ophiophragmus Lyman, 1865}

\section{Amphiodia rïsei (Lütken \& Lyman, 1860) \\ Figura 43}

Diagnose: Disco arredondado, escamas do disco bem desenvolvidas. Placas centrodorsal e primárias evidentes. Escudos radiais contíguos. Escudos orais em forma de losango. Escudos adorais tocando-se anteriormente e ultrapassando o escudo oral. Três espinhos braquiais (Borges \& Amaral 2005; Benavides-Serrato et al. 2011; Alitto et al. 2018).

Coloração: Disco castanho com manchas esbranquiçadas irregulares nos braços, ou disco branco com manchas marrom ou avermelhado (Tommasi 1970b; Benavides-Serrato et al. 2011).

Hábitat: Substrato arenoso, em profundidades de 5-28 m.

Distribuição geográfica: Oceano Atlântico: Estados Unidos, Antilhas e Brasil (Hendler et al. 1995; Alvarado et al. 2008; Borrero-Pérez et al. 2008). Brasil: Amapá até o Paraná (Tommasi 1970b; Borges \& Amaral 2005; Gondim et al. 2013; Alitto et al. 2018).
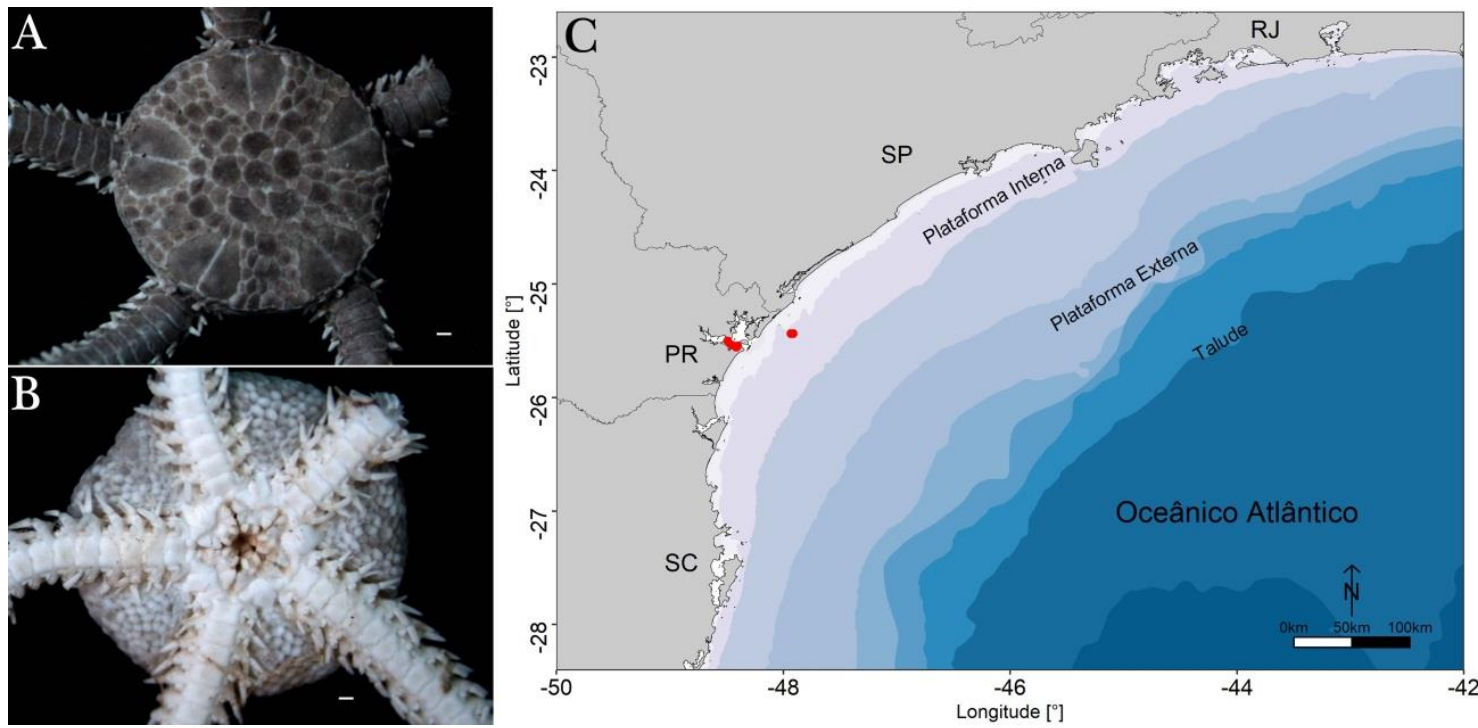

Figura 43. Amphiodia riisei - ZUEC OPH 2252: A. Vista dorsal, B. Vista ventral, G. Ocorrência de $A$. riisei na plataforma continental interna e estuário. Escala: $0.5 \mathrm{~mm}$.

\section{Amphioplus Verrill, 1899}

\section{Amphioplus lucyae (Tommasi, 1971)}

Figura 44

Diagnose: Placas primárias evidentes. Quatro a cinco papilas orais sub-iguais. Cinco espinhos braquiais robustos nos primeiros dez segmentos, diminuindo para quatro nos segmentos intermediários e três nas extremidades dos braços (Tommasi 1971; Borges et al. 2002; Borges \& Amaral 2005).

Coloração: Disco amarelado claro. Braços esbranquiçados (Tommasi 1971). 
Hábitat: Substratos arenosos, em profundidades de $8 \mathrm{~m}$.

Distribuição geográfica: Oceano Atlântico: Brasil (Tommasi 1971; Borges \& Amaral 2005) e Uruguai (Carranza et al. 2007). Brasil: Rio de Janeiro até o Rio Grande do Sul (Capítoli \& Monteiro 2000; Borges et al. 2002; Netto et al. 2005).
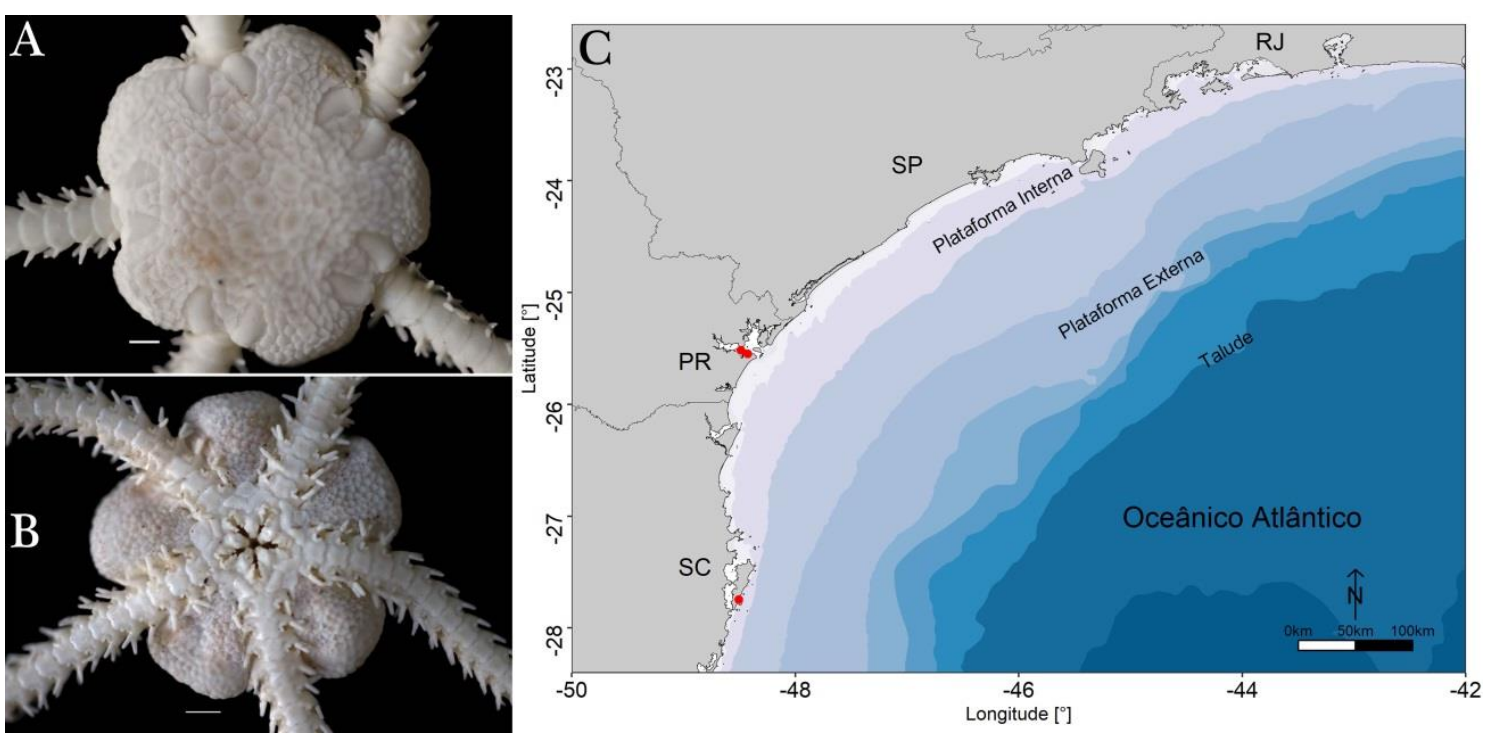

Figura 44. Amphioplus lucyae - ZUEC OPH 1513: A. Vista dorsal, B. Vista ventral, C. Ocorrência de $A$. lucyae na plataforma continental interna e estuário. Escala: $0.5 \mathrm{~mm}$.

\section{Amphipholis Ljungman, 1866 Amphipholis januarii Ljungman, 1866}

Figura 45

Diagnose: Disco arredondado ou pentagonal, com leves reentrâncias inter-radiais, coberto por pequenas escamas imbricadas. Escudos radiais estreitos e alongados. Duas papilas orais, distal triangular e nitidamente maior que a proximal. Um par de papilas infradentais separadas uma da outra. Placas braquiais dorsais portando três ou quatro espinhos braquiais rombudos; o segundo ou terceiro possui um ou dois dentículos no ápice (Borges \& Amaral 2005; Gondim et al. 2013; Alitto et al. 2018).
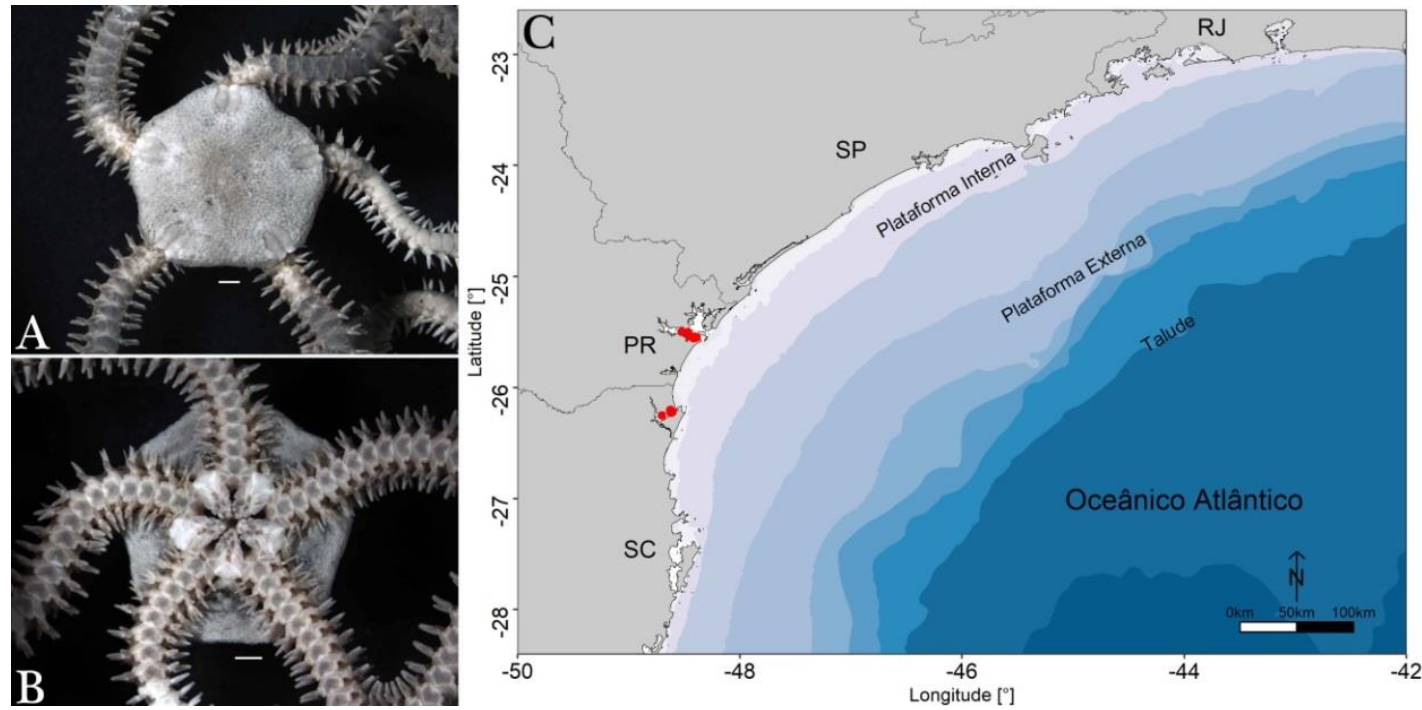

Figura 45. Amphipholis januarii - ZUEC OPH 2268: A. Vista dorsal, B. Vista ventral, C. Ocorrência de $A$. januarii nos estuários do Complexo Estuarino de Paranaguá (Paraná) e Baía da Babitonga (Santa Catarina). Escala: $0.5 \mathrm{~mm}$. 
Coloração: Disco pode variar do marrom claro, verde claro amarelado até cinza. Braços verde acinzentado ou marrom (Hendler et al. 1995).

Hábitat: Substrato arenoso, associado a algas, corais ou briozoários, em profundidades de até 18 m.

Distribuição geográfica: Oceano Atlântico: Estados Unidos, Antilhas, Belize, Panamá, Tobago e Brasil (Hendler et al. 1995; Alvarado et al. 2008). Brasil: Pará até o Paraná (Tommasi 1970b; Borges \& Amaral 2005; Alitto et al. 2018).

\section{Amphipholis Ljungman, 1866}

\section{Amphipholis squamata (Delle Chiaje, 1828)}

Figura 46

Diagnose: Disco redondo. Placas centrodorsal e primárias evidentes. Escudos radiais duas vezes mais longos que largos. Escudos orais losangulares. Placa braquial dorsal pouco mais larga que longa, em forma de leque. Placa braquial ventral com pequenas reentrâncias laterais. Duas escamas tentaculares. Três espinhos braquiais (Borges \& Amaral 2005; Gondim et al. 2013; Alitto et al. 2018).

Coloração: Disco pode variar do cinza claro, branco, amarelo, avermelhado, laranja e rosa. Braços castanhos claros, amarelados ou esbranquiçados (Tommasi 1970b; Hendler et al. 1995; Benavides-Serrato et al. 2011).

Hábitat: Substrato arenoso, esponjas, corais, fendas, sob rochas, conchas, fital e colônias de poliquetas, em profundidade de até $18 \mathrm{~m}$.

Distribuição geográfica: Espécie cosmopolita, exceto nas regiões polares. Oceano Atlântico: Canadá, Estados Unidos, México, Antilhas, Belize, Costa Rica, Panamá, Colômbia, Brasil e Uruguai (Bernasconi 1965; Hendler et al. 1995; Borges \& Amaral 2005; Benavides-Serrato et al. 2011; Gondim et al. 2013; Alitto et al. 2018).
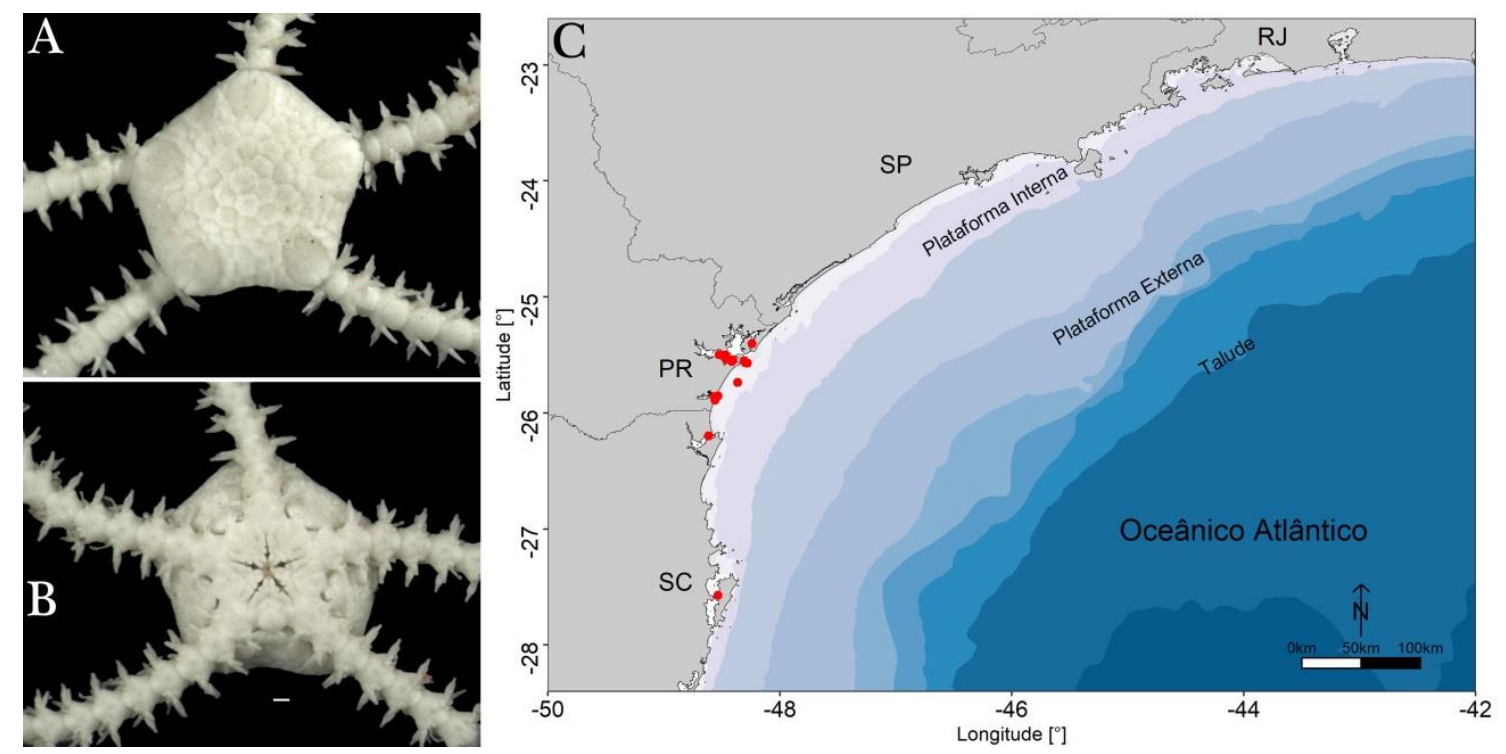

Figura 46. Amphipholis squamata - ZUEC OPH 2151: A. Vista dorsal, B. Vista ventral, C. Ocorrência de $A$. squamata na plataforma continental interna e estuários. Escala: $0.5 \mathrm{~mm}$. 
Amphiura Forbes, 1843

\section{Amphiura complanata Ljungman, 1867}

Figura 47

Diagnose: Disco com reentrâncias radiais e inter-radiais, coberto por escamas pequenas e imbricadas. Escudos radiais estreitos, mais longos que largos, divergentes e unidos apenas distalmente. De seis a sete espinhos braquiais, a partir do $13^{\circ}$ segmento o espinho braquial ventral é modificado em gancho (Tommasi 1970b; Borges \& Amaral 2005).

Coloração: Branca acinzentada.

Hábitat: Substrato arenoso ou lamoso, em profundidades de 6-430 m.

Distribuição geográfica: Oceano Atlântico: Brasil, Uruguai e Argentina (Tommasi 1970b; Borges et al. 2002; Martínez 2008). Brasil: Espírito Santo até o Rio Grande do Sul (Tommasi 1970b; Borges \& Amaral 2005).
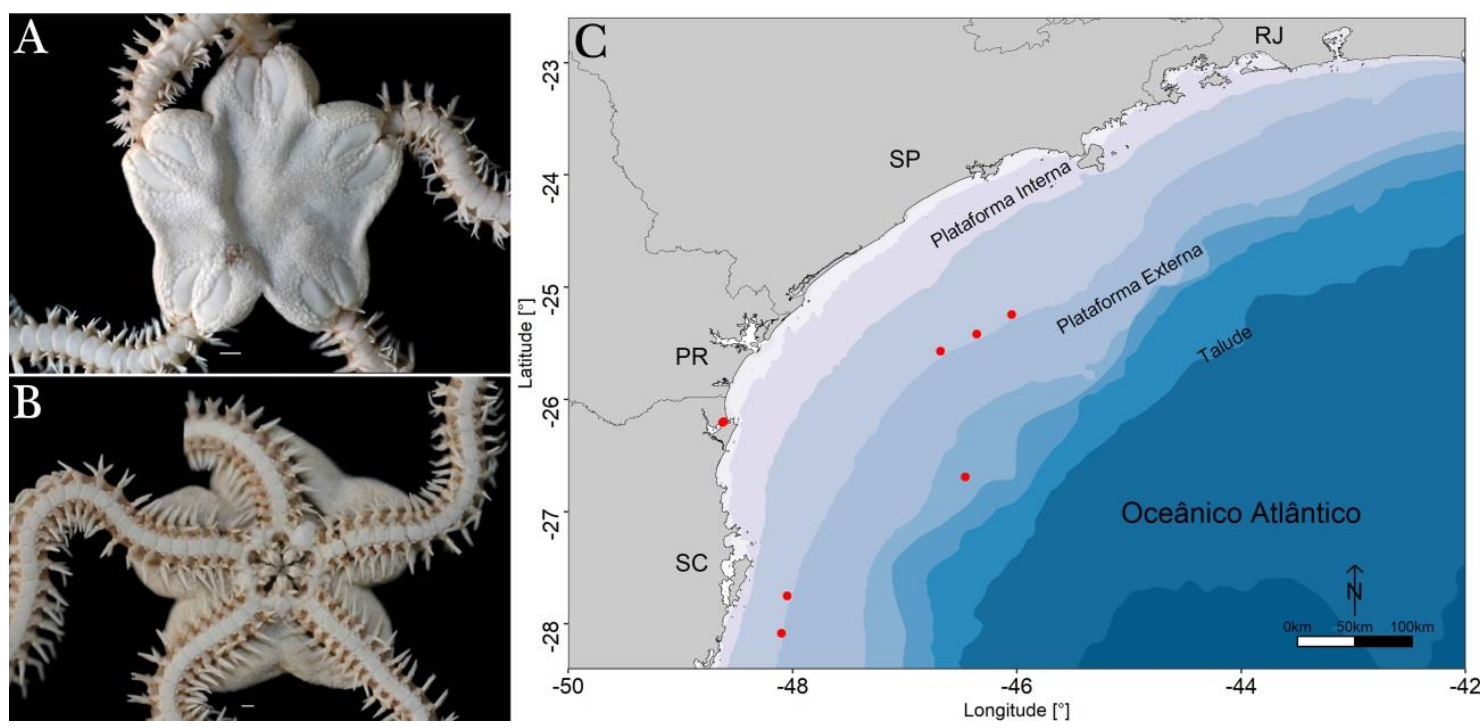

Figura 47. Amphiura complanata - ZUEC OPH 815: A. Vista dorsal, B. Vista ventral, G. Ocorrência de $A$. complanata na plataforma continental interna e externa. Escala: $0.5 \mathrm{~mm}$.

\section{Amphiura flexuosa Ljungman, 1867 Figura 48}

Diagnose: Disco com reentrâncias radiais e inter-radiais, coberto por escamas. Escudos radiais alongados, levemente curvos, separados por várias escamas e mais afilados proximalmente. Escudo oral ovalado com bordo distal mais afilado e leves reentrâncias látero-posteriores. Cinco espinhos braquiais afilados e pontiagudos nos primeiros segmentos, diminuindo para quatro nas extremidades (Tommasi 1970b; Borges \& Amaral 2005).

Coloração: Disco rosado (Tommasi 1970b).

Hábitat: Substrato arenoso ou lodoso, em profundidades de 18-500 m.

Distribuição geográfica: Oceano Atlântico: Estados Unidos, Antilhas, Brasil, Uruguai e Argentina (Borges et al. 2002; Martínez 2008). Brasil: Bahia até o Rio Grande do Sul (Tommasi 1970b; Borges \& Amaral 2005). 

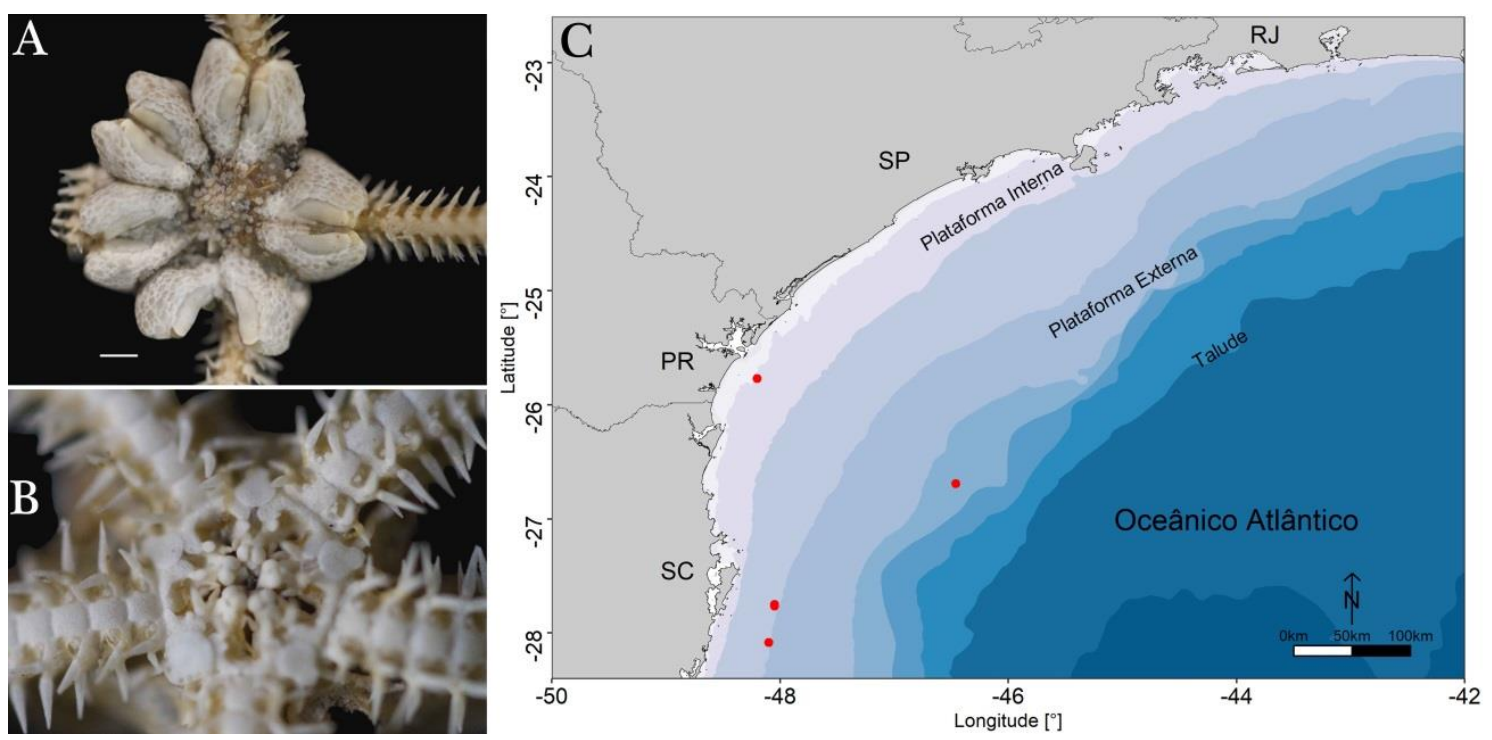

Figura 48. Amphiura flexuosa - ZUEC OPH 1580: A. Vista dorsal, B. Vista ventral, G. Ocorrência de $A$. flexuosa na plataforma continental interna, externa e talude. Escala: $0.5 \mathrm{~mm}$.

\section{Amphiura kinbergi Ljungman, 1872 Figura 49}

Diagnose: Disco com reentrâncias radiais e inter-radiais, coberto por escamas apenas ao redor dos escudos radiais. Escudos radiais afilados, levemente unidos, separados por várias escamas e mais afilados proximalmente. Cinco espinhos braquiais afilados e pontiagudos nos primeiros segmentos, diminuindo para quatro nas extremidades (Tommasi 1970b; Borges \& Amaral 2005; Alitto et al. 2018).

Coloração: Disco marrom escuro e escudos radiais e braços marrom claro.

Hábitat: Substrato arenoso, em profundidades de 5-78 m.
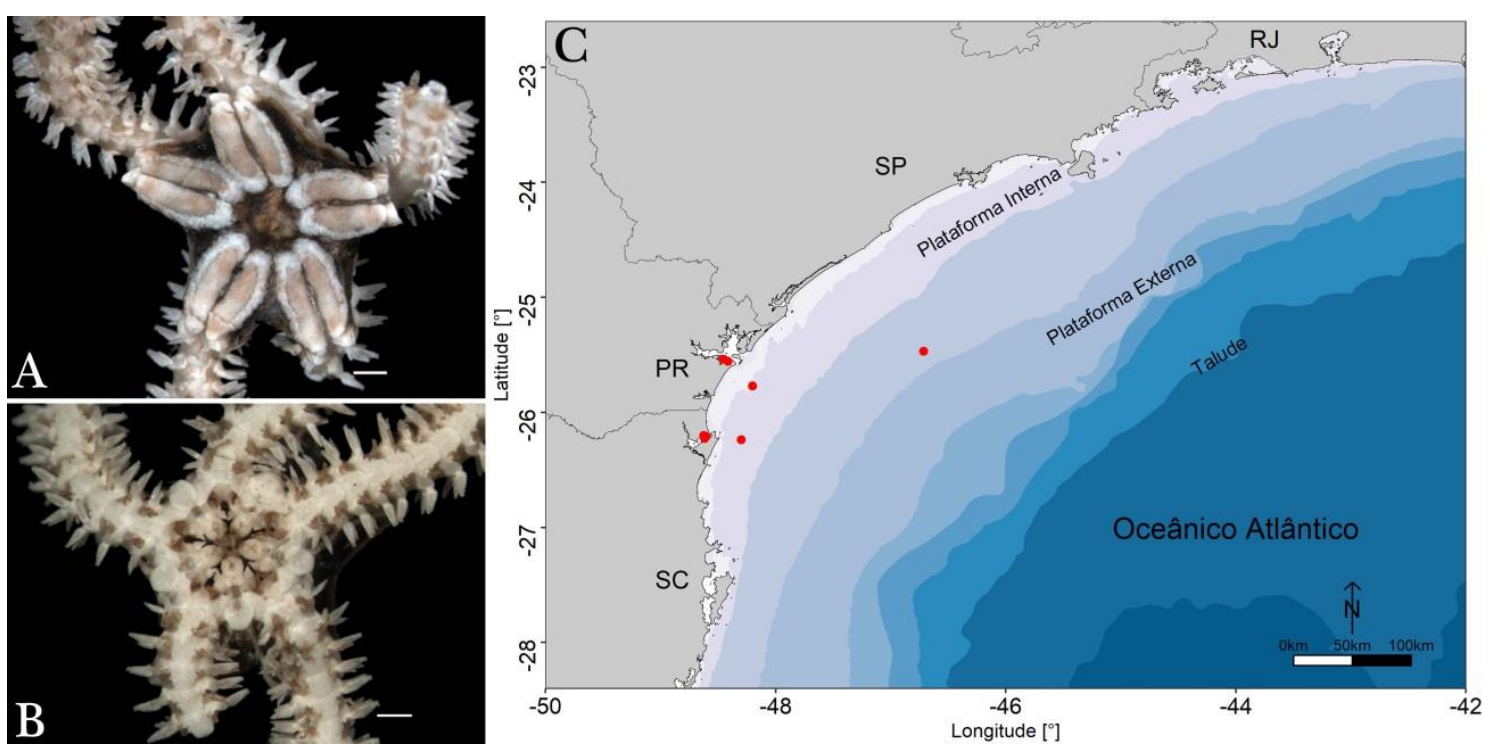

Figura 49. Amphiura kinbergi - ZUEC OPH 2274: A. Vista dorsal, B. Vista ventral, C. Ocorrência de $A$. kinbergi na plataforma continental interna e estuário. Escala: $0.5 \mathrm{~mm}$. 
Distribuição geográfica: Oceano Atlântico: Estados Unidos e Brasil (Borges \& Amaral 2005). Brasil: Pará, Maranhão, Ceará (Albuquerque 1986), Alagoas (Lima et al. 2011), São Paulo, Paraná, Santa Catarina (Tommasi 1970b; Manso et al. 2008; Alitto et al. 2018).

\section{Amphiura muelleri Marktanner-Turnerstscher, 1887 Figura 50}

Diagnose: Disco coberto por escamas pequenas e imbricadas, sendo as placas primárias maiores e evidentes. Escudos radiais estreitos e separados posteriormente. Quatro espinhos braquiais afilados. Escudo oral com margens arredondadas e leves reentrâncias látero-posteriores. Uma escama tentacular (Tommasi 1970b; Borges \& Amaral 2005).

Coloração: Branca amarelada.

Hábitat: Substrato arenoso, em profundidades de 358 a $768 \mathrm{~m}$.

Distribuição geográfica: Oceano Atlântico: Brasil: São Paulo, Paraná, Santa Catarina (Tommasi 1970b; Borges \& Amaral 2005).
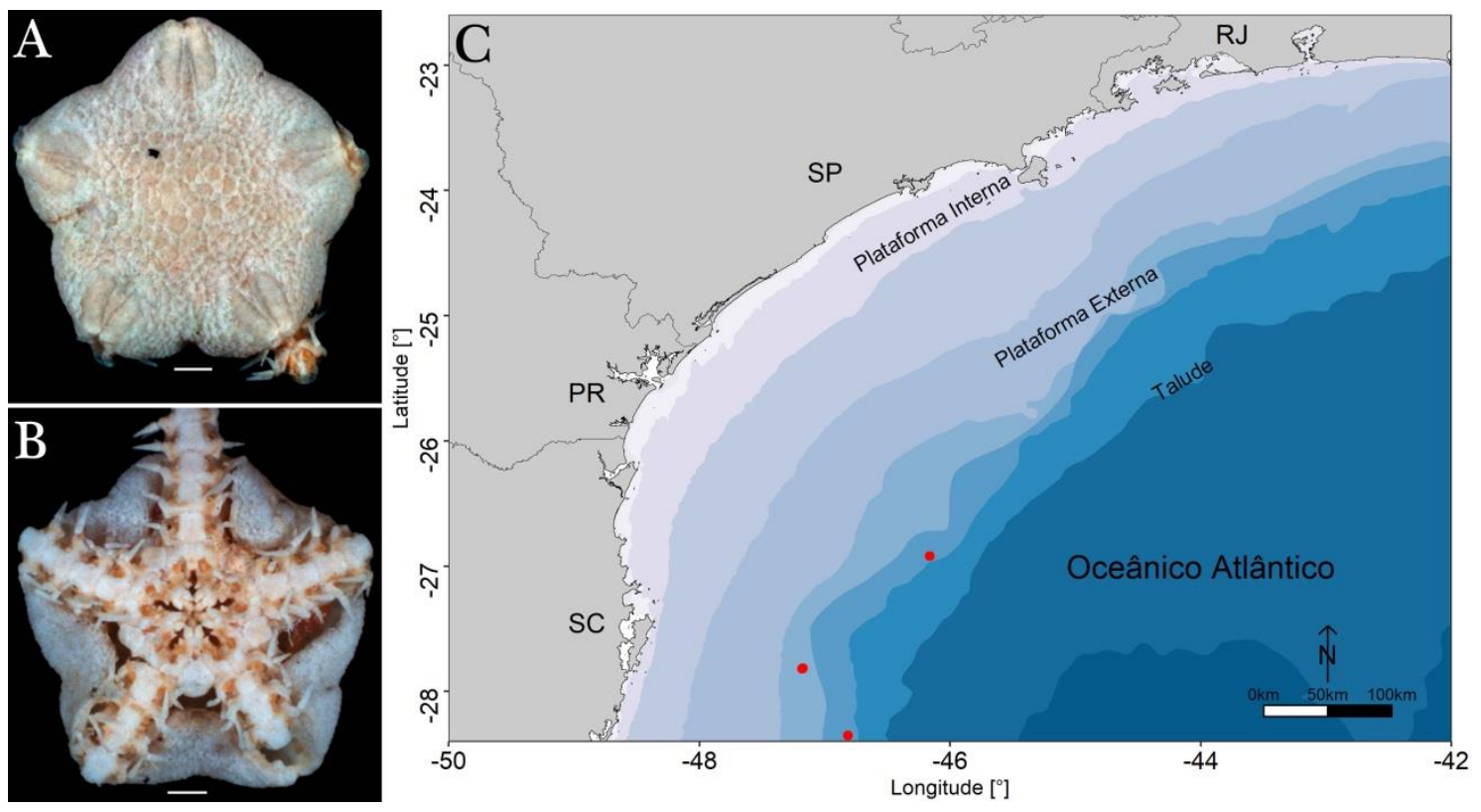

Figura 50. Amphiura muelleri - ZUEC OPH 799: A. Vista dorsal, B. Vista ventral, C. Ocorrência de $A$. muelleri no talude continental. Escala: $0.5 \mathrm{~mm}$.

\section{Microphiopholis Turner, 1985}

\section{Microphiopholis atra (Stimpson, 1852)} Figura 51

Diagnose: Disco arredondado com uma série marginal interradial de escamas maiores que as demais, em posição vertical formando um bordo no disco. Escudos radiais curtos e largos, com a margem externa curva, unidos na porção mediana posterior e separados anteriormente por escamas. Escudos orais losangulares, mais longos que largos com as bordas distais e proximais afiladas. Três espinhos braquiais pontudos (Tommasi 1970b; Borges \& Amaral 2005; Alitto et al. 2018). 
Coloração: Disco e braços cinza, marrom claro ou rosado. Braços podem conter manchas esbranquiçadas (Tommasi 1970b; Benavides-Serrato et al. 2011).

Hábitat: Substrato arenoso e rochoso, em profundidades de 1-18 m.

Distribuição geográfica: Oceano Atlântico: Antilhas (Tommasi 1970b), Colômbia, Venezuela (Alvarado 2011) e Brasil (Tommasi 1970b; Borges \& Amaral 2005). Brasil: Maranhão até Santa Catarina (Tommasi 1970b; Borges \& Amaral 2005; Alitto et al. 2018).
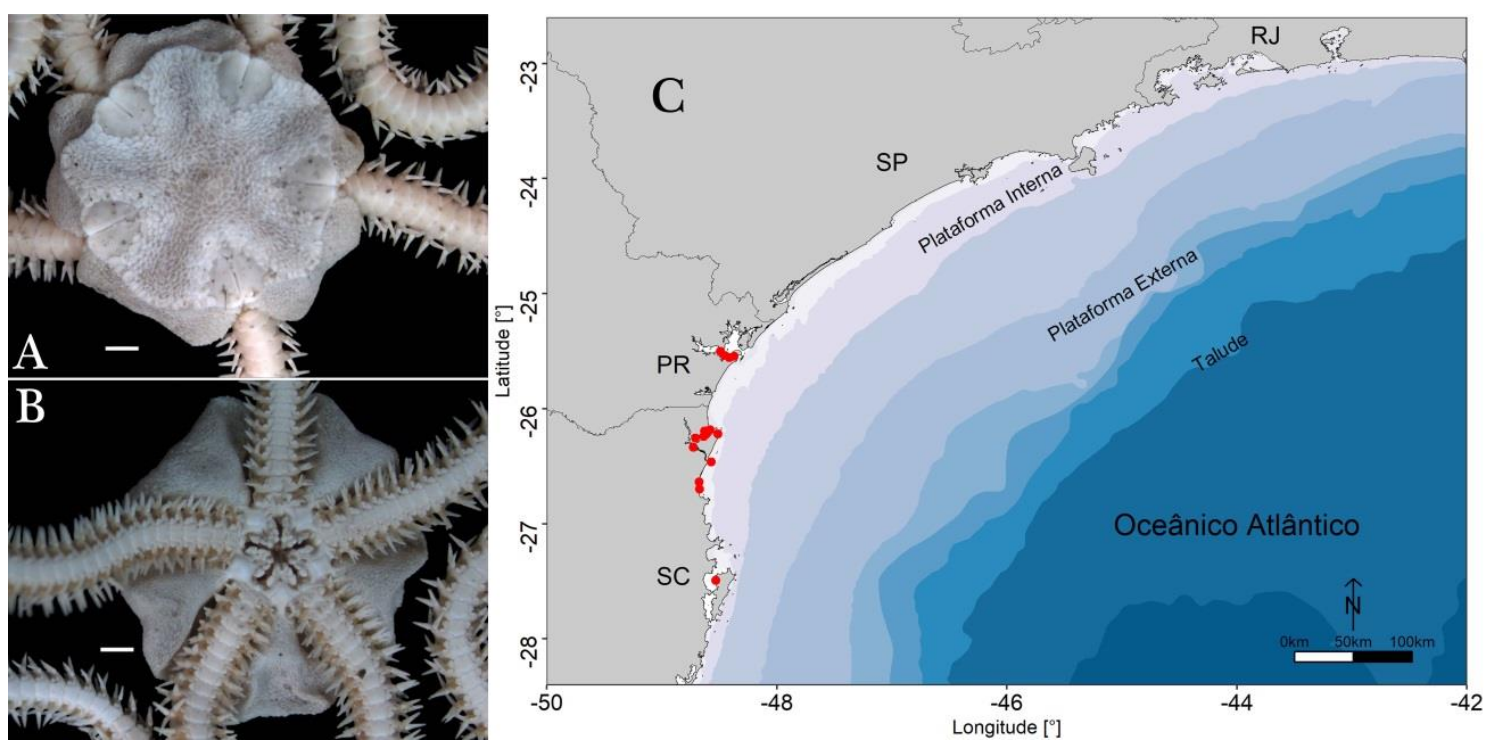

Figura 51. Microphiopholis atra - ZUEC OPH 2116: A. Vista dorsal, B. Vista ventral, C. Ocorrência de $M$. atra na plataforma continental interna e estuários. Escala: $0.5 \mathrm{~mm}$.

\section{Microphiopholis subtilis (Ljungman, 1867)} Figura 52

Diagnose: Disco pentagonal, coberto por escamas pequenas e imbricadas. Escudos radiais estreitos, mais longos que largos, unidos distalmente e separados proximalmente por escamas. Escudos orais sub-losangulares, afilados anteriormente e arredondados no bordo distal, com leves reentrâncias látero-posteriores. Fendas bursais amplas. Três espinhos braquiais afilados e pontudos (Tommasi 1970b; Alitto et al. 2018).
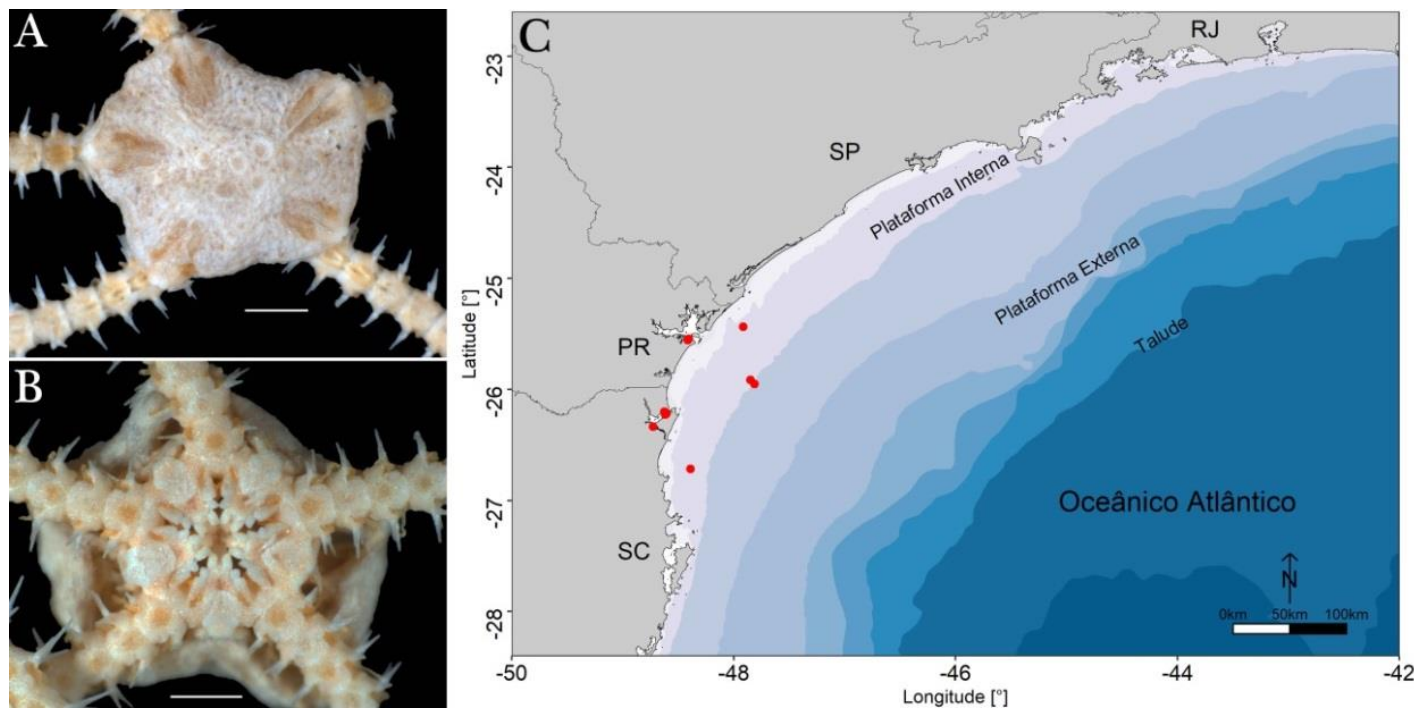

Figura 52. Microphiopholis subtilis - ZUEC OPH 2140: A. Vista dorsal, B. Vista ventral, C. Ocorrência de M. subtilis na plataforma continental interna e estuário. Escala: $0.5 \mathrm{~mm}$. 
Coloração: Disco alaranjado, avermelhado ou esbranquiçado, braços podem apresentar manchas alaranjadas ou avermelhadas (Tommasi 1970b; Alitto et al. 2018).

Hábitat: Substrato arenoso, lodoso ou com conchas e cascalhos, em profundidades de 2-50 m.

Distribuição geográfica: Oceano Atlântico: Porto Rico e Brasil (Tommasi 1970b; Borges 2006; Alitto et al. 2018). Brasil: Bahia (Tommasi et al. 1988; Magalhães et al. 2005), Rio de Janeiro (Manso \& Absalão 1988), São Paulo (Tommasi 1970b; Netto et al. 2005; Alitto et al. 2018), Paraná, Santa Catarina e Rio Grande do Sul (Oliveira et al. 2010).

\section{Ophiocnida Lyman, 1865}

\section{Ophiocnida loveni (Ljungman, 1867) \\ Figura 53}

Diagnose: Disco arredondado, coberto por escamas grandes e irregulares, recobertas por fina granulação. Escudos radiais triangulares, pouco mais longos que largos. Região oral interradial do disco coberta por grânulos espiniformes. Escudos orais losangulares. Mandíbulas curtas e com uma depressão mediana. Placas laterais com três a quatro espinhos braquiais (Tommasi 1970b; Manso et al. 2008).

\section{Coloração: Branca.}

Hábitat: Substrato arenoso, em profundidades de 2-39 m.

Distribuição geográfica: Oceano Atlântico: Brasil: Pernambuco (Lima \& Fernandes 2009), Bahia (Magalhães et al. 2005; Manso et al. 2008), Rio de Janeiro (Tommasi 1970b; Tommasi \& Aron 1987), Paraná e Santa Catarina (Lima \& Fernandes 2009; Barboza 2010).
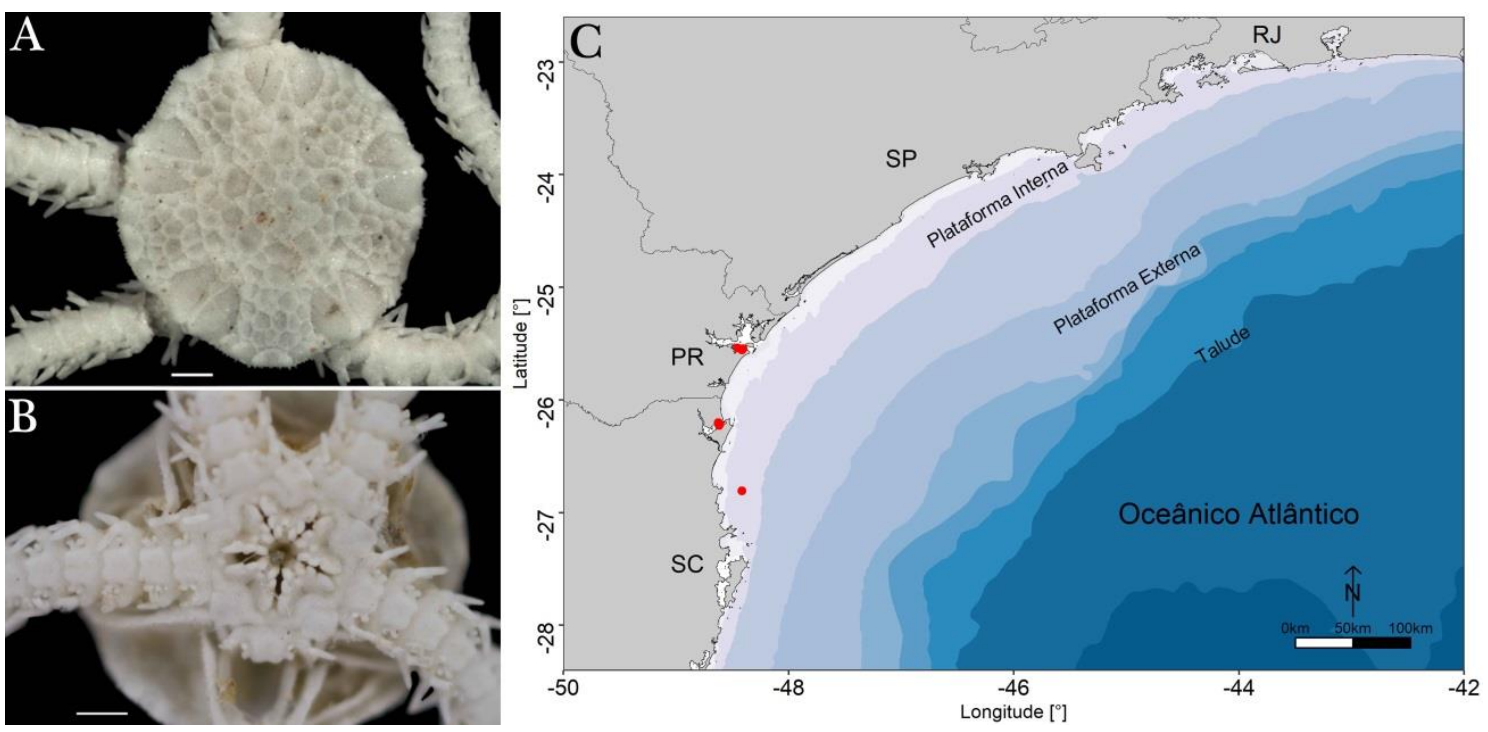

Figura 53. Ophiocnida loveni - ZUEC OPH 2370: A. Vista dorsal, B. Vista ventral, G. Ocorrência de $O$. loveni na plataforma continental interna e estuário. Escala: $0.5 \mathrm{~mm}$.

\section{$\square$ Ophiocnida scabriuscula (Lütken, 1859) Figura 54}

Diagnose: Disco dorsalmente coberto por escamas, contendo alguns pequenos espinhos curtos e finos. Escudos radiais mais longos que largos, divergentes, unidos distalmente, sem espinhos. 
Escudos orais losangulares, com os bordos arredondados. Placas braquiais dorsais mais largas que longas, sub-retangulares. Duas escamas tentaculares sub-iguais. Três espinhos braquiais lateralmente achatados, com extremidade truncada (Tommasi 1970b; Borges \& Amaral 2005; Gondim et al. 2013).

Coloração: Disco varia de marrom a amarelado e a extremidade distal dos escudos radiais são brancas. Braços marrom-amarelado com manchas nas placas braquiais dorsais (Netto 2006).

Hábitat: Substrato arenoso e cascalho, em profundidades de $3 \mathrm{~m}$.

Distribuição geográfica: Oceano Atlântico: Estados Unidos, Antilhas, México, Panamá, Colômbia, Venezuela e Brasil (Hendler et al. 1995; Borges \& Amaral 2005; Hernández-Herrejón et al. 2008). Brasil: do Maranhão até Paraná (Tommasi 1970b; Borges \& Amaral 2005; Gondim et al. 2013).
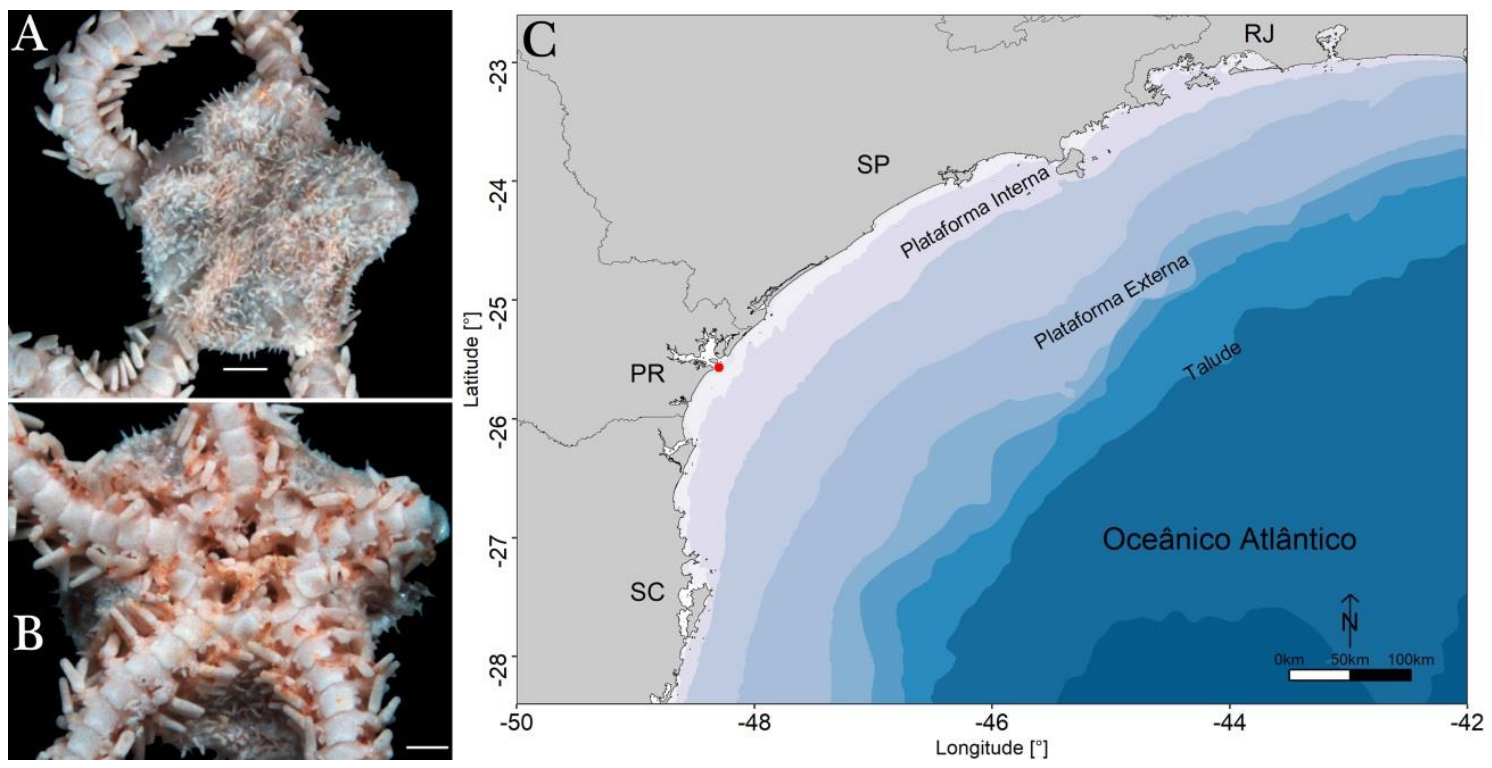

Figura 54. Ophiocnida scabriuscula - ZUEC OPH 514: A. Vista dorsal, B. Vista ventral, C. Ocorrência de $O$. scabriuscula na Ilha do Mel (Paraná). Escala: $0.5 \mathrm{~mm}$.

\section{Ophiophragmus Lyman, 1865}

\section{Ophiophragmus luetkeni (Ljungman, 1872)} Figura 55

Diagnose: Disco arredondado ou pentagonal coberto por escamas pequenas e imbricadas. Escudos radiais divergentes, bem desenvolvidos. Série marginal de espinhos afilados na face superior, formando uma franja. Duas escamas tentaculares no início do braço, uma na região mediana e nenhuma nas extremidades. Três espinhos braquiais, mediano mais curto e rombudo que os demais (Tommasi 1970b; Borges \& Amaral 2005; Alitto et al. 2018).

Coloração: Disco dorsalmente cinza violáceo. Placas dorsais do braço com uma faixa transversal cinza mais escura na região distal. Região ventral esbranquiçada ou acinzentada (Tommasi 1970b).

Hábitat: Substrato arenoso, lodoso ou areno-lodoso, em profundidades de 3-49 m. 
Distribuição geográfica: Oceano Atlântico: Ilhas Virgens Britânicas e Brasil (Borges \& Amaral 2005). Brasil: Bahia até Santa Catarina (Tommasi 1970b; Monteiro 1987; Manso et al. 2008; Barboza 2010; Alitto et al. 2018).
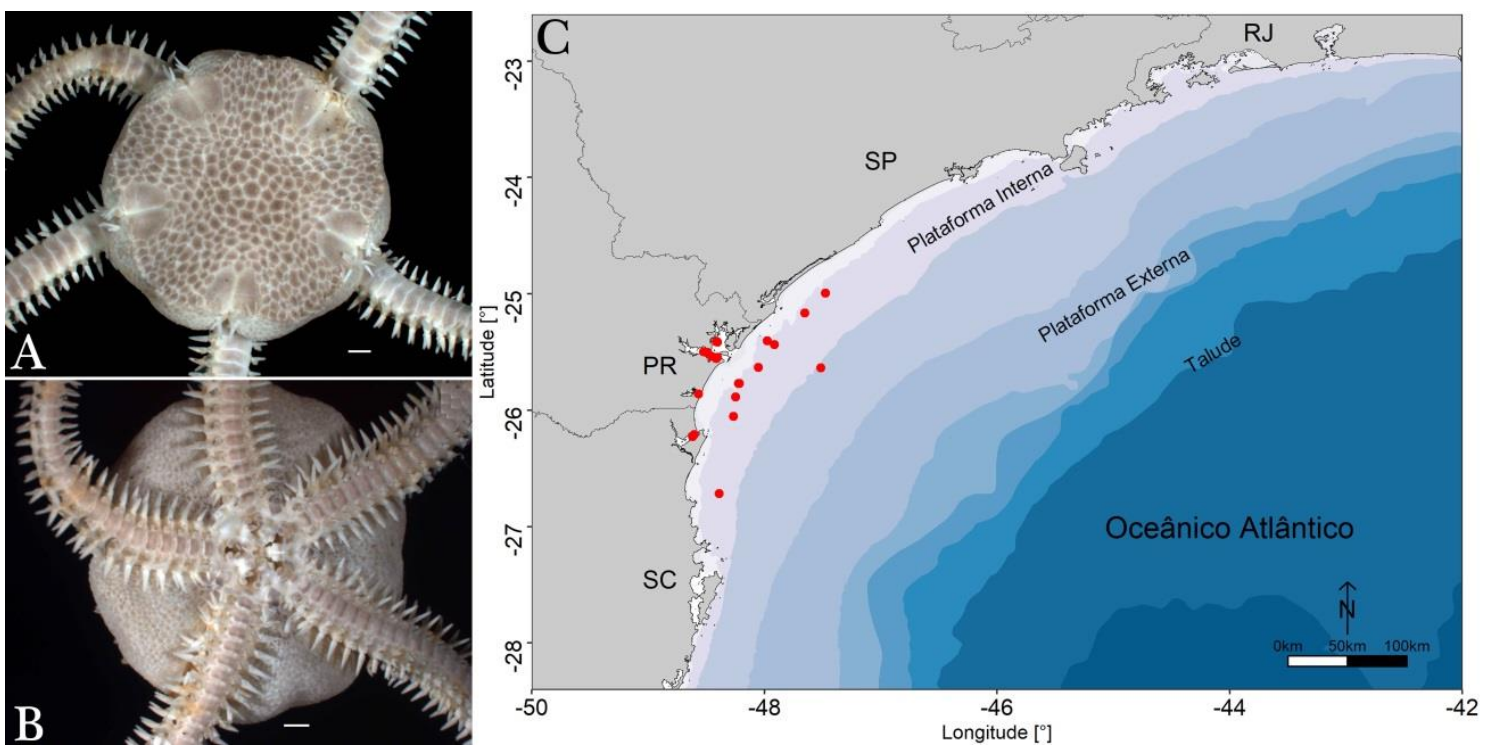

Figura 55. Ophiophragmus luetkeni - ZUEC OPH 2316: A. Vista dorsal, B. Vista ventral, G. Ocorrência de O. Iuetkeni na plataforma continental interna e estuários. Escala: $0.5 \mathrm{~mm}$.

\section{Ophiactidae Matsumoto, 1915 \\ Hemipholis Lyman, 1865}

\section{Hemipholis cordifera (Bosc, 1802)}

Figura 56

Diagnose: Disco arredondando com leves reentrâncias radiais, com escamas bem definidas, dispostas irregularmente. Escudos radiais cuneiformes, levemente divergentes e separados por escamas. Ausência de escamas na face ventral. Cinco braços longos, portando três espinhos braquiais sub-iguais, afilados em cada placa braquial (Tommasi 1970b; Borges \& Amaral 2005; Alitto et al. 2018).
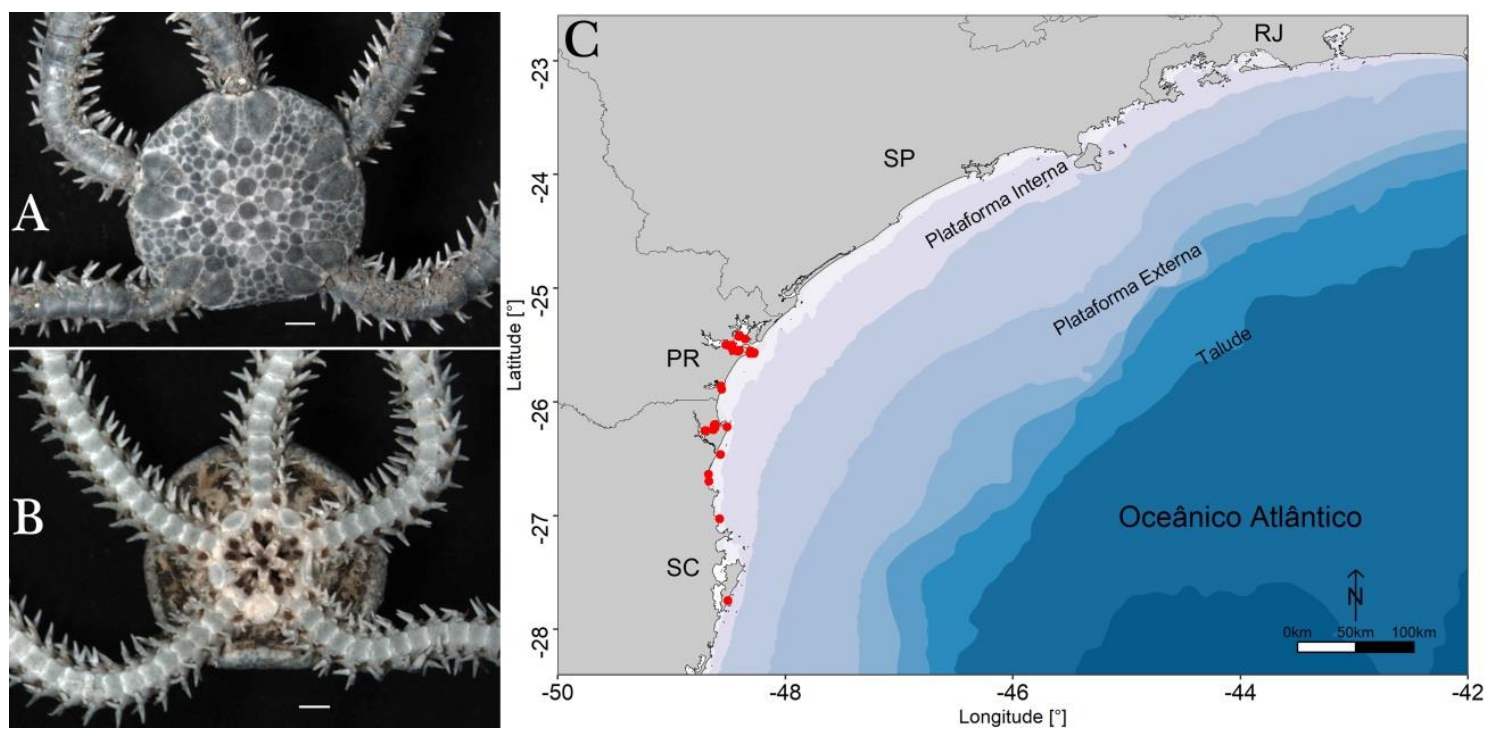

Figura 56. Hemipholis cordifera - ZUEC OPH 2191: A. Vista dorsal, B. Vista ventral, C. Ocorrência de $H$. cordifera na plataforma continental interna e estuários. Escala: $0.5 \mathrm{~mm}$. 
Coloração: Pode variar com tons de azul, verde, castanho, amarelo e cinza. Os escudos radiais apresentam uma cor diferente do disco (Tommasi 1970b).

Hábitat: Substrato arenoso, lodoso e rochoso, em profundidades de 1-18 m.

Distribuição geográfica: Oceano Atlântico: Estados Unidos (Hendler et al. 1995) e Brasil (Borges \& Amaral 2005). Brasil: Pará ao Rio Grande do Sul (Tommasi 1970b; Borges \& Amaral 2005; Alitto et al. 2018).

\section{Ophiactis Lütken, 1856}

\section{Ophiactis brasiliensis Manso, 1988}

Figura 57

Diagnose: Disco arredondado coberto por escamas grandes de formato irregular e finamente granulados. Região inter-radial ventral e marginal com alguns espinhos pontiagudos esparsos. Escudo radial mais longo que largo. Placas orais com fina granulação. Cinco a seis braços portando quatro espinhos braquiais rômbicos cobertos por dentículos (Manso 1988; Manso et al. 2008).

Coloração: Disco pode conter manchas verde oliva ou azulados na região dorsal, na região ventral é esbranquiçado (Manso et al. 2008).

Hábitat: Substrato arenoso, nas profundidades de $48 \mathrm{~m}$.

Distribuição geográfica: Oceano Atlântico: Brasil: Pernambuco até o Paraná (Magalhães et al. 2005; Netto et al. 2005; Manso et al. 2008; Lima \& Fernandes 2009).
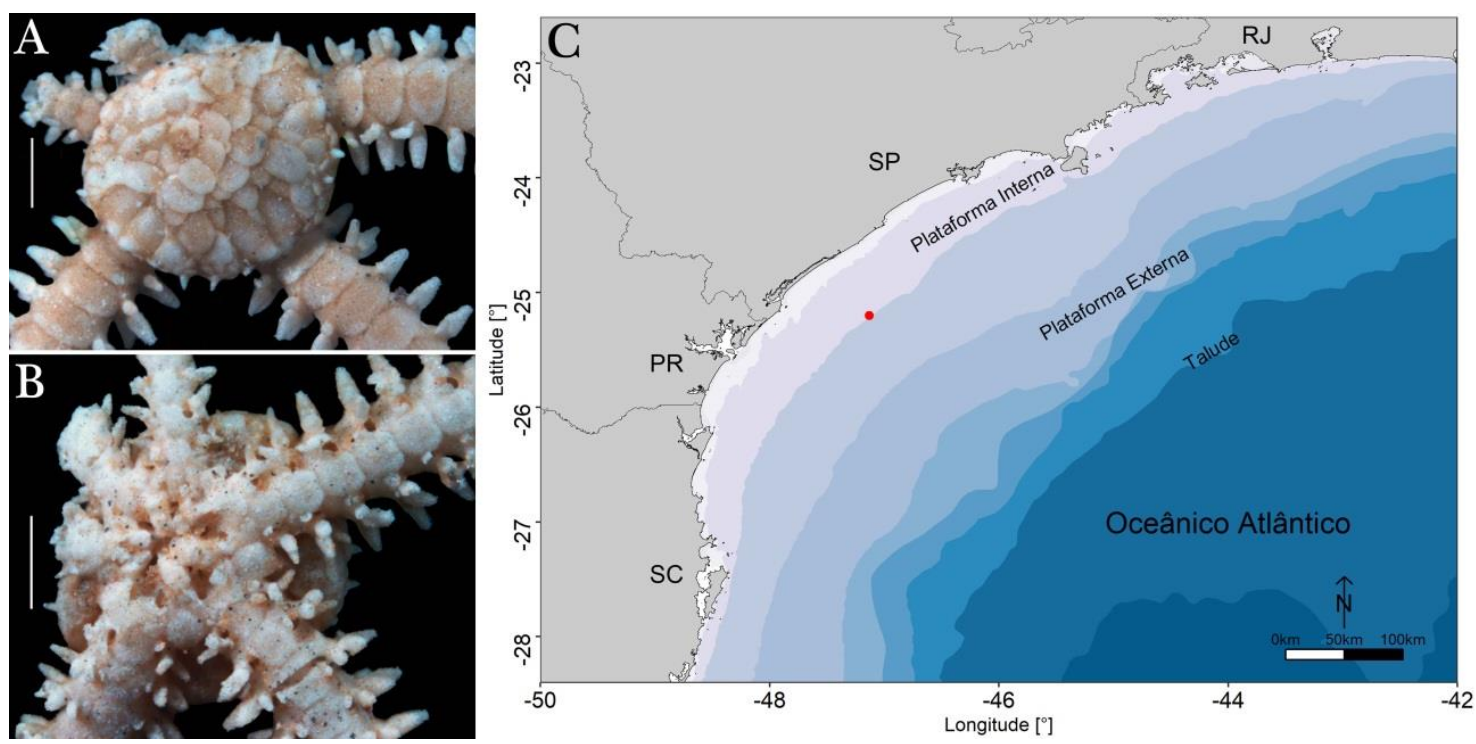

Figura 57. Ophiactis brasiliensis - ZUEC OPH 551: A. Vista dorsal, B. Vista ventral, C. Ocorrência de $O$. brasiliensis na plataforma continental interna. Escala: $0.5 \mathrm{~mm}$.

Ophiactis lymani Ljungman, 1872

Figura 58

Diagnose: Disco subcircular, coberto por escamas grandes e irregulares. Escudos radiais mais longos que largos, unidos distalmente e separados proximalmente por duas escamas. Escudo oral sublosangular, afilados anteriormente e levemente curvo no bordo distal. Placas superiores 
dos braços em forma de leque. Três espinhos braquiais sub-iguais (Tommasi 1970b; Borges \& Amaral 2005; Alitto et al. 2018).

Coloração: Disco cinza, com a região central mais clara. Braços com faixa cinza escuro (Manso et al. 2008).

Hábitat: Substrato arenoso, ou associado a algas, briozoários e esponjas, em profundidades de até $18 \mathrm{~m}$.

Distribuição geográfica: Oceano Atlântico: a oeste das Antilhas, México (Miloslavich et al. 2010) e Brasil (Borges \& Amaral 2005; Alitto et al. 2018), a leste do Senegal até o Golfo da Guiné. Oceano Índico: Ilha Reunião (Borges \& Amaral 2005).
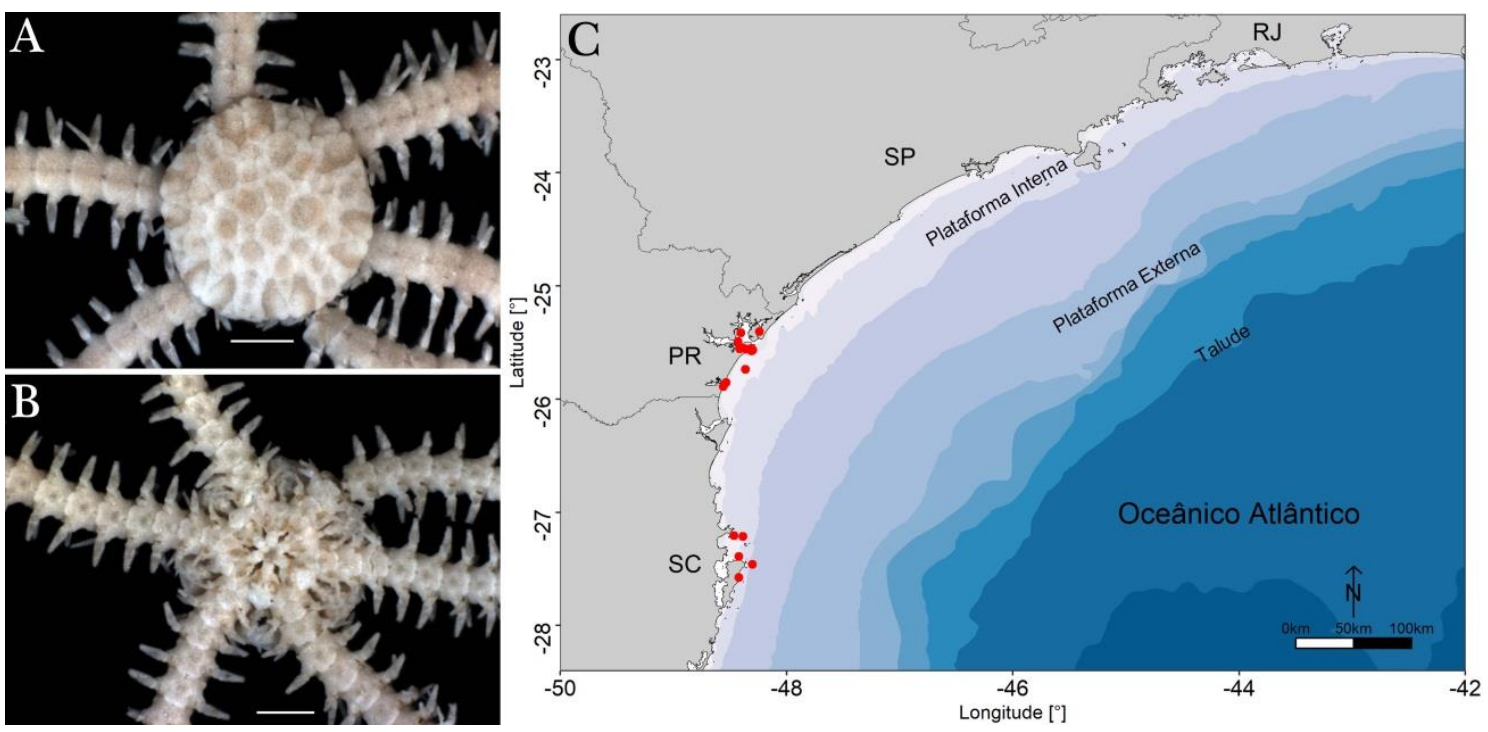

Figura 58. Ophiactis lymani - ZUEC OPH 2178: A. Vista dorsal, B. Vista ventral, C. Ocorrência de $O$. lymani na plataforma continental interna e estuários. Escala: $0.5 \mathrm{~mm}$.

\section{Ophiactis savignyi (Müller \& Troschel, 1841)}

Figura 59

Diagnose: Disco arredondado, dorsalmente coberto por escamas irregulares, imbricadas, portando alguns espinhos no disco. Escudos radiais grandes e triangulares, unidos distalmente e separados proximalmente. Fendas bursais amplas. Placas braquiais portando cinco a seis espinhos braquiais robustos com dentículos marginais (Borges \& Amaral 2005; Gondim et al. 2013; Alitto et al. 2018).

Coloração: Disco verde oliva, marrom-esverdeado ou marrom-amarelado com manchas brancas e/ou negras nas placas do disco e do braço (Tommasi 1970b; Hendler et al. 1995).

Hábitat: Substrato biológico, associado a esponjas, algas, colônias de briozoários, poliquetas e outras espécies de ofiuroides, em profundidades de até $7 \mathrm{~m}$.

Distribuição geográfica: Oceano Atlântico, Indo-Pacífico e leste do Pacífico (Gondim et al. 2013). Brasil: em toda à costa (Borges \& Amaral 2005; Gondim et al. 2013; Alitto et al. 2018). 

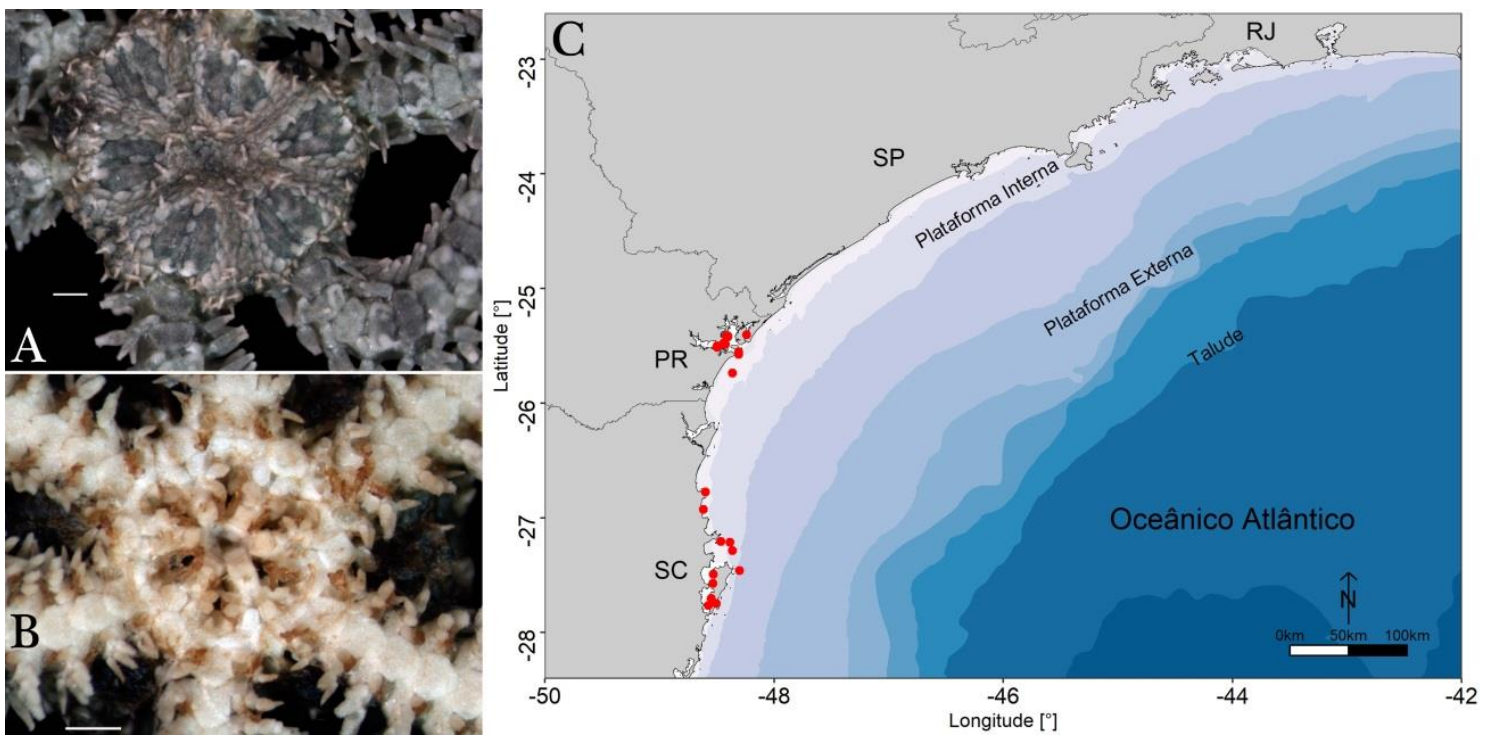

Figura 59. Ophiactis savignyi - ZUEC OPH 2380: A. Vista dorsal, B. Vista ventral, C. Ocorrência de $O$. savignyi na plataforma continental interna e estuários. Escala: $0.5 \mathrm{~mm}$.

\section{Ophionereididae Ljungman, 1867 \\ Ophionereis Lütken, 1859}

\section{Ophionereis reticulata (Say, 1825)} Figura 60

Diagnose: Disco arredondado, com reentrâncias inter-radiais. Escudos radiais pequenos, ovais, separados um do outro. Duas primeiras placas da superfície dorsal mais largas que longas, posteriores subtrapezoidais. Placas acessórias semi-triangulares, presentes em quase todo o braço (Tommasi 1970b; Borges \& Amaral 2005).
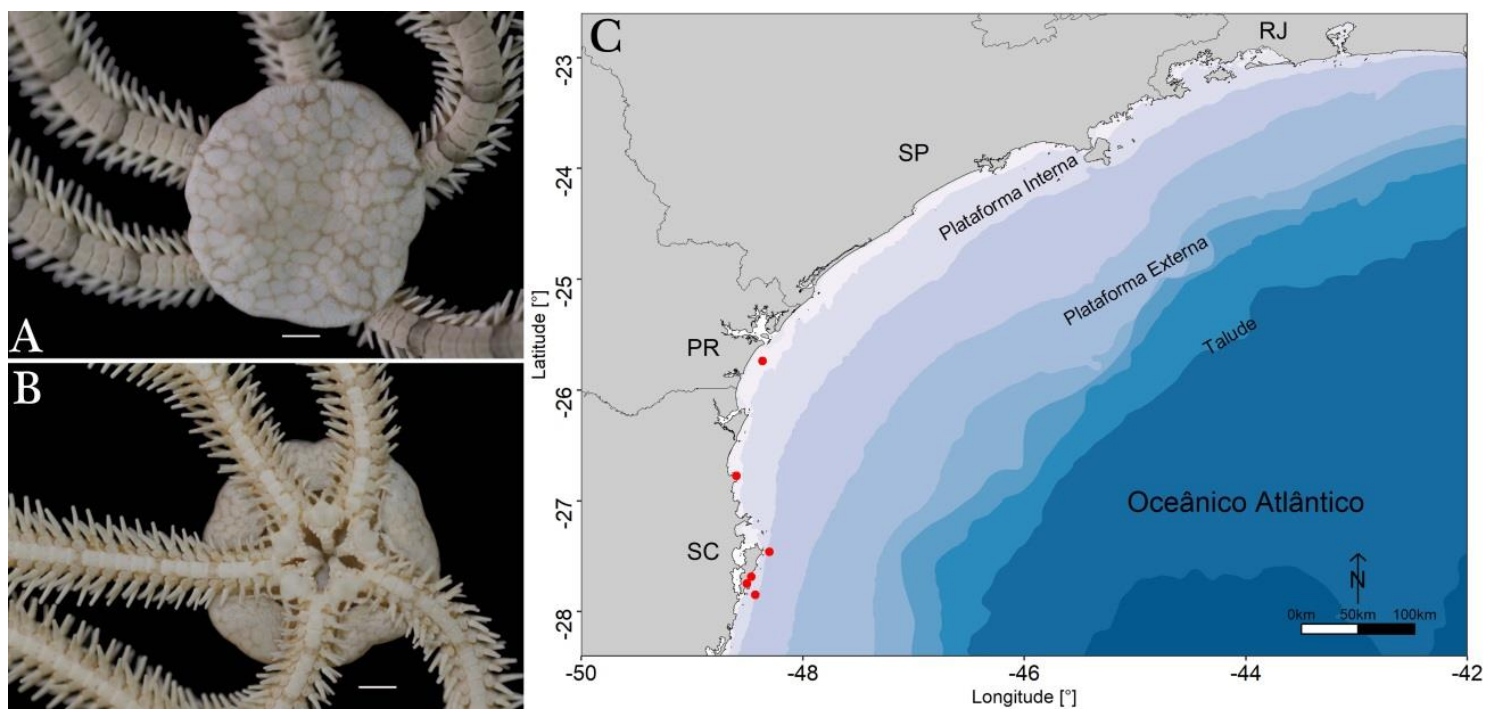

Figura 60. Ophionereis reticulata - ZUEC OPH 1896: A. Vista dorsal, B. Vista ventral, G. Ocorrência de $O$. reticulata na plataforma continental interna e estuários. Escala: $0.5 \mathrm{~mm}$.

Coloração: Espécie com padrão de coloração bem definido, no qual observa-se um retículo, variando de marrom, verde a avermelhado compondo um desenho irregular formado por um fino traço escuro, sobre o animal acinzentado (Tommasi 1970b; Borges \& Amaral 2005). 
Hábitat: Substrato não consolidado, em profundidades de até $7 \mathrm{~m}$. Porém, segundo Borges \& Amaral (2005) também é comum em substrato rochoso, corais ou algas, em profundidades de 0$250 \mathrm{~m}$.

Distribuição geográfica: Oceano Atlântico: Estados Unidos, América Central e do Sul até o Brasil (Hendler et al. 1995; Borges \& Amaral 2005; Laguarda-Figueras et al. 2009; Pawson et al. 2009). Brasil: Amapá até Santa Catarina (Albuquerque 1986; Borges \& Amaral 2005).

\section{Ophiotrichidae Ljungman, 1867 \\ Ophiothela Verrill, 1867}

\section{Ophiothela mirabilis Verrill, 1867 \\ Figura 61}

Diagnose: Disco com aparência estrelada, com reentrâncias interradiais, dorsalmente coberto pelos escudos radiais e por placas, pequenas e irregulares, entre estes. Grânulos arredondados e esparsos sobre toda superfície dorsal, maiores entre os escudos radias. Seis braços com articulação, portando três a quatro espinhos braquiais com dentículos marginais translúcidos em forma de gancho (Alitto et al. 2018).

Coloração: Cor variável (Tahera 2001). No Brasil, geralmente é laranja ou rosa claro (Alitto et al. 2018).

Hábitat: Substrato biológico, principalmente corais e esponjas, em profundidades de até $7 \mathrm{~m}$.

Distribuição geográfica: Oceano Atlântico: Pequenas Antilhas, Caribe e Brasil (Hendler et al. 2012). Oceano Pacífico: Oceania (Verrill 1869; Clark 1976). Oceano Índico: Madagáscar (Cherbonnier \& Guille 1978), Moçambique, Mar Vermelho (Clark \& Rowe 1971), Austrália (Rowe \& Gates 1995). Brasil: Bahia até Santa Catarina (Hendler et al. 2012; Alitto et al. 2018; Lawley et al. 2018).
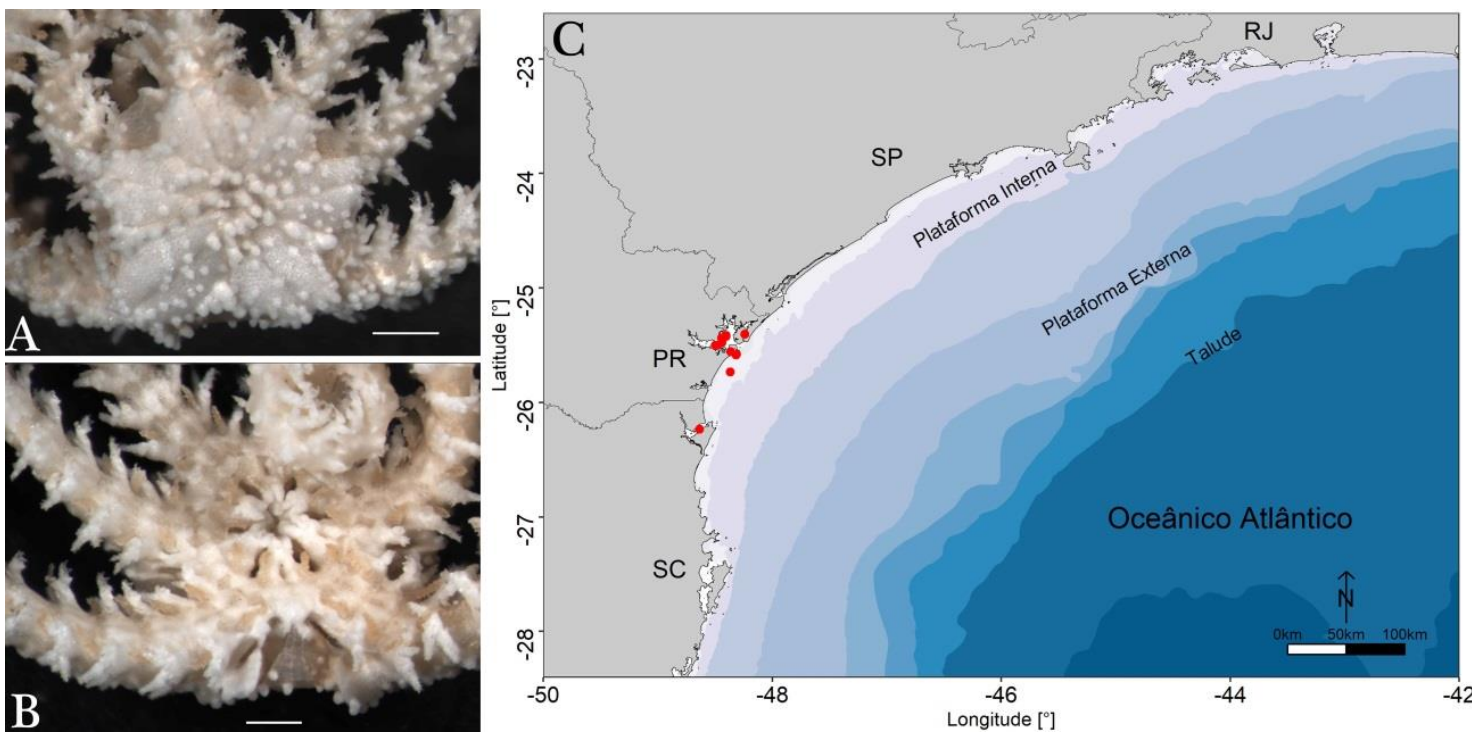

Figura 61. Ophiothela mirabilis - ZUEC OPH 2377: A. Vista dorsal, B. Vista ventral, G. Ocorrência de $O$. mirabilis no Complexo Estuarino de Paranaguá (Paraná). Escala: $0.5 \mathrm{~mm}$.

Ophiothrix Müller \& Troschel, 1840

Ophiothrix angulata (Say, 1825)

Figura 62 
Diagnose: Disco pentagonal com reentrâncias radiais, cobertos por espinhos bífidos e trífidos, hialinos e pequenos. Escudos radiais proporcionalmente pequenos, afilados anteriormente, alargados e unidos na porção distal, portando espinhos. De cinco a oito espinhos braquiais longos, translúcidos e com as margens denteadas. A partir do quarto ou quinto segmento braquial, espinho mais ventral menor e modificado em gancho, com dentes hialinos voltados para o disco (Borges \& Amaral 2005; Santana et al. 2017; Alitto et al. 2018).

Coloração: Cor variável, de rosa ao violeta escuro e podendo apresentar uma listra preta ou branca na superfície dos braços (Tommasi 1970b; Hendler et al. 1995).

Hábitat: Substrato arenoso, cascalho, conchas, rochas, corais, algas e esponjas, em profundidades de até $5 \mathrm{~m}$.

Distribuição geográfica: Oceano Atlântico: Estados Unidos até o Uruguai (Borges \& Amaral 2005; Alvarado \& Solís-Marín 2013; Santana et al. 2017; Alitto et al. 2018).
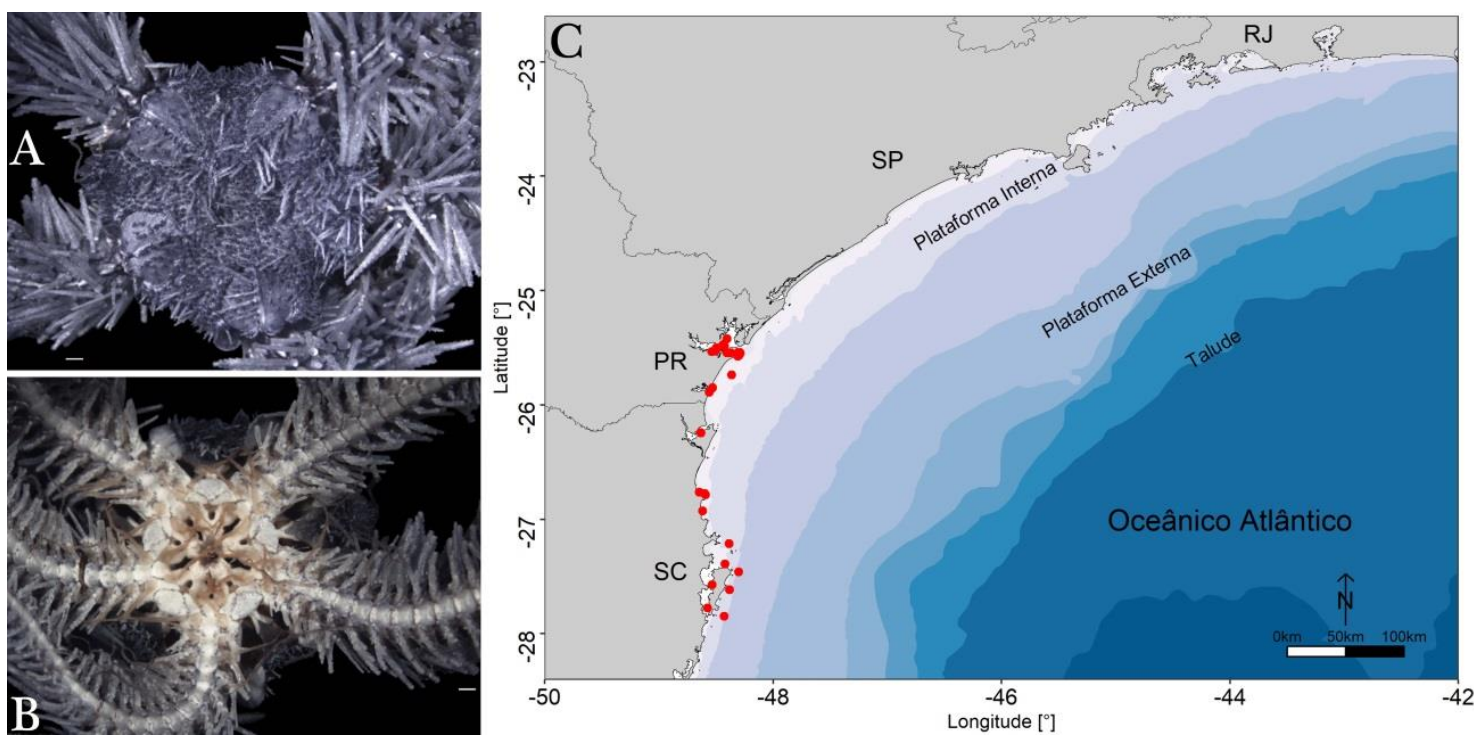

Figura 62. Ophiothrix angulata - ZUEC OPH 2194: A. Vista dorsal, B. Vista ventral, G. Ocorrência de $O$. angulata na plataforma continental interna e estuários. Escala: $0.5 \mathrm{~mm}$.

\section{Ophiacanthidae Ljungman, 1867 Ophiacantha Müller \& Troschel, 1842 \\ Ophiacantha anomala G.O. Sars, 1872 Figura 63}

Diagnose: Disco coberto por espinhos longos com múltiplas pontas laterais e uma coroa de espinhos irregular na extremidade. Escudos radiais visíveis apenas na extremidade distal. Escudo oral mais largo que longo, sublosangular com os bordos proximais e distais levemente arredondados. Uma papila apical bem desenvolvida e de 3-5 papilas laterais afiladas. Seis braços portando 7-8 espinhos braquiais longos, com dentículos hialinos. Duas escamas tentaculares nos primeiros e segundos poros tentaculares, os demais portam somente uma escama (Barboza 2015).

Coloração: Branca amarelada.

Hábitat: Substrato não consolidado. Informação de profundidade ausente para ESB, porém na Bacia de Campos foi registrada entre 1128 e 1135 m. 
Distribuição geográfica: Oceano Atlântico: ao norte Islândia, Noruega, Estados Unidos (Flórida) e Marrocos (Paterson 1985; Bartsch 1987; Martynov \& Litvinova 2008), ao sul Ilha Ascensão e Brasil: Espírito Santo, Rio de Janeiro e Paraná (Lyman 1878; Barboza 2015).
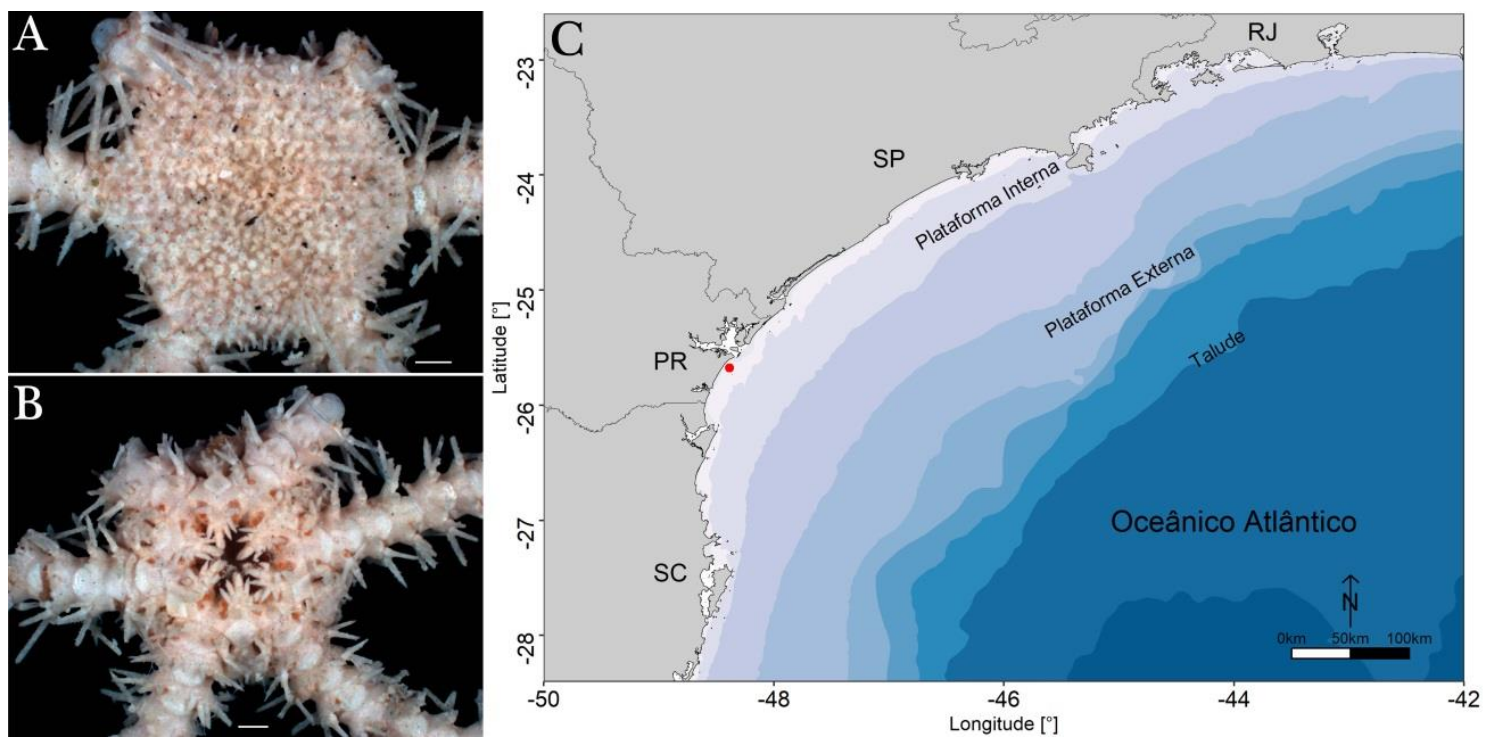

Figura 63. Ophiacantha anomala - ZUEC OPH 2382: A. Vista dorsal, B. Vista ventral, C. Ocorrência de $O$. anomala na plataforma continental interna. Escala: $0.5 \mathrm{~mm}$.

\section{Ophiacantha aristata Koehler, 1895}

Figura 64

Diagnose: Disco coberto por pele espessa, coberta de pequenos espinhos de múltiplas pontas. Escudos radiais cobertos pela pele, separados entre si. Placas braquiais dorsais separadas entre si por desenvolvidas placas braquiais laterais. Placas braquiais ventrais mais largas que longas, bordo proximal afilado, distal arredondado e separadas pelas placas braquiais laterais. De 8-9 espinhos braquiais longos, com dentículos hialinos. Uma escama tentacular desenvolvida, espiniforme e rugosa (Barboza et al. 2010; Barboza 2015).
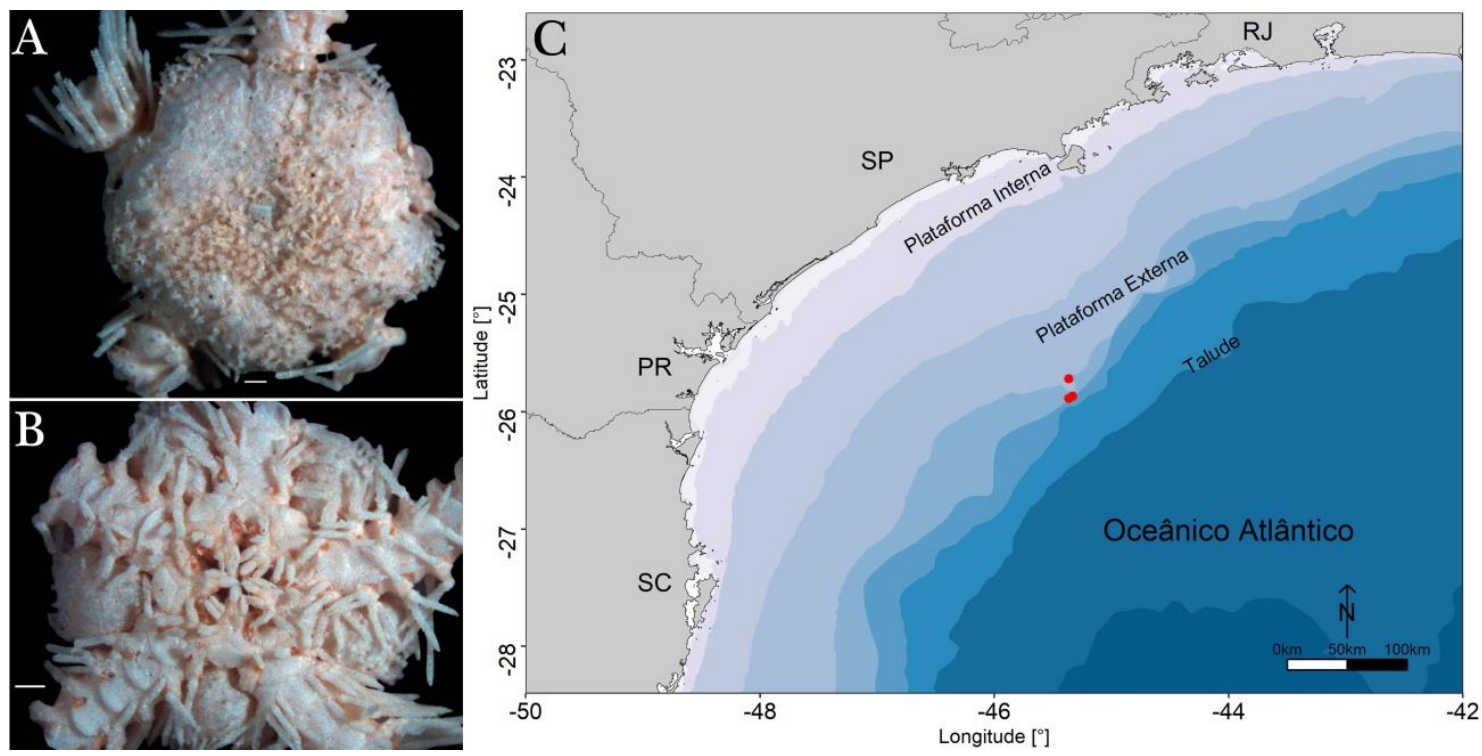

Figura 64. Ophiacantha aristata - ZUEC OPH 1857: A. Vista dorsal, B. Vista ventral, G. Ocorrência de $O$. aristata no talude continental. Escala: $0.5 \mathrm{~mm}$. 
Coloração: Branca amarelada.

Hábitat: Substrato não consolidado, nas profundidades de 680-755 m.

Distribuição geográfica: Oceano Atlântico: a nordeste Ilhas Canárias até a Islândia, Espanha e Portugal (García-Diez et al. 2005; Rodrigues et al. 2011) a sudoeste do Brasil: Rio de Janeiro até Rio Grande do Sul (Borges 2001; Barboza et al. 2010; Barboza 2015).

\section{$\square$ Ophiacantha vepratica Lyman, 1878 \\ Figura 65}

Diagnose: Disco coberto por grânulos com uma coroa de espinhos robusta no centro do disco. Escudos orais mais largos que longos, com os bordos proximal e lateral pontiagudos e o distal arredondado. Escudos adorais mais longos do que largos, unidos na região proximal. Mandíbula com um grande dente e três papilas orais laterais, sendo a distal mais arredondada e as demais pontiagudas. De 7-9 espinhos braquiais alongados e denticulados. Uma escama tentacular ovalada tão longa quanto a placa braquial ventral (O’Hara \& Stöhr 2006).

Coloração: Branca amarelada.

Hábitat: Substrato não consolidado. Informação de profundidade ausente para ESB, porém nas Ilhas Kermadec foi registrada a $1116 \mathrm{~m}$.

Distribuição geográfica: Oceano Pacífico: Indonésia, Nova Caledônia, Ilhas Kermadec, Ilhas Chatham (O’Hara \& Stöhr 2006). Oceano Atlântico: Golfo do México (Lyman 1878). Brasil: Paraná (presente estudo).
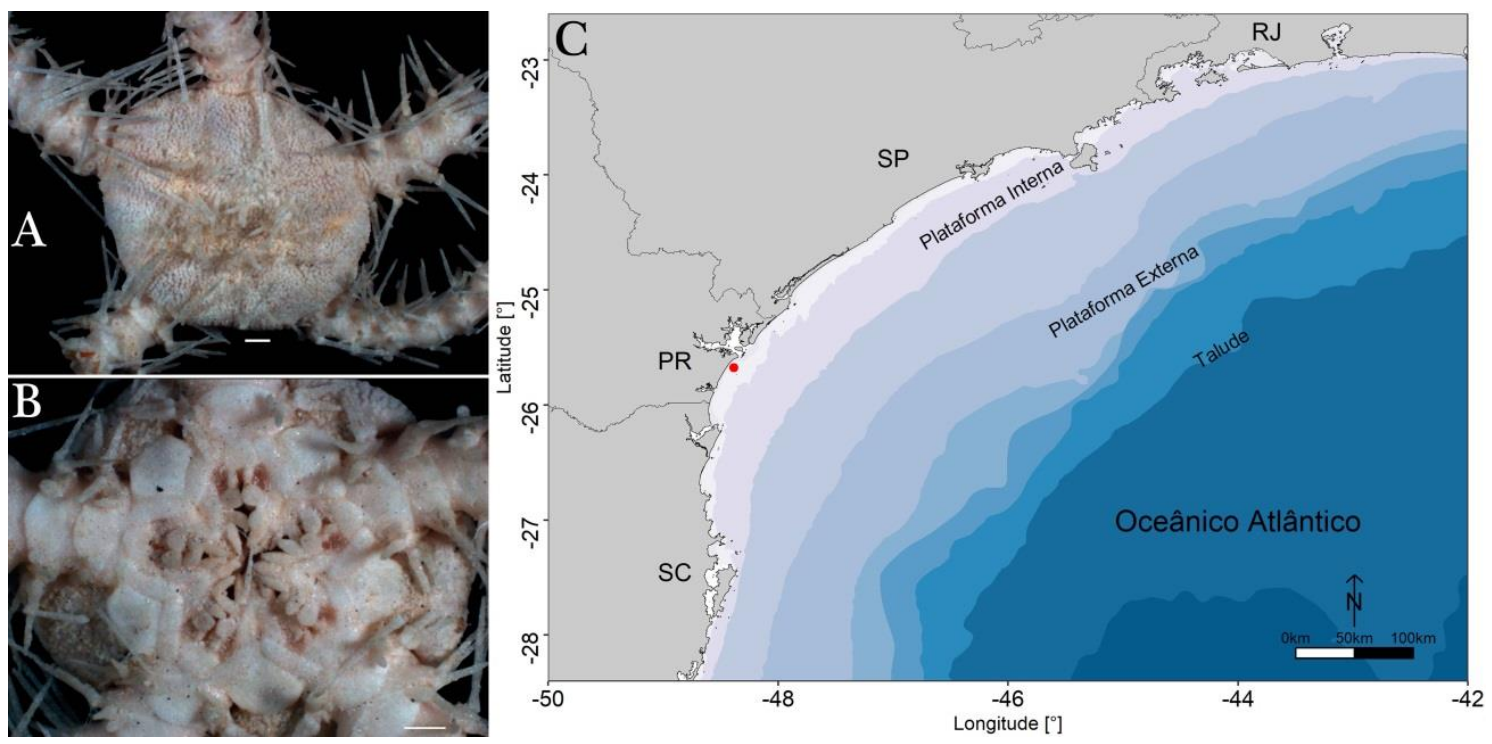

Figura 65. Ophiacantha vepratica - ZUEC OPH 2381: A. Vista dorsal, B. Vista ventral, C. Ocorrência de $O$. vepratica na plataforma continental interna. Escala: $0.5 \mathrm{~mm}$.

Ophiodermatidae Ljungman, 1867

Ophioderma Müller \& Troschel, 1840

Ophioderma januarii Lutken, 1856

Figura 66 
Diagnose: Disco pentagonal, escudos radiais cobertos por grânulos. Região radial com uma reentrância do disco que descobre 3-4 placas braquiais dorsais, marginada por pequenas escamas nuas, sem grânulos. Duas fendas bursais ao longo de cada braço, distal levemente mais larga que a proximal. Escudos orais cordiformes a ovalados. De 5-7 papilas orais laterais afiladas e subiguais. Uma papila infradental no ápice (às vezes duas), semelhante às papilas orais laterais. Cinco braços delgados, afilando em direção as extremidades, portando sete a dez espinhos braquiais achatados em cada placa braquial lateral (Monteiro et al. 1992; Borges \& Amaral 2005; Alitto et al. 2018).

Coloração: Disco verde oliva ou castanho amarelado, com algumas manchas mais claras e irregulares, superfície ventral esbranquiçada. A coloração dos braços é variada, com faixas transversais alternadas entre claro e escuro (Tommasi 1970b; Monteiro et al. 1992; Alitto et al. 2018).

Hábitat: Substrato arenoso, na profundidade de $18 \mathrm{~m}$.

Distribuição geográfica: Oceano Atlântico: México, Antilhas e Brasil (Alvarado \& Solís-Marín 2013). Brasil: Amapá até Paraná (Tommasi 1970b; Borges \& Amaral 2005; Alitto et al. 2018).
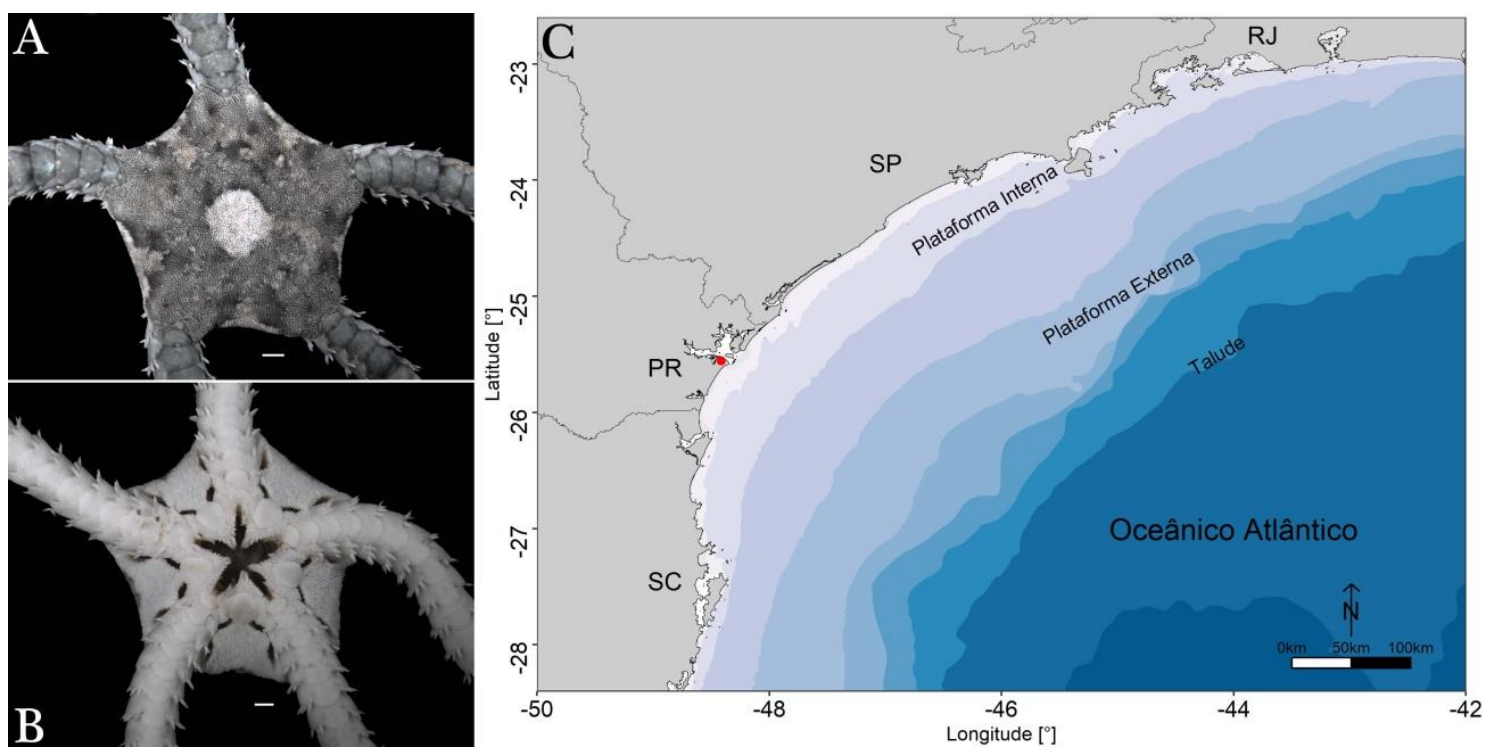

Figura 66. Ophioderma januarii - ZUEC OPH 2202: A. Vista dorsal, B. Vista ventral, C. Ocorrência de $O$. januarii no Complexo Estuarino de Paranaguá (Paraná). Escala: $0.5 \mathrm{~mm}$.

\section{Discussão}

A escassez de estudos sobre os Echinodermata no Brasil tem sido fortemente enfatizada (Magalhães et al. 2005; Manso et al. 2008; Brites et al. 2011; Ventura et al. 2013). Alguns fatores, como amostragem inadequada, pouco incentivo para projetos e para a formação de especialistas em taxonomia, estão entre as possíveis razões do nosso parco conhecimento sobre o grupo (Queiroz et al. 2013; Ventura et al. 2013).

Importantes estudos e resultados inovadores mostraram-se a comunidade científica a partir de dados em coleções ex situ. A exemplo, Woolley et al. (2016) utilizaram mais de 165 mil registros de Ophiuroidea de coleções científicas de várias partes do mundo para pesquisar os padrões de diversidade. Os autores concluíram que a riqueza de espécies de mar profundo é mantida pela migração de espécies de regiões mais rasas. Estes resultados têm grandes implicações para identificar áreas a serem protegidas em alto-mar, tanto dentro como fora das jurisdições nacionais (Woolley et al. 2016). Isto evidencia o quanto coleções científicas são fonte 
crucial de informações e constituem um acervo básico a partir do qual a diversidade pode ser reconhecida, localizada e protegida.

A maioria de nossos dados foi extraída de coleções científicas que datam de 1946 até 2015. Esta compilação revelou um potencial de riqueza e distribuição dos Echinodermata, até então desconhecida para o ESB. O ESB é uma área de transição entre águas tropicais e polares, caracterizada por ser extremamente recortada e heterogênea (Borzone et al. 1999). Essa configuração gera uma diversidade de habitats e um complexo sistema deposicional em mosaicos, que favorece a ocorrência de uma maior diversidade de espécies de equinodermos com diferentes hábitos de vida. Dentre as classes de Echinodermata, Ophiuroidea foi o grupo que apresentou maior diversidade com 34 espécies incluindo espécies exclusivas de profundidades superiores a 100 metros, como as famílias Ophiacanthidae e Ophiuridae (Borges et al. 2001). Echinoidea e Asteroidea apresentaram maior riqueza específica na plataforma interna até $50 \mathrm{~m}$. Holothuroidea e Crinoidea foram as classes com menor número de registros e foram encontradas habitando preferencialmente substratos consolidados.

Estes dados podem ser usados em futuros monitoramentos de impactos antropogênicos, estratégias de conservação dos ecossistemas marinhos e em estudos sobre taxonomia, ecologia, evolução e diversidade funcional.

Diante deste cenário, nós enfatizamos o uso de coleções científicas, uma vez que elas nos permitem acessar informações por um longo período de tempo. Além disso, são cada vez mais relevantes devido às atuais degradações nos ecossistemas marinhos e aquecimento global (Zaher \& Young 2003; Graham et al. 2004).

\section{Agradecimentos}

O presente trabalho foi realizado com apoio da Coordenação de Aperfeiçoamento de Pessoal de Nível Superior - Brasil (CAPES) - Código de Financiamento 001. Sinceros agradecimentos aos pesquisadores e taxonomistas que apoiaram na identificação de muitos dos equinodermos que estão contidas neste Guia: Dr $^{a}$ Yara A.G. Tavares (responsável pela Coleção de equinodermos do LABMAR-UNESPAR), Dr. Rafael Metri (Laboratório de Ecologia e Conservação da UNESPAR) pelo compartilhamento de informações e material; Dr. Carlos Alberto Borzone (pesquisador e responsável pela coleção de equinodermos do LEPA-CEMUFPR); Dr ${ }^{\mathrm{a}}$ Odete Lopes Lopez (curadora de invertebrados do MHNCI); Acir José da Silva Franco (biólogo e curador da coleção de equinodermos MZPUC/PR); Dr. Luciano Lorenzi (pesquisador e responsável pela Coleção de Bentos do Laboratório de Bentologia da Univille SC); Dr. Carlos Renato Rezende Ventura (curador e especialista da coleção de equinodermos do MN-UFRJ); Dr. Marcos Domingos Siqueira Tavares, Dr ${ }^{\mathrm{a}}$ Luciana Martins e $\operatorname{Dr}^{\mathrm{a}}$ Aline Benetti (curadores e pesquisadores do Museu de Zoologia da Universidade de São Paulo - MZUSP). Dr ${ }^{\mathrm{a}}$ Jéssica Prata de Oliveira (UFPB/DSE) especialista em Holothuroidea por fornecer as imagens de ossículos dérmicos da espécie Trachythyone crassipeda. A Gabriela Granadier e Helena Serrano pelo auxílio na obtenção de imagens dos exemplares de ZUEC. Agradecemos aos avaliadores anônimos pela revisão crítica do manuscrito.

\section{Referências}

Albuquerque M.N. (1986) Ophiuroidea Gray, 1840 (Echinodermata) da plataforma continental do norte e nordeste brasileiro. Tese de Doutorado, Universidade de São Paulo, São Paulo.

Alitto R.A.S., Bueno M.L., Di Domenico M. \& Borges M. (2016) Annotated checklist of Echinoderms from Araçá Bay, Southeastern Brazil. Check List, 12: 1-15. DOI: 10.15560/12.1.1836

Alitto R.A.S., Bueno M.L., Guilherme P.D.B., Di Domenico M., Christensen A.B. \& Borges M. (2018) Shallow-water brittle stars (Echinodermata: Ophiuroidea) from Araçá Bay (Southeastern Brazil), with spatial distribution considerations. Zootaxa, 4405: 1-66. DOI: 10.11646/zootaxa.4405.1.1 
Alvarado J.J. (2011) Echinoderm diversity in the Caribbean Sea. Marine Biodiversity, 41: 261-285. DOI: $10.1007 / \mathrm{s} 12526-010-0053-0$

Alvarado J.J. \& Solís-Marín F.A. (2013) Echinoderm research and diversity in Latin America. Berlin/Heidelberg: Springer. 665 p. DOI: 10.1007/978-3-642-20051-9

Alvarado J.J., Solís-Marín F.A. \& Ahearn C. (2008) Equinodermos (Echinodermata) del Caribe Centroamericano. Revista de Biología Tropical, 56: 37-55.

Barboza C.A.M. (2010) Variabilidade espacial das associações de ofiuróides ao longo de um gradiente de contaminação no Canal da Cotinga, Baía de Paranaguá, Paraná. Dissertação de Mestrado, Pós-Graduação em Ciências Biológicas - Zoologia. Universidade Federal do Paraná, Paraná.

Barboza C.A.M. (2015) Taxonomia de Ophiuroidea (Echinodermata) da Bacia de Campos Atlântico SW e Biogeografia da Costa Brasileira. Tese de Doutorado, Programa de PósGraduação em Biologia Marinha. Universidade Federal Fluminense, Rio de Janeiro.

Barboza C.A.d.M., Frensel R. \& Campos L.S. (2010) Ophiacantha aristata Koehler, 1896 (p. 258259). In: Lavrado H.P. \& Brasil A.C.D.S. (Eds). Biodiversidade da região oceânica profunda da Bacia de Campos: Megafauna e Iciofauna Demersal. Rio de Janeiro: SAG Serv. 373 p.

Bartsch I. (1987) Notes on Ophiuroidea (Echinodermata) from the northeastern Atlantic Ocean. I. Ophiacanthidae. Spixiana, 10: 115-130.

Benavides-Serrato M., Borrero-Pérez G. \& Diaz-Sanchez C.M. (2011) Equinodermos del Caribe colombiano I: Crinoidea, Asteroidea y Ophiuoridea. Santa Marta: Serie de Publicaciones Especiales de Invemar 22. $384 \mathrm{p}$.

Benavides-Serrato M., Borrero-Pérez G.H., Solano Ó.D. \& Rodolfo Navas G. (2005) Listado taxonómico de los asteroideos (Echinodermata: Asteroidea) de la plataforma y el talud superior del Caribe colombiano. Revista de Biología Tropical, 53: 171-194.

Bernasconi I. (1943) Los asteroideos sudamericanos de la familia Luidiidae. Anales del Museo Argentino de Ciencias Naturales, 7: 1-20.

Bernasconi I. (1955) Equinoideos y asteroideos de la colección del Instituto Oceanográfico de la Universidad de San Pablo. Boletim do Instituto Oceanográfico, 6: 51-91. DOI: 10.1590/S037355241955000100002

Bernasconi I. (1957) Equinoideos y Asteroideos de la Colección del Instituto Oceanografico de la Univerdidad de San Pablo. Boletim do Instituto Oceanográfico, 7: 119-148.

Bernasconi I. (1965) Ophiuroidea de Puerto Deseado (Santa Cruz, Argentina). Physis, 25: 143152.

Bernasconi I. \& D'Agostino M.M. (1977) Ofiuroideos del mar Epicontinental Argentino. Revista del Museo Argentino de Ciencias Naturales "Bernardino Rivadavia", Hidrobiología, 5: 65114.

Besteiro C. \& Ugorri V. (1988) Inventário dos Equinodermos de Galicia (Echinometra) (p. 51). In: Castro D.O., Castro-Sada O. \& Coruña A. (Eds). Volume I. Seminário de Estudos Galegos: 1-51 p.

Borges M. (2001) Biodiversidade de Ophiuroidea (Echinodermata) da plataforma e talude continental da costa sul-sudeste brasileira. Dissertação de Mestrado, Pós-Graduação em Ciências Biológicas - Zoologia. Universidade Estadual Paulista "Julio de Mesquita Filho", Rio Claro.

Borges M. (2006) Taxonomia, distribuição e biologia reprodutiva de Ophiuroidea (Echinodermata) das Regiões Sudeste e Sul do Brasil. Tese de Doutorado, Pós-Graduação em Ciências Biológicas - Zoologia. Universidade Estadual Paulista "Julio de Mesquita Filho", Rio Claro.

Borges M. \& Amaral A.C.Z. (2005) Classe Ophiuroidea (p. 237-272). In: Amaral A.C.Z., Rizzo A.E. \& Arruda E.P. (Eds). Manual de identificação dos invertebrados marinhos da região sudestesul do Brasil. São Paulo: EdUSP. 288 p.

Borges M. \& Amaral A.C.Z. (2007) Ophiuroidea (Echinodermata): quatro novas ocorrências para o Brasil. Revista Brasileira de Zoologia, 24: 855-864. DOI: 10.1590/S0101-81752007000400001 
Borges M., Alitto R.A.S. \& Amaral A.C.Z. (2015) From baby to adult: ontogenetic series of nine species of Ophiuroidea from Atlantic Southwestern. Revista de Biología Tropical, 63: 361381. DOI: $10.15517 /$ rbt.v63i2.23170

Borges M., Monteiro A.M.G. \& Amaral A.C.Z. (2002) Taxonomy of Ophiuroidea (Echinodermata) from the continental shelf and slope of the southern and southeastern Brazilian coast. Biota Neotropica, 2: 1-69. DOI: 10.1590/S1676-06032002000200010

Borges M., Monteiro A.M.G. \& Amaral A.C.Z. (2006) A new species of Ophiomisidium (Echinodermata: Ophiuroidea) from the continental shelf and slope off southern Brazil. Journal of the Marine Biological Association of the United Kingdom, 86: 1449-1454. DOI: $10.1017 / \mathrm{S} 0025315406014500$

Borrero-Pérez G.H., Benavides-Serrato M. \& Diaz-Sanchez C.M. (2012) Equinodermos del Caribe colombiano II: Echinoidea y Holothuroidea. Santa Marta: Serie de Publicaciones Especiales de Invemar. $250 \mathrm{p}$.

Borrero-Pérez G.H., Benavides-Serrato M., Solano Ó. \& Navas G. (2008) Brittle-stars (Echinodermata: Ophiuroidea) from the continental shelf and upper slope of the Colombian Caribbean. Revista de Biología Tropical, 56: 169-204.

Borzone C.A., Pezzuto P.R. \& Marone E. (1999) Oceanographic Characteristics of a Multi-Specific Fishing Ground of the Central South Brazil Bight. Marine Ecology, 20: 131-146. DOI: 10.1046/j.1439-0485.1999.00070.x

Brites A.D., Hadel V.F. \& Tiago C.G. (2011) Crinoidea, Asteroidea, Echinoidea, Holothuroidea (p. 273-279). In: Amaral A.C.Z. \& Nallin S.A.H. (Eds). Biodiversidade e ecossistemas bentônicos marinhos do litoral Norte de São Paulo, Sudeste do Brasil. Campinas: Unicamp. 573 p.

Brito I.M. (1960) Os Equinóides regulares do litoral do Río de Janeiro. Avulso/Universidade do Brasil, Centro de Estudos Zoológicos, 13: 1-10.

Brito I.M. (1968) Asteróides e equinóides do Estado da Guanabara e adjacências. Boletim do Museu Nacional, 260: 1-51.

Brogger M.I., Martinez M.I., Zabala S. \& Penchaszadeh P.E. (2013) Reproduction of Ophioplocus januarii (Echinodermata: Ophiuroidea): a continuous breeder in northern Patagonia, Argentina. Aquatic Biology, 19: 275-285. DOI: 10.3354/ab00537

Campos E.J.D., Ikeda Y., Castro B.M., Gaeta S.A., Lorenzzetti J.A. \& Stevenson M.R. (1996) Experiment Studies Circulation in the Western South Atlantic. Eos, Transactions American Geophysical Union, 77: 253-259.

Capítoli R.R. \& Monteiro A.M.G. (2000) Distribuição e abundância de ofiuróides na plataforma interna do extremo sul do Brasil. Atlántica, 22: 41-56.

Carranza A., Borges M., Rodríguez M. \& Borthagaray A.I. (2007) Ophiuroidea (Echinodermata) from La Coronilla-Cerro Verde (Uruguay): a new record for the Uruguayan coast. Biota Neotropica, 7: 103-107.

Carrera-Rodríguez C.J. \& Tommasi L.R. (1977) Asteroidea de la plataforma continental de Rio Grande do Sul (Brasil), colecionados durante los viajes del N/Oc."Prof. W. Besnard” para el proyecto Rio Grande do Sul. Boletim do Instituto Oceanográfico, 26: 51-130. DOI: 10.1590/S0373-55241977000100004

Carvalho A.L.P.S. \& Ventura C.R.R. (2002) The reproductive cycle of Asterina stellifera (Möbius) (Echinodermata: Asteroidea) in the Cabo Frio region, southeastern Brazil. Marine Biology, 141: 947-954. DOI: 10.1007/s00227-002-0881-y

Cherbonnier G. \& Guille A. (1978) Echinodermes: ophiurides. Paris: Editions du CNRS. 252 p.

Chesher R.H. (1968) The Systematics of Sympatric Species in West Indian Spatangoids: A Revision of the Genera Brissopsis, Plethotaenia, Paleopneustes, and Saviniaster. Studies in Tropical Oceanography, 7: 1-256.

Clark A.M. (1976) Tropical epizoic echinoderms and their distribution. Micronesica, 12: 111-117.

Clark A.M. \& Downey M.E. (1992) Starfishes of the Atlantic. London, UK: Chapman \& Hall. 820 p.

Clark A.M. \& Rowe F.W.E. (1971) Monograph of shallow-water Indo-West Pacific echinoderms. London: Trustees of the British Museum (Natural History). 306 p. 
Darrigran G., Vilches A., Legarralde T. \& Damborenea C. (2007) Guía para el estudio de macroinvertebrados. I. - Métodos de colecta y técnicas de fijación. La Plata, Argentina: Facultad de Ciencias Naturales y Museo, Universidad Nacional de La Plata (ProBiota, FCNyM, UNLP, Serie Técnica y Didáctica). 86 p.

de Mahiques M.M., Tessler M.G., Maria Ciotti A., da Silveira I.C.A., Sousa S.H.d.M., Figueira R.C.L., Tassinari C.C.G., Furtado V.V. \& Passos R.F. (2004) Hydrodynamically driven patterns of recent sedimentation in the shelf and upper slope off Southeast Brazil. Continental Shelf Research, 24: 1685-1697. DOI: 10.1016/j.csr.2004.05.013

Ditadi A.S.F. (1987) Manual de técnicas para a preparação de coleções zoológicas. Echinodermata. Campinas: Sociedade Brasileira de Zoologia. 9 p.

Eleftheriou A. \& McIntyre A.D. (2008) Methods for the study of marine benthos. Oxford: UK: Blackwell Science. 418 p.

Féral J.P. \& Massin C. (1982) Digestive system: Holothuroidea (p. 191-212). In: Jangoux M. \& Lawrence J. (Eds). Echinoderm Nutrition. Rotterdam: Balkema. 700 p. DOI: 10.1002/iroh.19840690142

Fernandes M.L.B., Tommasi L.R. \& Lima E.J.B. (2002) Filo Echinodermata de Pernambuco (p. 405-427). In: Tabarelli M. \& Silva J.M.C. (Eds). Diagnóstico da biodiversidade de Pernambuco. Recife: Massangana. 722 p.

Francisco V. \& Pauls S. (2008) Especies del orden Clypeasteroida (Echinodermata: Echinoidea) de las costas de Venezuela. Revista de Biología Tropical, 56: 215-228.

Frensel R.R., Barboza C.A.M., Moura R.B. \& Campos L.S. (2010) Southwest Atlantic deep-sea brittle stars (Echinodermata: Ophiuroidea) from Campos Basin, Brazil (p. 173-180). In: Harris L.G., Boetger A.S., Walker C.W. \& Lesser M.P. (Eds). Echinoderms: Durham. Durham, New Hampshire, U.S.A.: Balkema, Rotterdam. 720 p. DOI: 10.1201/9780203869543-c20

García-Diez C., Porteiro F.M., Meirinho A., Cardigos F. \& Tempera F. (2005) Taxonomic review of selected invertebrate groups collected during the Campaigns of the Prince Albert I of Monaco in the Azorean waters. Universidade dos Açores, ARQUIPÉLAGO. Ciências Biológicas e Marinhas: 35-59.

Gondim A.I. (2012) Taxonomia das classes Asteroidea e Echinoidea da região Nordeste do Brasil. Dissertação de Mestrado, Programa de Pós-Graduação em Ciências Biológicas - Área de Concentração Zoologia. Universidade Federal da Paraíba, Paraíba.

Gondim A.I., Alonso C., Dias T.L.P., Manso C.L.C. \& Christoffersen M.L. (2013) A taxonomic guide to the brittle-stars (Echinodermata, Ophiuroidea) from the State of Paraíba continental shelf, Northeastern Brazil. ZooKeys, 307: 45-96. DOI: 10.3897/zookeys.307.4673

Gondim A.I., Christoffersen M.L. \& Dias T.L.P. (2014) Taxonomic guide and historical review of starfishes in northeastern Brazil (Echinodermata, Asteroidea). ZooKeys, 449: 1-56. DOI: 10.3897/zookeys.449.6813

González D.N., Solano O.D. \& Navas G.R. (2002) Equinodermos colectados por la expedición CIOH-INVEMAR-SMITHSONIAN desde Cartagena hasta el Golfo de Urabá, Caribe Colombiano. Boletín de Investigaciones Marinas y Costeras, 31: 85-132.

Graham C.H., Ferrier S., Huettman F., Moritz C. \& Peterson A.T. (2004) New developments in museum-based informatics and applications in biodiversity analysis. Trends in Ecology \& Evolution, 19: 497-503. DOI: 10.1016/j.tree.2004.07.006

Haig J.A. \& Rouse G.W. (2008) Larval development of the featherstar Aporometra wilsoni (Echinodermata: Crinoidea). Invertebrate Biology, 127: 460-469. DOI: 10.1111/j.17447410.2008.00134.x

Hemery L.G., Roux M., Améziane N. \& Eléaume M. (2013) High-resolution crinoid phyletic inter-relationships derived from molecular data. Cahiers de Biologie Marine, 54: 511-523.

Hendler G., Migotto Á.E., Ventura C.R.R. \& Wilk L. (2012) Epizoic Ophiothela brittle stars have invaded the Atlantic. Coral Reefs, 31: 1005. DOI: 10.1007/s00338-012-0936-6

Hendler G., Miller J.E., Pawson D.L. \& Kier P.M. (1995) Sea stars, sea urchins, and allies: echinoderms of Florida and the Caribbean. Washington: Smithsonian Institution Press. 390 p. DOI: $10.1017 / \mathrm{s} 0025315400031568$ 
Hernández-Herrejón L., Solís-Marín F.A. \& Laguarda-Figueras A. (2008) Ofiuroideos (Echinodermata: Ophiuroidea) de las aguas mexicanas del golfo de México. Revista de Biología Tropical, 56: 83-167.

Hess H. (2011) Articulata (p. 1-23). In: Hess H., Messing C.G. \& Ausich W.I. (Eds). Treatise on Invertebrate Paleontology, Part T, Echinodermata 2 Revised, Crinoidea. Lawrence, Kansas: University of Kansas Press. $261 \mathrm{p}$.

Hess H., Ausich W.I., Brett C.E. \& Simms M.J. (1999) Fossil Crinoids. Cambridge, UK: Cambridge University Press. $292 \mathrm{p}$.

Hickman C.P. (1998) A field guide to sea stars and other echinoderms of Galápagos. Lexington, Virginia: Sugar Spring Press. 83 p.

Humason G.L. (1962) Animal tissue techniques. San Francisco: W.H. Freeman. 496 p.

Hyman L. (1955) The Invertebrates. The Celomate Bilateria. London: McGraw-Hill Book Company. $763 \mathrm{p}$.

Klein J.A., Borzone C.A. \& Pezzuto P.R. (2001) A macro e megafauna bêntica associada aos bancos da vieira Euvola ziczac (MOLLUSCA: BIVALVIA) no litoral sul do Brasil. Atlántica, 23: $17-26$.

Kroh A. \& Mooi R. (2018) World Echinoidea Database. Disponível em: http://www.marinespecies. org/echinoidea (Acessado em 12/11/2018).

Kroh A. \& Smith A.B. (2010) The phylogeny and classification of post-Palaeozoic echinoids. Journal of Systematic Palaeontology, 8: 147-212. DOI: 10.1080/14772011003603556

Laguarda-Figueras A., Hernández-Herrejon L.A., Solís-Marín F.A. \& Durán-González A. (2009) Ofiuroideos del Caribe Mexicano y Golfo de México. México: Comisión Nacional para el Conocimiento y Uso de la Biodiversidad, UNAM, Instituto de Ciencias del Mar y Limnología. $248 \mathrm{p}$.

Laguarda-Figueras A., Solís-Marín F.A., Durán-González A., Ahearn C.G., Sánchez B.E.B. \& Torres-Vega J. (2005) Equinodermos (Echinodermata) del Caribe Mexicano. Revista de Biología Tropical, 53: 109-122.

Larrauri L.R.A. (1978) Los equinodermos de la Costa Atlantica de Colombia. Phd thesis, Facultad de Ciencias del Mar. Fundacion Universidad de Bogota Jorge Tadeo Lozano, Colombia.

Lawley J.W., Fonseca A.C., Faria-Júnior E. \& Lindner A. (2018). Occurrence of the non-indigenous brittle star Ophiothela cf. mirabilis Verrill, 1867 (Echinodermata, Ophiuroidea) in natural and anthropogenic habitats off Santa Catarina, Brazil. Check List, 14(2): 453-459.

Lima-Verde J.S. (1969) Primeira contribuição ao inventário dos equinodermas do nordeste brasileiro. Arquivos de Ciências do Mar, 9: 9-13.

Lima E.J.B. \& Fernandes M.L.B. (2009) Diversidade de equinodermos (Echinodermata) no Estado de Pernambuco (Brasil). Revista Brasileira de Zoociências, 11: 55-63.

Lima M.L.F., Correia M.D., Sovierzoski H.H. \& Manso C.L.C. (2011) New records of Ophiuroidea (Echinodermata) from shallow waters off Maceió, State of Alagoas, Brazil. Marine Biodiversity Records, 4: 1-10. DOI: 10.1017/S175526721100090X

Lyman T. (1878) Ophiuridae and Astrophytidae of the exploring voyage of H.M.S. Challenger. Bulletin of the Museum of Comparative Zoology, 5: 66-168.

Magalhães W.F., Martins L.R. \& Alves O.F.S. (2005) Inventário dos Echinodermata do Estado da Bahia. Brazilian Journal of Aquatic Science and Technology, 9: 61-65. DOI: 10.14210/bjast.v9n1.p61-65

Manso C.L.C. (1988) Uma nova espécie de Ophiactis (Echinodermata: Stelleroidea) da costa sudeste do Brasil. Revista Brasileira de Biologia, 48: 375-379.

Manso C.L.C. \& Absalão R.S. (1988) Ophiuroidea: Situação Pré Operacional nos sacos de Piraquara, região sob influência da descarga da Central Nuclear Almirante Álvaro Alberto (CNAAA). Revista Brasileira de Biologia, 48: 75-82.

Manso C.L.C., Alves O.F.S. \& Martins L.R. (2008) Echinodermata da Baía de Todos os Santos e da Baía de Aratu (Bahia, Brasil). Biota Neotropica, 8: 179-196. DOI: 10.1590/S167606032008000300017 
Martínez S. (2008) Shallow water Asteroidea and Ophiuroidea of Uruguay: composition and biogeography. Revista de Biología Tropical, 56: 205-214.

Martins L.R. (2012) Estudo Taxonômico dos Holothuroidea (Echinodermata) de águas rasas da costa Brasileira. Dissertação de Mestrado, Programa de Pós-graduação em Diversidade Animal. Universidade Federal da Bahia, Salvador.

Martynov A.V. \& Litvinova N.M. (2008) Deep-water Ophiuroidea of the northern Atlantic with descriptions of three new species and taxonomic remarks on certain genera and species. Marine Biology Research, 4: 76-111. DOI: 10.1080/17451000701840066

Messing C.G. (1997) Living Comatulids (p. 3-30). In: Waters J.A. \& Maples C.G. (Eds). The Paleontological Society Papers. Cambridge: Cambridge University Press. 355 p. DOI: $10.1017 / \mathrm{S} 1089332600000188$

Miloslavich P., Díaz J.M., Klein E., Alvarado J.J., Díaz C., Gobin J., Escobar-Briones E., Cruz-Motta J.J., Weil E. \& Cortes J. (2010) Marine Biodiversity in the Caribbean: Regional Estimates and Distribution Patterns. PLoS ONE, 5: e11916. DOI: 10.1371/journal.pone.0011916

Monteiro A.M.G. (1987) Ophiuroidea (Echinodermata) da região de Ubatuba (SP) - Aspectos morfológicos e ecológicos. Tese de Doutorado, Pós-Graduação do Istituto de Oceanografia. Universidade de São Paulo, São Paulo.

Monteiro A.M.G., Reis M.O. \& Pardo E.V. (1992) Morfologia comparativa e distribuição batimétrica de duas espécies de Ophiuroidea, na região costeira de Ubatuba. Boletim do Instituto Oceanográfico, 40: 39-53.

Netto L.F. (2006) Echinodermata do Canal de São Sebastião, São Sebastião (SP). Dissertação de Mestrado, Departamento de Zoologia. Universidade de São Paulo, São Paulo.

Netto L.F., Hadel V.F. \& Tiago C.G. (2005) Echinodermata from São Sebastião Channel (São Paulo, Brazil). Revista de Biología Tropical, 53: 207-218.

O’Hara T. \& Stöhr S. (2006) Deep water Ophiuroidea (Echinodermata) of New Caledonia: Ophiacanthidae and Hemieuryalidae (p. 33-141). In: Richer de Forges B. \& Justine J.L. (Eds). Tropical Deep-Sea Benthos. Paris: Mémoires du Muséum national d'Histoire naturelle. 417 p.

Oliveira J.P. (2013) Holothuroidea (Echinodermata) da região Nordeste do Brasil. Dissertação de Mestrado, Programa de Pós-graduação em Ciências Biológicas - Zoologia. Universidade Federal da Paraíba, Paraíba.

Oliveira J.P., Oliveira J. \& Manso C.L.C. (2010) Inventário da coleção de equinodermos do LABIMAR, Campus Prof ${ }^{0}$. Alberto Carvalho, Universidade Federal de Sergipe. Scientia Plena, 6: 1-14.

O'Loughlin P.M. \& Waters J.A. (2004) A molecular and morphological revision of genera of Asterinidae (Echinodermata: Ophiuroidea). Memoirs of Museum Victoria, 61: 1-40.

Papavero N. (1994) Fundamentos práticas de taxonomia zoológica: Coleções, bibliografia, nomenclatura. São Paulo: Editora da Universidade Paulista. 285 p.

Paterson G.L.J. (1985) The deep-sea Ophiuroidea of the north Atlantic Ocean. Bulletin of the British Museum (Natural History) Zoology, 49: 1-162.

Pawson D.L. (1982) Holothuroidea (p. 813-818). In: Parker S.P. (Ed.). Synopsis and classification of living organisms. New York: McGraw-Hill. 2424 p.

Pawson D.L. (2007) Phylum Echinodermata. Zootaxa, 1668: 749-764.

Pawson D.L., Pawson D.J. \& King R.A. (2010) A taxonomic guide to the Echinodermata of the South Atlantic Bight, USA: 1. Sea cucumbers (Echinodermata: Holothuroidea). Zootaxa, 2449: $1-48$.

Pawson D.L., Vance D.J., Messing C.G., Solís-Marín F.A. \& Mah C.L. (2009) Echinodermata of the Gulf of Mexico (p. 1177-1204). In: Felder D.L. \& Camp D.K. (Eds). Gulf of Mexico-Origins, Waters, and Biota. Texas: Texas A\&M University Press. 1393 p.

Pérez-Farfante I. (1959) Los erizos irregulares de Cuba. Revista de la Universidad central de Las Villa, 1: 331-372.

Petzelt C. (2005) Are Echinoderms of Interest to Biotechnology? (p. 1-6). In: Matranga V. (Ed.). Echinodermata. Berlin, Heidelberg: Springer Berlin Heidelberg. 275 p. DOI: 10.1007/3-54027683-1_1 
Pomory C.M. (2004) A guide to the shallow-water Echinodermata of the Texas coast. Contributions in Marine Science, 36: 1-188.

Pomory C.M. (2007) Key to the common shallow-water brittle stars (Echinodermata: Ophiuroidea) of the Gulf of Mexico and Caribbean Sea. Caribbean Journal of Science, Special Publication, 10: 1-42.

Prata J., Manso C.L.C. \& Christoffersen M.L. (2014) Aspidochirotida (Echinodermata: Holothuroidea) from the northeast coast of Brazil. Zootaxa, 3889: 127-150. DOI: 10.11646/zootaxa.3889.1.8

Queiroz V., Sales L., Neves E. \& Johnsson R. (2013) Holotúrias do litoral da Bahia (Echinodermata: Holothuroidea): inventário e novos registros. Arquivos de Ciências do Mar, 46: 107-112.

Roberts D., Gebruk A., Levin V. \& Manship B.A.D. (2000) Feeding and digestive strategies in deposit-feeding holothurians. Oceanography and Marine Biology, 38: 257-310.

Rodrigues C.F., Paterson G.L.J., Cabrinovic A. \& Cunha M.R. (2011) Deep-sea ophiuroids (Echinodermata: Ophiuroidea: Ophiurida) from the Gulf of Cadiz (NE Atlantic). Zootaxa, 2754: 1-26.

Rouse G.W., Jermiin L.S., Wilson N.G., Eeckhaut I., Lanterbecq D., Oji T., Young C.M., Browning T., Cisternas P., Helgen L.E., Stuckey M. \& Messing C.G. (2013) Fixed, free, and fixed: The fickle phylogeny of extant Crinoidea (Echinodermata) and their Permian-Triassic origin. Molecular Phylogenetics and Evolution, 66: 161-181. DOI: 10.1016/j.ympev.2012.09.018

Roux M., Messing C.G. \& Améziane N. (2002) Artificial keys to the genera of living stalked crinoids (Echinodermata). Bulletin of Marine Science, 70: 799-830.

Rowe F.W.E. \& Doty J.E. (1977) The shallow-water holothurians of Guam. Micronesica, 13: 217250.

Rowe F.W.E. \& Gates J. (1995) Echinodermata. Melbourne: CISIRO. 510 p.

Samyn Y., Vandenspiegel D. \& Massin C. (2006) Taxonomie des holothuries des Comores. $A b c$ Taxa, 1: 1-130.

Santana A., Manso C.L.C., Almeida A.C.S. \& Alves O.F.d.S. (2017) Redescription and designation of a neotype for Ophiothrix angulata (Say, 1825 (Echinodermata: Ophiuroidea: Ophiotrichidae). Zootaxa, 4344: 291-307. DOI: 10.11646/zootaxa.4344.2.5

Serafy D.K. (1979) Memoirs of the Hourglass Cruises. V (III): Echinoids (Echinodermata: Echinoidea). St. Petesburg, Flórida: Florida Departament of Natural Resources. 120 p.

Smirnov I.S., Piepenburg D., Ahearn C. \& Juterzenka K.V. (2014) Deep-sea fauna of European seas: An annotated species checklist of benthic invertebrates living deeper than $2000 \mathrm{~m}$ in the seas bordering Europe. Invertebrate Zoology, 11: 192-209.

Stöhr S., O'Hara T.D. \& Thuy B. (2012) Global diversity of brittle stars (Echinodermata: Ophiuroidea). PLoS ONE, 7: e31940. DOI: 10.1371/journal.pone.0031940

Tahera Q. (2001) Echinoderms Epizoic on gorgonian corals from Karashi Coast. Pakistan Journal of Biological Sciences, 4: 1177-1179.

Thomas L.P. (1967) The systematic position of Amphilimna (Echinodermata: Ophiuroidea). Proceedings of the Biological Society of Washington, 80: 123-130.

Tommasi L.R. (1958) Os equinodermos do litoral de São Paulo. II. Diadematidae, Schizasteridae, Brissidae, Cidaroidae (Echinoidea) e Asteroidea do bentos costeiro. Contribuições do Instituto Oceanográfico, 2: 1-27.

Tommasi L.R. (1965) Lista dos crinóides recentes do Brasil. Contribuições do Instituto Oceanográfico, 9: 1-33.

Tommasi L.R. (1966) Lista dos equinóides recentes do Brasil. Contribuições do Instituto Oceanográfico, 11: 1-50.

Tommasi L.R. (1969a) Lista dos Holothuroidea recentes do Brasil. Contribuições do Instituto Oceanográfico, 15: 1-29.

Tommasi L.R. (1969b) Nova contribuição à lista dos crinóides recentes do Brasil. Contribuições do Instituto Oceanográfico, 17: 1-8. 
Tommasi L.R. (1970a) Lista de asteróides recentes do Brasil. Contribuições do Instituto Oceanográfico, 18: 1-61.

Tommasi L.R. (1970b) Os ofiuróides recentes do Brasil e de regiões vizinhas. Contribuições Avulsas do Instituto Oceanográfico, 20: 1-146.

Tommasi L.R. (1971) Equinodermes do Brasil: I. sôbre algumas espécies novas e outras pouco conhecidas, para o Brasil. Boletim do Instituto Oceanográfico, 20: 1-21. DOI: 10.1590/S037355241971000100001

Tommasi L.R. (2004) Classe Asteroidea, Crinoidea, Holothuroidea e Echinoidea (p. 161-163). In: Amaral A.C.Z. \& Rossi-Wongstschowski C.L.D.B. (Eds). Biodiversidade Bentônica da Região Sudeste-Sul do Brasil - Plataforma Externa e Talude Superior. São Paulo: Instituto Oceanográfico, USP. 216 p.

Tommasi L.R. \& Abreu J. (1974) Equinodermes do Brasil. IV. Sobre seis espécies novas de Ophiuroidea da Região ao Largo da Ilha Grande (RJ). Boletim do Instituto Oceanográfico, 23 : 17-32.

Tommasi L.R. \& Aron M.A. (1987) Equinodermes dos bancos submarinos da cadeia de montanhas Vitória-Trindade. Relatórios Internos do Instituto Oceanográfico, 18: 1-9.

Tommasi L.R., Castro S.M. \& Sousa E.C.P.M. (1988) Echinodermata coletados durante as campanhas oceanográficas do N/Oc." Almirante Saldanha" no Atlantico Sul Ocidental. Relatórios Internos do Instituto Oceanográfico, 21: 1-11.

Uthicke S. \& Benzie J.A.H. (2003) Gene flow and population history in high dispersal marine invertebrates: mitochondrial DNA analysis of Holothuria nobilis (Echinodermata: Holothuroidea) populations from the Indo-Pacific. Molecular Ecology, 12: 2635-2648. DOI: 10.1046/j.1365-294X.2003.01954.x

Ventura C.R.R., Borges M., Campos L.S., Costa-Lotufo L.V., Freire C.A., Hadel V.F., Manso C.L.C., Silva J.R.M.C., Tavares Y. \& Tiago C.G. (2013) Echinoderm from Brazil: Historical research and the current state of biodiversity knowledge (p. 301-344). In: Alvarado J.J. \& Solís-Marín F.A. (Eds). Echinoderm research and diversity in Latin America. Berlin/Heidelberg: Springer. 665 p. DOI: $10.1007 / 978-3-642-20051-9$

Verrill A.E. (1869) On new and imperfectly known echinoderms and corals. Proceedings of the Boston Society of Natural History, 12: 381-391.

Woolley S.N., Tittensor D.P., Dunstan P.K., Guillera-Arroita G., Lahoz-Monfort J.J., Wintle B.A., Worm B. \& O'Hara T. (2016) Deep-sea diversity patterns are shaped by energy availability. Nature, 533: 393-396. DOI: 10.1038/nature17937

Xavier L.A.R. (2010) Inventário dos equinodermos do Estado de Santa Catarina, Brasil. Brazilian Journal of Aquatic Science and Technology, 14: 73-78. DOI: 10.14210/bjast.v14n2.p73-78

Zaher H. \& Young P.S. (2003) As coleções zoológicas brasileiras: panorama e desafios. Ciência e Cultura, 55: 24-26. 


\section{Glossário}

Abactinais

Aboral

Adambulacrais

Adradial

Afilado

Âmbito

Anel calcário

Ápice

Bívio

Canal pétreo

Carapaça

Carenal

Centrodorsal

Claviforme

Cone anal

Contíguas

Cordiforme

Corpúsculo calcário

Cuneiformes

Delgadas

Dentículos
Mesmo que aboral ou dorsal, região contrária à boca.

Mesmo que dorsal ou abactinal.

Refere-se a cada uma das séries de placas dispostas ao longo da superfície oral do braço de Asteroidea.

Termo utilizado para se referir a uma estrutura ou região localizada nas áreas mais próxima ao centro do corpo.

Que parece delgado como um fio; fino, delicado.

Nos Asteroidea é a borda lateral do corpo com maior diâmetro, para Echinoidea se refere a maior circunferência horizontal da borda da carapaça.

Conjunto de peças calcárias localizadas ao redor da parte inicial do esôfago das holotúrias e, provavelmente homólogo à lanterna de Aristóteles dos ouriços-do-mar.

Extremo superior, topo ou ponta.

Região dorsal nos Holothuroidea.

Tubo geralmente contendo ossículos, começa no anel vascular aquífero e termina em um madreporito.

Estrutura rígida que consiste em uma série de placas fundidas entre si.

Linha mediana dorsal dos raios.

Nos Crinoidea é o ossículo central que une o esqueleto a haste do corpo. Nos Ophiuroidea é a placa central da superfície dorsal do disco.

Que tem forma de clave.

Projeção carnosa com ânus posicionado no ápice.

Que está em contato, junto, próximo.

Que tem a forma semelhante a um coração.

Numerosas e pequenas formações calcárias imersas na parede do corpo. Ver ossículo.

Que tem a forma de cunha.

Fino, com pouca espessura.

Nos Ophiuroidea, dente muito pequeno, projeção presente em alguns espinhos. 
Disco

Distal

Dorsal

Escama

Escudo

Espinhos

Espineletes

Espinhos primários

Espinhos secundários

Espiniforme

Fascíolas

Fenda
Parte ou região central do corpo, de onde projetam-se os braços em Ophiuroidea e Asteroidea.

Estrutura ou região do corpo mais distante do centro do disco.

Superfície ou região do corpo oposta à boca.

Nos Ophiuroidea são estruturas em número e localização variáveis; são encontradas principalmente sobre o disco e não individualmente identificáveis, porém, podem se diferenciar em:

tentacular - escama associada com os tentáculos dos braços, apoiada na placa braquial ventral ou na lateral, pode recobrir o poro tentacular e proteger o tentáculo, quando retraído;

tentacular oral- escama situada dos lados da placa oral, recobrindo o poro tentacular oral.

Placa calcária na região do disco.

adoral - um par de placas situadas uma de cada lado do escudo oral.

oral - placas relativamente grandes, situadas no extremo distal das mandíbulas.

radial - pares de placas sobre a superfície dorsal marginal do disco, próximo da base de cada braço.

Projeções calcárias alongadas, mais ou menos cilíndricas ou cônicas e frequentemente afiladas, porém de formato e tamanhos variados. São móveis, articulados e ligados ao endoesqueleto sem fundir-se a ele.

Espinhos encontrados nas paxilas dos Asteroidea.

Primeiros espinhos formados nos equinoides. Espinhos grandes articulados aos tubérculos primários das placas ambulacrais $\mathrm{e}$ interambulacrais.

Espinhos menores que os primários e articulados aos tubérculos secundários das placas ambulacrais e interambulacrais nos equinoides.

Que tem a forma de espinho.

Faixa estreita de tubérculos minúsculos e densamente distribuídos na carapaça dos Spatangoida que portam espinhos modificados (clávulas). De acordo com a posição, podem ser denominados de anal, subanal, interno, peripetálico, lateromarginal e marginal.

Abertura estreita e alongada.

oral - Espaço entre duas mandíbulas vizinhas nos Ophiuroidea. 
bursal - Abertura da bursa nos Ophiuroidea, pequena bolsa localizada em ambos os lados dos braços, no inter-rádio ventral.

Hialino

Imbricadas

Interambulacrais

Labrum

Lanterna de Aristóteles

Que tem aparência de vidro, translucido.

Sobreposta, em série.

Região situada entre as duas áreas ambulacrais.

Conjunto de placas interambulacrais na região oral, próximo do peristômio.

Aparelho bucal, com cinco dentes calcários que ocorrem dentro de placas dispostas em forma de uma lanterna.

Lúnulas

Madreporito

Oral

Ossículos

Papila

Pápulas

Paxilas

Pedicelárias

Periprocto

Peristômio

Abertura ou fenda que atravessa completamente a carapaça de alguns ouriços irregulares.

Placa perfurada que se comunica com o sistema vascular aquífero.

Região da boca ou na mesma superfície na qual a boca se encontra.

Pequena estrutura esquelética.

Pequena elevação cônica ou protuberância. Nos Holothuroidea são expansões da parede do corpo. Nos Ophiuroidea, são elementos esqueléticos localizados na mandíbula ou disco:

dentária - situado na placa dental, próxima a extremidade ventral da mandíbula.

infradental ou apical - papilas orais, situadas debaixo do dente.

oral - pequenas placas ao lado da boca, apoiadas nas laterais das mandíbulas.

Evaginações dérmicas com função de troca gasosa.

Estrutura do endoesqueleto que basalmente consiste em uma coluna ereta, com sua extremidade superior expandida e coberta com pequenas projeções como tubérculos, grânulos, espineletes, ou espinhos formando uma coroa.

Pequenos apêndices especializados em forma de mandíbula constituída de duas a cinco valvas ou lâminas articuladas como pinça e um pedúnculo de comprimento variado.

Região ao redor do ânus. No animal vivo é coberta por uma membrana flexível que contém placas imersas e muitas vezes porta espinhos e pedicelárias.

Região ao redor da boca. É coberta por uma membrana flexível, que porta placas. 
Pés ambulacrais

Pétala

Pínulas

Placa

Plastrão

Proximal

Rômbico
Extensões do sistema hidrovascular. Geralmente possuem formato cilíndrico que se projetam para o exterior do corpo por aberturas na epiderme.

Parte do sistema ambulacral localizado na superfície aboral dos Echinoidea "irregulares”, as quais são alargadas lembrando pétalas.

Apêndice não ramificado e segmentado em lados alternados dos segmentos braquiais.

Cada uma das unidades calcarias que compõe o esqueleto, com exceção dos ornamentos superficiais que recebem nomes específicos.

abactinal - nos Asteroidea, situada na região dorsal do disco.

ambulacral - nos Echinoidea, situada ao longo de cada ambulacro, tipicamente em pares e perfuradas por poros.

anal - cada uma das placas que recobrem o ânus.

braquial - Nos Ophiuroidea, são as placas que recobrem o braço, podendo ser dorsal, ventral ou lateral, sendo esta última á que suporta os espinhos braquiais.

centrodorsal - uma das primeiras placas formadas na superfície dorsal do disco, localizada no centro. Em algumas espécies pode ser observada mesmo no indivíduo adulto.

genital - Nos Echinoidea são cinco placas do sistema apical, onde terminam as placas interambulacrais.

inferomarginal - Nos Asteroidea são as placas que compõem a fileira inferior das placas marginais. Limitam as placas actinais.

ocular - Mesmo que placa terminal. Nos Echinoidea são placas do sistema apical, onde terminam as placas ambulacrais.

primária - primeiras placas a serem formadas na superfície dorsal do disco, em número de cinco, em posição radial e, nos adultos, podem formar juntamente com a centrodorsal uma roseta central no disco, ou podem estar separadas por escamas e/ou placas desenvolvidas secundariamente.

superomarginal - Placa que forma o bordo do disco e dos raios dos Asteroidea. Limitam as placas abactinais.

Nos Echinoidea é um conjunto de placas interambulacrais na região oral.

Estrutura ou região do corpo mais próxima do centro.

Em formato de rombo, de losango; rombiforme. 
Sistema apical

Sulco ambulacral

Sutura

Tégmen

Tegumento

Tentáculos

Trigeminadas

Trívio

Truncado

Tubérculos

Túbulos de Cuvier

Vesículas de Poli

Vértebra
Nos Echinoidea é o conjunto de dez placas especializadas, das quais cinco são genitais e cinco são oculares dispostas alternadamente e localizadas no ponto mais alto da carapaça.

dicíclico - Quando as placas genitais estão em contato com o periprocto e as placas ocelares estão redor.

hemicíclico - Quando algumas placas oculares estão em contato com o periprocto e as demais estão separadas por placas genitais.

monocíclico - Quando as placas oculares e genitais estão em contato com o periprocto.

Depressão ou fissura que parte da boca até a extremidade dos braços e funciona como um canal alimentar nos Asteroidea.

Região de ligação entre placas ou ossículos.

Suave membrana que cobre todos os órgãos viscerais dos crinoides. Recobre o cálice.

Invólucro ou estrutura que envolve, reveste e protege um órgão.

Nos Holothuroidea são pés ambulacrais altamente modificados, dispostos circularmente ao redor da boca.

dendrítico - Ramificação em forma de árvore.

digitados - Ramificações em forma de dedo.

peltados - Extremidade em forma de escudo.

pinados - Ramificações em forma de pena.

Nos Echinoidea, contém três pares de poros na mesma placa.

Região ventral nos Holothuroidea.

Que termina em segmento reto, cortado, mutilado.

Projeções da carapaça que suportam os espinhos.

Estruturas de defesa de alguns Holothuroidea que podem ser toxicas.

São sacos preenchidos por fluido conectados ao anel vascular de água.

Em Ophiuroidea é o ossículo interno de cada segmento braquial. 